ASCORBIC ACID CONCENTRATIONS IN PLASMA, GASTRIC JUICE AND GASTROINTESTINAL MUCOSA. EFFECTS OF GASTRITIS AND ORAL Infirmary at Leeds, UK.

Aims High dietary ascorbic acid (AA) reduces gastric cancer risk, and may act in gastric juice by reducing $\mathrm{N}$-nitroso compound formation or in mucosa by scavenging free radicals. We investigated whether oral AA supplementation increases mucosal-and juice levels, and if this is modified by gastritis (a cancer risk factor).

Methods Subjects were recruited from patients undergoing endoscopy for dyspepsia. 34 patients were supplemented with $A A 500 \mathrm{mg}$ b.d. for 14 days prior to endoscopy, ceasing supplementation on the day before endoscopy. 49 patients were not supplemented. At endoscopy samples of blood and gastric juice were taken. Mucosal biopsies were also obtained from patients as detailed below. AA levels were measured in all specimens, and the biopsies examined histologically.

Results 37/49 unsupplemented patients and 20/34 supplemented patients had gastritis. Antral and body biopsies were obtained from all unsupplemented patients, and from 26 of the supplemented group. 6 unsupplemented and 26 supplemented patients had oesophageal and duodenal (1st [D1] and 2nd [D2] parts) biopsies taken.

Median AA concentrations $(\mu \mathrm{mol} / \mathrm{Kg})$ were:

\begin{tabular}{|l|c|c|c|c|c|l|l|}
\cline { 2 - 8 } \multicolumn{1}{c|}{} & plasma & juice & oesoph & body & antrum & D1 & D2 \\
\hline unsupp1 & 22 & 33 & 399 & 601 & 819 & 544 & 750 \\
\hline supp 1 & 77 & 88 & 1023 & 782 & 1167 & 1276 & 1482 \\
\hline
\end{tabular}

\begin{tabular}{|c|c|c|}
\cline { 2 - 3 } \multicolumn{1}{c|}{} & normal & gastritis \\
\hline unsuppl juice & 90 & 18 \\
\hline suppl juice & 145 & 75 \\
\hline \multicolumn{2}{|c|}{ Conclusions 1$)$ Oral supplementation significantly }
\end{tabular}

raises $A A$ concentrations in plasma $(p<0.001)$, juice $(p<0.001)$ and upper GI mucosa $(p<0.05)$. 2) Gastritis significantly reduces $A A$ levels in juice even in supplemented patients $(p<0.05)$. 3) Gastritis does not effect $A A$ concentrations in upper GI mucosa. 4) $A A$ is found in high concentrations in the mucosa throughout the upper GI tract. SUPPLEMENTATION. A Waring, IM Drake, $C$ Schorah, ATR Axon, $K$ White. Centre for Digestive Diseases, The General

HEPATOCELLULAR CARCINOMA (HCC) IN AUTO-IMMUNE CHRONIC ACTIVE HEPATITIS (AIH): THE ROLE OF HEPATITIS C (HCV) INECTION.

SD Ryder, J Koskinas, IG McFarlane, PM Rizzi, N Naoumov and R Williams. Institute of Liver Studies, King's College Hospital, London.

Background. The risk of hepatocellular carcinoma in AIH is thought low, despite the presence of long standing cirrhosis. With the increasing recognition of $\mathrm{HCV}$ infection in $\mathrm{AIH}$ and cryptogenic liver disease we examined 8 cases of HCC complicating AIH. Patients. All 8 patients presented with HCC between 1980 and 1992, 4 male, 4 female. All patients had steroid responsive AIH with positive anti-smooth muscle and ANF. Median duration of disease was 24.6 years and all patients had biopsy prove cirrhosis. 4 patients had a history of blood transfusion and 1 previous intravenous drug abuse. One patient had post transfusion hepatitis 7 years prior to presentation with HCC. One patient had HCC diagnosed incidentally at transplantation and is still alive 3 years post-transplant. The other 7 presented with advanced symptomatic disease, median survival 4.5 months Methods. Serum samples (up to 9 years pre HCC diagnosis) were tested for antibodies to HCV (Abbott RIBA) and Polymerase chain reaction (PCR) for HCV. Liver tissue from liver adjacent to HCC was subjected to PCR using primers from the 5 ' non-coding region as were samples from prior liver biopsy specimens in all patients (up to 19 years prior to HCC). Results. At presentation with HCC $6 / 8$ patients had evidence of $\mathrm{HCV}$ infection. 2 patients had positive antibodies to HCV. These patients and 2 others had HCV RNA detectable in serum. Two additional patients with negative serum PCR had HCV RNA detected in liver tissue. Retrospective testing showed only one patient had HCV RNA in liver at presentation with AIH and probable acquisition of $\mathrm{HCV}$ infection from transfusion in 4 patients. Median time from HCV infection to HCC was 5 years. Conclusions. HCC complicating $\mathrm{AIH}$ is frequently associated with unsuspected $\mathrm{HCV}$ infection but this was usually contracted after diagnosis of autoimmune liver disease PCR in liver tissue is required to make the diagnosis of HCV infection in these immunosuppressed patients. HCC supervenes rapidly following HCV infection in these, already cirrhotic, patients.

\section{Liver T74-T81}

SEROTYPIC VARIATION AND CLINICAL CHARACTERISTICS OF CHRONIC HEPATITIS C DETECTED AT BLOOD DONOR SCREENING.

GLA Bird, E Spence, RNM MacSween ${ }^{\circ}$, D Frame ${ }^{+}$, P Yap $^{+}, \mathbf{P}$ Simmonds $\diamond, P R$ Mills. Departments of Gastroenterology and Pathology ${ }^{\circ}$ Western Infirmary, Glasgow, Scottish National Microbiology $\diamond$, University of Edinburgh, UK.

In the first two years of screening for HCV (1991-1993), the Glasgow and West of Scotland Blood Transfusion Service has tested 305,012 volunteer blood donations, of which 214 have been positive for $\mathrm{HCV}$ as determined by 2 nd generation ELISA, RIBA2 testing and PCR. We have evaluated the clinical findings, histological severity of disease and their relationship with HCV serotype in asymptomatic donors with chronic $\mathrm{HCV}$.

54 asymptomatic subjects (mean age 32, range 22-46, 22 females) underwent clinical evaluation, liver biopsy and typing by restriction fragment length polymorphisms. In 5 there was a history of jaundice or hepatitis. 22 subjects had abused IV drugs (IVDA). 16 patients had received blood products and one drug abuser also had a blood transfusion. After exclusion of subjects with tattoos and/or pierced ears, occupational risk factors and homosexuality, only 2 had no identifiable risk factors. In the 39 with a clearly defined risk factor (transfusion and IVDA), the mean interval between HCV exposure and liver biopsy was 12 years (range 4-30). All subjects had evidence of chronic liver disease as shown by raised transaminases (mean AST 68, range 19-202 [normal 10-35]; ALT 132, range 12-423 [normal 10-50]) $(n=50)$ and/or clinical signs $(n=18)$. The liver biopsy was abnormal in all subjects with features of a very low grade chronic hepatitis comprising intra-acinar, portal and periportal features now recognised as characteristic of chronic $\mathrm{HCV}$ infection; one subject had an established cirrhosis. Serotyping $(n=35)$ showed no relationship between mode of transmission or biochemical or histological severity of disease (17 type 1, 4 type 2, 14 type 3 ).

These findings confirm that chronic hepatitis $C$ is present in all asymptomatic subjects with $\mathrm{HCV}$ viraemia irrespective of liver function tests. The low prevalence of cirrhosis $(\mathbf{1 . 8 \%})$ despite a mean period of infection of 12 years suggests a slow rate of progression to irreversible liver damage. Clinical features and mode of transmission are not related to HCV serotype.
TIMP-1 ACTIVITY IN LIPOCYTE CONDITIONED MEDIA PREDOMINATES OVER COLLAGENASE EVEN AFTER TNF $\alpha$ STIMULATION

Iredale JP, Goddard S, Murphy G* \& Arthur MJP

University Medicine, Southampton General Hospital, UK.

*Strangeways Research Laboratory, Cambridge, UK.

We have recently described expression of the collagenase inhibitor Tissue Inhibitor of Metalloproteinase-1 (TIMP-1) by activated hepatic lipocytes and demonstrated that TIMP-1 mRNA expression is enhanced in comparison with interstitial collagenase (IC) mRNA in cirrhotic liver. These studies describe investigation of the IC/TIMP-1 activity relationship in a cell culture model of lipocyte activation.

Human hepatic lipocytes were extracted from normal donor liver. and the margin of hepatic resection as previously described and cultured on plastic for 21-44 days. In addition passaged lipocytes (6th passage) from two isolations were established in culture on plastic.

By Northern analysis, mRNA for IC could not be detected in total lipocyte RNA, but was present after stimulation with $\mathrm{TNF} \alpha 30 \mathrm{ng} / \mathrm{ml}$. In contrast TIMP-1 mRNA was present in unstimulated lipocytes and up-regulated in response to TNF $\alpha$.

By activity assay of serum free conditioned media, IC could not be detected in both unstimulated and TNF $\alpha$ stimulated primary lipocyte cultures $(n=4)$ and passaged lipocytes $(n=6)$. In contract TIMPactivity was present in unstimulated primary and passaged cultures 2.5 $( \pm 1.62, n=4)$ and $9.28( \pm 2.9, n=6)($ mean $\pm S D)$ units $/ 10^{\circ}$ cells/24 hrs respectively. Furthermore, TIMP-1 activity in paired cultures was up-regulated in response to TNF $\alpha: 3.69( \pm 2.6, n=4)$ and $11.42( \pm 5, n=6)$ (mean $\pm S D$ ) units $/ 10^{6}$ cells $/ 24 \mathrm{hrs}$ respectively.

In this model of lipocyte activation, TIMP-1 activity remains predominant even in the presence of up-regulated IC transcription. Predominance of TIMP-1 expression may favour the accumulation of interstitial collagens in liver fibrosis. 


\section{CLINICAL SIGNIFICANCE OF SOLUBLE INTERCELLULAR ADHESION MOLECULE-1 (ICAM-1) IN CHRONIC LIVER DISEASE} AGLim, RP Jazrawi, HA Ahmed, AC Douds, M Zuin, JD Maxwell, TC Northfield.

Dept of Medicine, St George's Hospital Medical School, London, UK.

ICAM-1 is important in the migration of inflammatory cells from the circulation and their adhesion to target tissue. A soluble form, sICAM-1 has been described in chronic liver disease, but its function remains unclear. Our aims were to determine whether sICAM-1 has relative disease specificity, and whether it correlates with pathogenic mechanisms. sICAM-1 was measured by ELISA in 41 patients with primary biliary cirthosis $(\mathrm{PBC})$ (stage $1=10$; stage $2=9$; stage $3=8$; stage $4=14$ ), 9 with primary sclerosing cholangitis (PSC), 15 with alcoholic liver disease (ALD) and in 17 healthy controls. Liver function tests were determined by routine methods, lymphocyte activation by measuring interleukin-2 receptor expression using two colour flow cytometry. Kinetic assessment of cholestasis was performed in a sub-group of PBC patients $(n=9)$ by direct measurements of rates of hepatic uptake and excretion of ${ }^{75}$ SeHCAT. SICAM-1 was elevated in all three disease groups compared to controls. PBC (median $602 \mathrm{ng} / \mathrm{ml}$, range 226-3276; $\mathrm{p}<0.0001)$, PSC $(1077,393-4219 ; \mathrm{p}<0.0001)$ and $\operatorname{ALD}(393,96-908$; $\mathrm{p}<0.05)$. The levels in PBC and PSC were also significantly higher than ALD. In PBC, sICAM-1 was higher in late compared to early disease $(p<0.0002)$, and correlated significantly with histological progression, and markers of cholestasis (alkaline phosphatase, g-glutamyl transpeptidase and conjugated bilirubin). However, it did not correlate as well with markers of hepatocellular damage (alanine transaminase and albumin). There was a trend towards an inverse correlation with hepatic excretory rate $(p=0.07)$ but not with hepatic uptake rate of ${ }^{75}$ SeHCAT. These latter parameters are direct measurements of cholestasis and hepatocellular function respectively. No correlation was detected with lymphocyte interleukin-2 receptor expression. We conclude that serum sICAM- 1 is specifically elevated in autoimmune cholestatic liver diseases. In PBC it is related to progression of disease and is a marker of bile duct damage and cholestasis.

\section{ACTIVATED LYMPHOCYTES IN THE LIVER OF PATIENTS WITH PRIMARY SCLEROSING CHOLANGITIS. RESULTS OF A MORPHOMETRIC STUDY.}

EBG Martins, AK Graham, CJ Healey, RW Chapman, KA Fleming. Dept of Gastroenterology and Nuffield Dept of Pathology, John Radcliffe Hospital, Oxford. OX3 9DU.

After being exposed to antigen, lymphocytes become activated and may express activation and memory markers. It is believed that only cells expressing either of these markers participate in cell mediated immune phenomena. AIM: To analyse the presence of the activation markers HLA-DR, high affinity interleukin-2 receptor (CD25) and transferrin receptor (CD71); as well as the memory marker CD45RO in the portal lymphocyte infiltrate in patients with primary sclerosing cholangitis PSC. Methods: Frozen $5 \mu \mathrm{m}$ thick sections were cut from Menghini core liver biopsies from 13 cases of PSC, 7 primary biliary cirrhosis (PBC), 7 auto-immune chronic active hepatitis (AIH), 6 alcoholic liver disease (ALD), 6 large duct obstruction (LDO) and 3 normal biopsies (NOR), were studied using immunohistochemistry with an alkaline phosphatase (APAAP) technique. Monoclonal antibodies against CD3, CD45RO, CD71, HLA-DR and CD25 were used. An irrelevant antibody was used as negative control. An area of $0.25 \mathrm{~mm}^{2}$ in portal areas was studied using an optical microscope connected to an image analysis system (Roche Pathology Workstation). Results: All the lymphocytes expressed HLA-DR and CD45RO in all biopsies, including ALD, although the mononuclear infiltrates were much more dense in PSC, PBC and AIH than in the other conditions. Cells expressing CD25 represented less than $5 \%$ of the infiltrate in all PSC, PBC, AIH, and LDO (where CD25+ cells were only detected in $3 / 6$ biopsies). CD25 expression was not seen in ALD and NOR. Cells expressing CD71 were found in all ALD biopsies (less than 5\% of the total mononuclear infiltrate), but were not present in any other condition. Conclusion: These results support the view that many of the hepatic immune mechanisms involved in PSC, PBC and AIH are similar, unlike ALD. They also contrast with previous reports of high expression of CD25 in portal areas of PSC and AIH.
BFFECT OF URSODEOXYCHOLIC ACID THRRAPY (UDCA) ON SURVIVAL IN PRIMARY BILIARY CIRRHOSIS (PBC) MALCOLM C. BATESON \& PETER GEDLING GENERAL HOSPITAL, BISHOP AUCKLAND, CO. DURHAM, UK

41 cases of symptomatic $\mathrm{PBC}$ in a resident population of 153,000 have been registered in 12 years. Diagnosis was confirmed by a biopsy in all but one, where it was unsafe because of clotting abnormality. 21 are still alive. giving a current prevalence similar to that documented to the whole of the North East of England (128/million). Outcome is known for all.

From June 1987 all 22 new cases were offered treatment with UDCA 750 or $1000 \mathrm{mg}$ daily, except one on prednisolone and cyclosporin for another reason. In addition 6 previously diagnosed cases were recruited for UDCA therapy.

Of the 27 given UDCA treatment, 2 stopped for early exacerbation of symptoms. 19 have taken treatment for six months to six years under hospital supervision, of whom 6 have died. Predictors of survival at entry included: histological stage $1(p<.041)$, lower age (median 64 vs. 71 years, p .01 ), lower bilirubin ( 9 vs. 25 micromol/l, p <.01), lower IgG level (11.8 vs. 19.9 $\mathrm{g} / \mathrm{l}, \mathrm{p}<.05)$, higher $\mathrm{Hb} .(13.4$ vs. $11.9 \mathrm{~g} / \mathrm{dl}, \mathrm{p}<.050$ ).

Life table analysis showed that survival in $\mathrm{PBC}$ treated with UDCA was still very significantly less than expected for the general population $(p<0.01)$. Results were compared with the other 13 cases not given UDCA (with very similar characteristics) in whom there were 9 deaths in a 9 year follow-up. There was a significant survival advantage for UDCA therapy $(71 \%$ vs. $37 \%$, at 5 years $)(p<.05)$.

CONCLUSION

Survival is still diminished in PBC after UDCA therapy and can be predicted from initial values, but it appears to be improved compared with untreated patients.

THE EFFECT OF $N^{9}$-MONOHETHYL-L-ARGININE (L-NHAA) ON PORTAL PRESSURE GRADIENT AND AZYGOS BLOOD FLOW AMONGST PATIENTS WITH CIRRHOSIS

E Forrest. A Jones, I Dillon. $\mathrm{P} G$ Hayes, Liver Research Laboratories, Department of Medicine, Royal Infirmary, Edinburgh EH3 9YW

It is proposed that the hyperdynamic circulation of cirrhosis is mediated through the induction of nitric oxide (NO) synthase by endotoxaemia. NO causes vasodilatation and may lead to increased splanchnic inflow contributing to portal hypertension.

We studied 7 patients with biopsy proven cirrhosis ( 6 male, 1 female). Child grades were $A: 1 ; B: 3 ; C: 3$. The NO synthase inhibitor $\mathrm{N}^{9}$-monomethyl-L-arginine (L-NMMA) was infused over 30 minutes at a dose of $3 \mathrm{mg} / \mathrm{kg}$. Free and wedged hepatic venous pressures (FHVP, WHVP) were measured at baseline and at 30 minutes. Azygos blood flow, heart rate and blood pressure were measured before and throughout the infusion. Hand temperature was measured using liquid crystal thermography before and at the end of the L-NMMA administration.

Results: There was a significant incremental rise in diastolic (mean $\pm \mathrm{SE} / 4 . j \pm 1.95$ to $87.1 \pm 4.35, \mathrm{p}<0.05$ ), systolic $(134.6 \pm 6.57$ to $149.4 \pm 7.32, p<0.05)$ and mean arterial pressures $(74.7 \pm 1.6$ to $106.9 \pm 4.33, p<0.05)$. The heart rate $f \in 11$ during the study $(79.7 \pm 6.11$ to $69.3 \pm$ 2.60 . $p<0.05)$. There was no significant change in hepâtic venous pressure gradient (HVPG = WHVP - FHVP) (16.3 +2.31 to $13.2+2.34, p=0.75$ ) or azygos blood flow $(14) .1+28.3$ to $124.6+35.1 . p=0.95)$. Those patients whose hands were anisothermic betore the infusion became i sothermic afterwards.

Conclusion: No synthase inhibition whilst having sigriticant hatmodynamic effects upon the peripheral circulation. had no significant effect upon the portal pressuie gradient or azygos blood flow. 
EXPERIENCE WITH FK506 CONVERSION THERAPY FOR LIVER ALLOGRAFT REJECTION IN CHILDREN

\author{
V.Bhatnagar, A.Dhawan, M.Rela, N.D.Heaton, \\ A.Baker, B.Portmann, A.P.Mowat, Roger \\ Williams, K.C.Tan \\ King's College Hospital, Denmark Hill, London
}

Reports in adults have suggested that FK506 has considerable efficacy in the management of acute cellular and chronic liver allograft rejection. There is little data available in children. We report our experience of the use of FK506 for the treatment of acute and chronic liver allograft rejection after liver transplantation in children. Primary immunosuppression was with cyclosporine, azathioprine and prednisolone. Episodes of rejection were confirmed histologically and the first and second episodes were treated with pulse dose steroids.

Fourteen paediatric liver transplant recipients (median age 6 years) (15\% of paediatric transplants) were converted to FK506 for acute rejection not responding to standard antirejection therapy ( 6 children) or for chronic rejection ( 8 children)

All 6 patients with acute rejection responded to FK506 and remain on a maintenance dose long term. Eight patients were given FK506 for chronic rejection. Two developed late hepatic artery thrombosis and were successfully retransplanted. There was no response to FK506 therapy in the remaining 6 children. Four children were retransplanted, 3 successfully, and one died from sepsis. Two children died awaiting retransplantation.

our experience suggests that FK506 is effective in the management of intractable acute rejection, but has no efficacy in the treatment of established chronic rejection.

\section{Oesophagus T82-T92}

SENSORY AND MOTOR REPRESENTATION OF THE HUMAN OESOPHAGUS ON THE CEREBRAL CORTEX

Q.Aziz, *J.C.Rothwell, **P.Furlong, J.Barlow, A.Hobson, S.Alani, **G. Harding and D.G.Thompson.

Departments of Medicine \& Neurophysiology, Hope Hospital, Manchester, *Institute of Neurology, London $\&{ }^{* *}$ Aston University, Birmingham.

BACKGROUND: Oesophageal Evoked Cortical Potentials (OECP's) and magneto-electric stimulation of the human brain have been used to study oesophageal sensory and motor pathways respectively, however, the oesophageal sensory and motor loci on the cortical hemispheres remain unknown. AIMS: To identify the centres for oesophageal sensation and motility on each cortical hemisphere. METHODS:

1) Sensory Pathways: In 8 right handed volunteers, oesophageal stimulation was performed using a $2 \mathrm{~cm}$ silicone balloon rapidly inflated at a frequency of $0.2 \mathrm{~Hz}, 5 \mathrm{~cm}$ above lower oesophageal sphincter. OECP's to two series of 50 inflations were averaged and recorded using 24 scalp surface electrodes referenced to both ear lobes.

2) Motor Pathways: In 8 right handed volunteers focal stimulation of $49,1 \mathrm{~cm}$ areas of each cerebral hemisphere was performed by discharging magneto-electric pulses using a magnetic stimulator. discharging magneto-electric pulses using a magnetic stimulator. Oesophageal EMG responses were recorded $2 \mathrm{~cm}$ below the upper
oesophageal sphincter using bipolar ring electrodes. RESULTS: 1) Sensory Locus: OECP's were recorded in all subjects. Group data: A primary cortical source was identified on each somatosensory cortex, 4-6cm lateral to the vertex. Individual data: showed predominance over the right hemisphere in 4 subjects and to the left hemisphere in 3 subjects, while one subject showed equal representation on both hemispheres. 2) Motor Locus: Oesophageal EMG responses were evoked from both hemispheres in all subjects. Group Data: The site evoked from both hemispheres in all subjects. Group Data: The site
of maximum cortical responsiveness was a $2-4 \mathrm{~cm}$ area overlying the frontal cortex on either side, $4-6 \mathrm{~cm}$ from the vertex. The maximum amplitude of the EMG responses obtained by stimulation of the right hemisphere, $65.4 \pm 7.7 \mu \mathrm{V}$, (Mean $\pm S E M)$ ) was larger than that from the left hemisphere, $33.5+3 \mu \mathrm{V},(p=0.01)$. Individual Data: In seven subjects, the oesophageal centre was larger on the right hemisphere and response amplitudes were twice as large in comparison to the left hemisphere $(\mathrm{p}<0.01)$. In one subject, in contrast the oesophageal motor centre was located on the left hemisphere. CONCLUSION: A sensory
and motor centre for the oesophagus is present on each cortical and motor centre for the oesophagus is present on each cortical
hemisphere, however, most subjects show unilateral hemispheric dominance which is independent of handedness.
ALTERED BLADDER FUNCTION AND OESOPHAGEAL PAIN THRESHOLD IN IRRIT BBLE BOWEL SYNDROME.

JM Marrero, AK Monga*, SL Stanton* and JD Maxwell. Dept of Medicine and Urogynecology*, St. George's Hospital Medical School, London SW17 ORE UK

The pathophysiology of irritable bowel syndrome (IBS) is poorly understood. Altered small bowel and colonic motility as well as lowered oesophageal/colonic pain thresholds are reported. These may reflect an altered visceral receptor sensitivity or an impaired periphera or central modulation of perceptive stimuli throughout the gut Genitourinary symptoms are also common suggesting a generalised alteration of smooth muscle in IBS. The aims of this study were to investigate bladder function and oesophageal sensitivity in female patients with documented IBS to ascertain whether a generalised disorder of smooth muscle exists. Methods: 12 premenopausal patients, mean age $28 \pm 1.9$, with IBS (normal upper GI endoscopy and oesophageal motility) were studied. Symptom scores were calculated based on Manning's criteria. None had previously complained of urinary problems. Balloon distension studies were performed with a latex balloon on a multilumen manometry catheter placed $5 \mathrm{~cm}$ above the lower oesophageal sphincter to assess oesophageal perception and pain before and after oesophageal perfusion with $300 \mathrm{ml}$ of $0.1 \mathrm{~N} \mathrm{HCl}$ Urinary symptoms were assessed by structured interview and urodynamic diagnosis made after twin channel cystometry was performed without knowledge of oesophageal results. Results: No significant differences were found in balloon distension volumes for oesophageal perception $(7.6 \mathrm{ml} \pm 1.3$ vs $6.1 \mathrm{~mL}+0.9, \mathrm{NS})$ or pain $(10.8$ $\mathrm{ml} \pm 1.3$ vs $9.6 \mathrm{ml} \pm 1$, NS) after acid perfusion. All 12 patients had urodynamic investigations: 3 had detrusor instability, 3 had sensory urgency. Patients with abnormal urodynamic tests had significantly higher IBS symptom scores than those with normal tests $(10.5 \pm 0.56$ vs $7.1 \pm 0.54, p<0.006$ ). Conclusions: Oesophageal pain thresholds in acid sensitised patients were unchanged, suggesting increased sensitivity already exists in patients with IBS. The correlation between a high IBS symptom score and detrusor instability and sensory urgency provide evidence that IBS may be part of a generalised disorder of smooth muscle.

NORMAL PHARYNGO-OESOPHAGEAL (PO) MOTILITY AT REST, DURING EATING AND SLEEP

\section{JA Wilson*. A Pryde. R C Heading}

Dept. Otolaryngology, Head and Neck Surgery*, Royal Infirmary, Glasgow and Dept. Medicine, Royal Infirmary, Edinburgh

The features of stationary PO motility have been well characterised using fine bore intraluminal strain gauge assemblies, but little is known of the PO diurnal pressure variation. The aim of this study was to compare PO deglutition dynamics at rest, during a meal and asleep and to evaluate the reliability of tonic upper oesophageal sphincter pressure (UOSP) measurements during station pull-through (SPT)

METHODS: 14 asymptomatic healthy volunteers, IIM, 3F, age 21-67 (median 30) years were studied with a 4 sensor gauge assembly (OD $2.5 \mathrm{~mm}$ ) linked to a microprocessor (Gaeltec Ltd), sample speed $8 \mathrm{~Hz}$. After UOS SPT $(0.5 \mathrm{~cm}$ stations, $20 \mathrm{sec} / \mathrm{station})$ the triple sensor was sited in the UOS during ambulatory overnight home monitoring. A semi automated analysis of 10 swallows in each time period was performed.

RESULTS: medians, in $\mathrm{mmHg}$; UOSPs an average of 3 radial sensors:

Tonic UOSP UOS Contraction Pharynx Contraction

SPT

Sleep-inactive

Sleep-swallowing

$$
43
$$

Interprandial

$20^{* *}$
32
$29^{*}$
34

$\begin{array}{lll}\text { *ating } & 34 & 140+ \\ & \mathrm{P}<0.05 \text { vs SPT UOSP, Mann-Whitney }\end{array}$

102

123

** $\quad \mathrm{P}<0.001$ vs SPT UOSP, $\mathrm{P}<0.02$ vs other UOSPs

$+\quad \mathrm{P}<0.05$ vs interprandial UOS contraction pressures

CONCLUSIONS: The increased UOS contractions during eating confirm previous stationary bread swallow studies. Dry swallow dynamics during sleep are similar to those in the awake subject. Conventional SPT methods appear to generate higher tonic UOS pressures than prolonged manometric recordings, presumably due to UOS stimulation by catheter withdrawal. Tonic UOSP in sleep shows a biphasic pattern, with a low pressure quiescent phase which contrasts with the higher resting pressure between swallows during a phase of greater arousal. 
THE USE OF A SODIUM ION SELECTIVE ELECTRODE TO DETECT BLE IN THE OESOPHAGUS

A Smythe, YF Mangnall, DI Watson \& AG Johnson

Department of Surgical and Anaesthetic Sciences, Royal Hallamshire

Hospital, Sheffield, UK.

Assessment of duodeno-oesophageal reflux is difficult, as there is no technique readily available which allows continuous ambulatory monitoring. A sodium ion selective electrode placed in the stomach has been previously shown to detect duodenogastric reflux by using sodium as an indirect marker. This relies on the difference in sodium concentration between gastric ( 5 to $60 \mathrm{mmol} / \mathrm{l}$ ) and duodenal, bile and pancreatic $(150 \mathrm{mmol} / \mathrm{l})$ fluids.

Methods and Results ; Seven subjects without symptomatic gastro-oesophageal reflux and 5 subjects with known duodenogastric reflux were studied with the electrode placed in the lower oesophagus. The baseline reading varied from 19 to $59 \mathrm{mV}$, and was deducted from subsequent recordings to allow comparison between subjects. $30 \mathrm{ml}$ volumes of varying sodium solutions $(40,80,100,140 \mathrm{mmol} / \mathrm{l})$ were swallowed to assess the response of the electrode to sodium ions. This revealed a constant rise in activity with increasing concentration $(12 \pm 0.54 \mathrm{mV}, 23 \pm 1.3,27 \pm 1.6,36 \pm 1.8$; mean \pm S.E.M. $)$.

The stomachs of subjects with duodenogastric reflux were aspirated via a nasogastric tube to obtain 9 different samples of gastric fluid. This was assayed for sodium and bile acid concentration. The fluid was then reinfused as $30 \mathrm{ml}$ boluses into the oesophagus through a tube to simulate oesophageal reflux. A rise of 12 to $16 \mathrm{mV}$ was recorded by the electrode to samples which contained between 58 and $81 \mathrm{mmol} / \mathrm{l}$ sodium, and a response of up to $6 \mathrm{mV}$ to concentrations less than $49 \mathrm{mmol} / \mathrm{l}$. This response was appropriate to the assayed bile acid concentration in all but one sample.

Conclusions ; The sodium ion selective electrode responds to sodium and bile containing fluids introduced into the oesophagus. It should be possible to use it for the continuous measurement of duodeno-oesophageal reflux.

THE NATURAL HISTORY OF REFLUX OESOPHAGITIS: A 10 YEAR FOLLOW-UP NI McDougall, BT Johnston, F Kee, JSA Collins, RJ McFarland, RGP Watson, AHG Love. Dept of Medicine, Queens University of Belfast, and Ulster Hospital, Dundonald, UK.

Aims: To study the long term effects of oesophagitis and its cost to the community.

Methods: Eighty-eight patients in whom grade I - III oesophagitis (modified Savary-Miller class.) was diagnosed in one centre 10 to 12 years ago were traced and invited to complete a detailed questionnaire on symptoms and drug therapy. Eleven patients had died (none due to oesophageal disease), 32 did not respond and 45 replied (22 male).

Results: Forty-five patients (mean age 56.9yrs, range 28 to $81 \mathrm{yrs}$ ) were followed-up after a mean of 138 months (121-153 months). Thirteen (29\%) had grade I oesophagitis at initial endoscopy and 32 $(71 \%)$ had grade II-III. Heartburn occurred at least monthly in 30 $(67 \%)$ patients of which $15(33 \%)$ had daily symptoms. Severity of symptoms was considered minor in $21(47 \%)$, moderate/major in 22 $(49 \%)$ or unbearable in $2(4 \%)$. Twenty-one $(47 \%)$ said their condition was better now than 10 years ago. Twenty-three (51\%) were currently on maintenance acid suppression $+/$ - antacids, and a further $11(24 \%)$ were on antacids alone at least weekly. Only 2 patients were not on any anti-reflux medication. No patient had undergone anti-reflux surgery or had developed an endoscopically proven stricture, although $4(9 \%)$ had daily dysphagia with liquids and solids. No significant differences were found on comparing the symptoms and drug consumption of those with grade I oesophagitis to those with grades II or III. A total of 8813 weeks of standard dosage of either H2-receptor antagonists or proton pump inhibitors had been taken over the review period - an average of 192 weeks of therapy per patient. Based on today's prices this approximates to a total cost of $£ 62,710$, or $£ 121$ per patient per year for acid suppression therapy alone.

Conclusions: Oesophagitis contributes significantly to morbidity in the community 10 years after initial diagnosis. Grade of oesophagitis did not influence the degree of symptoms or amount of therapy taken.
HIGH GRADE DYSPLASIA IN BARRETT'S OESOPHAGUS HOW SHOULD IT BE MANAGED?

Wright TA'. Myskow MW". Nash J", Gray M'. Kingsnorth AN". Departments of Surgery " and Pathology ", Royal Liverpool Hospital, Liverpool and Department of Pathology ', Broadgreen Hospital, Liverpool.

The natural history of high grade dysplasia (HGD) in Barrett's oesophagus is unknown. However, it is often quoted that patients with this degree of dysplasia on biopsy should be referred for oesophagectomy because they have a high risk (50$80 \%$ ) of having an associated invasive cancer. However, the studies which showed this were small. Recently, it has been suggested that careful endoscopic surveillance may be more appropriate in order to avoid unnecessary surgery which has a high morbidity and not insignificant mortality.

We have reviewed a total of 15 patients who had a diagnosis of HGD in Barrett's oesophagus between 1989 and 1993. All were male. In 7 , invasive cancer was subsequently diagnosed on repeat biopsy or resection. 6 of these 7 patients had suspicious lesions and one had an ulcer at the time of original endoscopy. All7 had dysphagia. Of the 8 others who have not developed invasive cancer none had clinical or endoscopic features of cancer: 4 had resections which showed HGD with no invasion and the other 4 patients who have not had resections have not developed invasive cancer despite careful endoscopic surveillance and extensive biopsy. One patient has had a consistent diagnosis of HGD for 3 years. In 2 patients only low grade dysplasia has been found subsequently and in one other patient moderate grade dysplasia remains.

We conclude that patients with HGD and signs or symptoms of oesophageal cancer should be considered for surgery. In patients who do not have dysphagia or endoscopic lesions regular endoscopic surveillance is a satisfactory alternative. HGD may not progress for many years and may even regress as shown in 3 of our patients.

MALIGNANT CYTOLOGY IN BARRETT'S OESOPHAGUS: AN INDICATION FOR OESOPHAGECTOMY?

R.H.Hardwick, B.F.Warren*, M.Lott*, D Alderson

University Departments of Surgery and Histopathology*, Bristol Royal Infirmary, Bristol BS2 8HW

Oesophageal cytology in the presence of inflammation and ulceration can be difficult to interpret. This is particularly important in Barrett's oesophagus, where a diagnosis of severe dysplasia may prompt major surgery. In seventy two patients with Barrett's oesophagus, six were identified in whom the cytological features were at variance with both histological assessment and clinical outcome.

Cytology and histology were obtained on at least three separate occasions from the six patients (mean age 66 yrs., median follow-up 36 months). These were reviewed independently by two pathologists, one with a special interest in gastrointestinal pathology, the other in cytopathology, without prior knowledge of the original reports. A consensus diagnosis was agreed for each slide. No histological report changed as a result of the review, but 7/19 cytology reports were downgraded from the original. It was noted that regenerative nuclear atypia was associated with excessive numbers of background hyperplastic cells in the cytological smears.

All six patients had ulceration in association with their Barrett's segment. Following review, cytological assessment indicated moderate or severe dysplasia in all patients. In addition, cytology at some time indicated one adenocarcinoma and one case highly suggestive for carcinoma. In contrast, there were no histological appearances of dysplasia or carcinoma. During endoscopic follow-up, no patient has developed macroscopic or histological evidence of oesophageal carcinoma.

In conclusion, dysplastic/malignant cytology in Barrett's oesophagus, particularly in the presence of ulceration, should prompt careful endoscopic follow up with multiple biopsies examined at many levels histologically. Oesophagectomy based on cytological abnormalities alone should not be performed. 


\section{THE USE OF ENDOLUMINAL ULTRASONOGRAPHY IN STAGING OESOPHAGEAL CARCINOMA}

\section{J.Vickers. M.Vipond. D Alderson.}

University Department of Surgery,

Phase 2 Building, Bristol Royal Infirmary

Marlborough Street.

Bristol BS2 8HW

The accuracy of computerised tomography (CT) or magnetic resonance imaging (MRI) in assessing local tumour invasion and lymph node involvement in oesophageal cancer is limited by image resolution. Endoluminal ultrasound (EUS) is a new endoscopic technique, capable of visualising individual layers of the oesophageal wall and adjacent lymph nodes.

Twenty five patients with oesophageal carcinoma underwent both EUS and CT scanning prior to oesophagectomy. Tumour and lymph node stages for EUS and CT (using the TNM system) were compared with subsequent histological stage.

EUS accurately identified the depth of invasion in twenty three patients. Understaging and overstaging occurred once each (sensitivity = $95 \%$, specificity $=80 \%$, positive predictive value $=0.95$, negative predictive value $=0.80$ ). EUS also accurately assessed nodal involvement, which was correctly predicted in twenty two patients, with two cases overstaged and one understaged (sensitivity $=95 \%$, specificity $=50 \%$, positive predictive value $=0.91$, negative predictive value $=0.67$.

CT was unreliable for the detection of either local infiltration or nodal spread. CT could detect generalised mural thickening (all cases) but not the precise depth of infiltration. CT failed to identify malignant nodes in any patient, and correctly matched histological lymph node stage only three times.

These early results indicate that EUS is a highly reliable method for imaging oesophageal tumours. It provides accurate preoperative staging data, and should help improve patient selection for the appropriate treatment of oesophageal cancers
LAPAROSCOPIC "PHYSIOLOGICAL" ANTI-REFLUX PROCEDURE: PRELIMINARY RESULTS OF A PROSPECTIVE SYMPTOMATIC AND OBJECTIVE STUDY.

A. Watson. R.T. Spychal, M.G. Brown, N. Peck. N. Callander. Royal North Shore Hospital, Sydney, Australia.

The "Physiological" anti-reflux procedure has been shown to be as effective as Nissen fundoplication in reflux control, but with a significant reduction in the incidence of mechanical complications. Its relative ease of performance and obviation of the necessity to divide the short gastric vessels make it potentially attractive for laparoscopic use.

The procedure was attempted laparoscopically in 26 patients as part of a prospective study involving independent symptomatic, manometric and $\mathrm{pH}$ assessment performed pre-operatively and three months post-operatively.

The procedure was successfully completed laparoscopically in 23 $(88 \%)$ patients in a mean operating time of 2.3 hours. Mean hospital stay was 3.8 days and mean return to work 1.8 weeks. There was no mortality, but a $15 \%$ incidence of peri-operative complications. $91 \%$ of patients had complete symptomatic relief and there was no incidence of gas-bloat or inability to belch/vomit. 11 patients have undergone objective testing to date, all having a normal post-operative $\mathrm{pH}$ profile the mean $\%$ total time $\mathrm{pH}<4$ falling from 10.9 to 1.1 . The incidence of LOS relaxation by $>$ $80 \%$ on swallowing was unchanged by surgery.

While greater numbers and longer follow-up are required, these preliminary results suggest as good symptomatic and objective outcome as following open surgery, with a shorter hospital stay and time off work. In addition to a lower incidence of mechanical complications, the relative ease of performance of this procedure confers an additional advantage over Nissen fundoplication when performed laparoscopically.
ENDOSCOPIC PALLIATION OF OESOPHAGEAL CANCER: EXPERIENCE WITH A NOVEL EXPANDABLE (MICROVASIVE) METAL PROSTHESIS. R. Merriman, P. Mac Mathuna, J. Crowe \& J. Lennon. Gastrointestinal Unit, Mater Misericordiae Hospital, University College Dublin.

The optimal palliation of malignant dysphagia has not been established. Furthermore, the role of expandable metal stents remains unclear. We report our preliminary results using a novel metal mesh prosthesis.

Patients and methods Fourteen patients (30-85yrs, male:female $6: 6$ ) with inoperable oesophageal cancer had a mean dysphagia score of 2.5 (Mellor \& Pinkas). The lesions ranged from 4-10 cms in lenght and tumour margins ranged from $18 \mathrm{cms}$ (proximal) to below the GOJ. Seven patients had prior unsuccessful attempts at laser palliation. An expandable mesh stent (Microvasive Ultraflex, 7 - $17 \mathrm{cms}$ in lenght) was inserted across the lesion endoscopically under fluroscopic control without complication.

Results Within 48 hours the stent was fully expanded and all patients were swallowing normally. Chest pain requiring NSAID or opiate occured in 4 patients while 4 patients had severe reflux symptoms responsive to omeprazole. After short term follow-up (median 10 weeks, range 2 22), 9 patients (75\%) had normal swallowing score (0) while 3 patients had recurrent dysphagia from tumour ingrowth which responded to laser therapy.

Conclusion, Our preliminary results suggest that the microvasive expandable metal prosthesis provides rapid and effective palliation for malignant dysphagia although tumour ingrowth may necessitate adjuunct therapy.
GASTROPLASTY AT FLEXIBLE ENDOSCOPY FOR GASTRO. OESOPHAGEAL REFLUX DISEASE. $C P$ Swain, $S S$ Kadirkamanathan, DF Evans, G Brown, E Gong, M Scott, E Yasaki, I Mills. Gastrointestinal Science Research Unit, The Royal London Hospital and Department of Medical Physics, University College, London.

We developed and applied in man a new minimally invasive operation for gastro-oesophageal reflux (GOR) at flexible endoscopy without laparotomy or laparoscopy. Using a newly developed sewing machine (ESM) mounted on a standard gastroscope endoscopic gastroplasty (EG) was performed as follows. The ESM was advanced $1 \mathrm{~cm}$ beyond the cardio-oesophageal mucosal junction and rotated to the right. A nylon stitch was passed deep to the muscularis propria, caught in the machine which was withdrawn and reloaded outside the mouth Another stitch was placed to the left of the midline, the stitched tissue was pulled tightly together with 3 half hitches which were tied outside the mouth and tightened using knot pusher mounted on an endoscope. This sequence was repeated extending oesophageal sleeve into stomach. EG was first performed in 8 beagle dogs. All recovered without bleeding or perforation. Median lower esophageal sphincter and endoscopic yield pressures increased from the pre-operative value of 5 and 10 to 14.5 and $20 \mathrm{~mm} \mathrm{Hg}(\mathrm{p}=0.04, \& 0.02)$ respectively. Intact stitches and knots were identified 1-6 months post procedure. This operation was performed in two patients with severe reflux symptoms unresponsive to omeprazole who declined conventional or laparoscopic surgery. The procedure was performed under light sedation, lasted $30 \mathrm{mins}$ and the patients were ambulant 1 hour later. A 36 year old female and a 57 year old male had EG with good symptomatic relief, but variable changes on $\mathrm{pH}$ and manometric measurements. Duration of $\mathrm{pH}<4$ on $24 \mathrm{hr}$ pHmetry decreased from 50 to $0 \mathrm{~min}$. with patient 1, but increased from 64 to $110 \mathrm{~min}$. with patient 2, after the procedure. Possible advantages of a flexible endoscopic operation for reflux include minimal tissue trauma, safety and reversability. Early results show that EG can give good clinical results in patients. 
ENDOSCOPY IN THE TRENT REGION 1992 Brian B Scott

\section{County Hospital, Lincoln LN2 5QY}

Previous surveys of G-I endoscopy in the whole Trent region in 1981 and 1986 showed a doubling of the number of both upper G-I endoscopies and colonoscopies whereas barium meal examinations had not changed and barium enema examinations had increased by $20 \%$. Numbers of ERCP and variceal sclerotherapy were also recorded and deficiencies in the provision of endoscopy services documented. A further survey of endoscopy in the whole region during 1992 has been undertaken and the results compared with 1986.

Upper G-I endoscopies had increased by $18 \%$ and colonoscopies by $64 \%$. There were 8.5 upper G-I endoscopies and 1.5 colonoscopies per 1000 of the population. At the same time there had been a dramatic fall in barium meals by $38 \%$ (to 4.6 per 1000) and just a slight rise of $3 \%$ (to 4.9 per 1000) in barium enemas. The contribution by surgeons had increased slightly to $30 \%$ for upper G-I endoscopy and $57 \%$ for colonoscopy. A total of 2531 ERCPs $(0.54$ per 1000 compared with 0.37 in 1986) were done at 13 of the 20 hospitals. $82 \%$ were done by physicians and 53을 were therapeutic. 1479 PEGs were done in 16 hospitals ( $97 \%$ by physicians). Variceal sclerotherapy was done in all except 5 hospitals compared with 11 in 1986 . There was an increase from 770 to 930 and surgeons contributed in only three hospitals. Six patients died - two at upper G-I endoscopy and 4 at ERCP. Intravenous sedation (usually midazolam but Diazemuls in 5 hospitals) was used routinely in 12 hospitals and was usually combined with lignocaine throat spray in 10 hospitals. There were 19 oesophageal perforations (ten during dilatation) only one of which caused death. Emergency endoscopy was available at night in only 10 hospitals. Uncensored open access endoscopy was offered by four hospitals and censored open access in another ten. Video systems were availahe in 16 hospitals but only 13 had a videoscope. There were serious deficiencies in the provision of facilities and; or staff at 14 of the hospitals.

\section{ENDOSCOPIC LASER PALLIATION FOR COLORECTAL CANCER}

\author{
CC Tan, SY Iftikhar. JG Freeman \\ Gastroenterology Unit, Derby City General Hospital, \\ Uttoxeter Road, Derby DE22 3NE, UK
}

Despite increasing success in surgical treatment for colorectal cancer, there remains nearly one in ten cases where surgery is not feasible because of patient's age, medical condition or cancer stage, and where local complications such as obstruction, bleeding, diarrhoea or tenesmus demand some form of palliation.

Since Nd YAG laser therapy became available in our unit in November 1988, we have treated 26 cases of colorectal cancer with laser, 16 men and 10 women of mean age 75 , with $17(65 \%)$ rectal, $8(31 \%)$ sigmoid and 1 $(4 \%)$ ascending colon tumours. Five $(20 \%)$ had previous resections while the rest were treated primarily with laser. They were considered inoperable because of advanced age in $5(19 \%)$, medical contraindications in $6(23 \%)$ and advanced stage of malignancy in $15(58 \%)$. They presented with symptoms primarily of obstruction in $7(27 \%)$, bleeding in $5(19 \%)$, diarrhoea in $4(15 \%)$ and a combination of these including tenesmus in 10 (38\%).

Initial therapy to relieve symptoms required a mean of $1.5(1-3)$ laser treatments over a mean of $15(1-2)$ weeks. Fifteen patients required and received subsequent maintenence therapy, with a mean of $2.8(1-15)$ laser treatments performed over a mean interval of $7.3(1-20)$ weeks. Twenty four patients $(92 \%)$ had satisfactory relief from their symptoms, $12(46 \%)$ with total relief and $12(46 \%)$ with partial relief. Only $2(8 \%)$ enjoyed no relief at all. The complication rate was $12 \%$ with 1 patient suffering hypotension, 1 cardiac failure and 1 stercoral perforation. The latter 2 patients died within 72 hours of laser treatment. Four patients remain alive after a mean follow up period of 51 months (9-84 months). The mean survival of the others was 5 months (0-23 months). Mean inpatient stays were 4.8 days (1-14 days) for completion of initial treatment, and 1.9 days (0.5-8 days) per maintenence laser treatment.

Laser palliation of colorectal cancer is efficacious and safe, allows improved quality of survival in more than $90 \%$ of patients, and compares favourably with surgical palliation and alternative means of palliation in those patients who are unfit or unsuitable for surgery.
GASTRIC CANCER PRESENTING WITH UNCOMPLICATED DYSPEPSIA IS RARE AND NOT WORTH SCREENING FOR BELON THE AGE OF 55.

Christie $J$, Codling $B$ and Valori $R$

Gloucester Royal Hospital, Great Western Road, Gloucester, GL1 3NN

It is recommended that people with recent onset, or persistent dyspepsia aged over 45 are endoscoped even if there are no suspicious symptoms. We tested the hypothesis that gastric cancer presenting with such uncomplicated dyspepsia is rare below the age of 55 .

Our sample was drawn from a pathology database of a District General Hospital (DGH) with a stable and welidefired population of 280,500 . This hospital has provided an open access endoscopy service for more than 15 years. All cases of gastric cancer during the latest 7 year period (1986-1992) were reviewed and ranked according to age. Cases with postcodes outside the catchment area of the hospital were excluded. Casenotes of those aged less than 55 at the time of diagnosis were reviewed. We defined uncomplicated dyspepsia as dyspepsia without suspicious indicators of malignant disease such as unexplained recent weight loss (>3kgs), dysphagia, haematemesis or melaena, anaemia, previous gastric surgery, palpable mass and perforation.

During the seven year period there were 319 cases of gastric cancer of which 26 were aged less than 55 . Twenty five of 26 patients (96\%) presented with one or more suspicious symptom or sign: weight loss 16 , dysphagia 7, provious gastric surgery 3, palpable mass 3 , anaemia 2 and perforation 1 . One patient presented with cerebral metastases.

Gastric cancer is rare below the age of $55(8.2 \%$ of ali cases) and, even in the presence of established open access endoscopy, presents with suspicious symptoms or signs $96 \%$ of the time. A DGH serving a population of 280,000 can expect to detect one case of gastric cancer aged less than 55 with uncomplicated dyspepsia every 7 years. The age limit for screening uncomplicated dyspepsia can be raised safely to 55 .
ENDOSCOPIC BALLOON SPHINCTEROPLASTY (EBS) FOR BILE DUCT STONES: EFFICACY AND FOLLOW-UP IN THE FIRST 90 PATIENTS. P. Mac Mathuna, P. White, E. Clarke, J. Lennon \& J. Crowe. Gastrointestinal Unit, Mater Misericordiae Hospital, University College Dublin, Ireland.

since papillotomy accounts for the major morbidity / mortality associated with ERCP we have previously proposed sphincteroplasty (EBS) as a safe and effective alternative for small to medium sized bile duct (BD) stones $(<20 \mathrm{~mm})$. We now report the efficacy and complications of EBS in a series of 90 patients.

Patients and Methods EBS was considered for BD stones up to $20 \mathrm{~mm}$ in 90 patients, 24 post cholecystectomy, (mean age 64, range 19-89, 66 female, 24 male), of whom 17 were under 40yrs. Stone size ranged from $3-20 \mathrm{~mm}$ (mean $10 \mathrm{~mm}, \max 8$ ). EBS was performed using a balloon tipped catheter (Microvasive) over a 0.21 guidewire inflated across the papilla (60secs $\times 2$ ) to a diameter of $10 \mathrm{~mm}$ allowing access for stone retrieval. Median follow-up was 10 months (range 0.5-20).

Results Using EBS alone, the bile duct was cleared in 70 patient's $(76 \%)$. Mechanical lithotripsy was used to remove large stones (15$20 \mathrm{~mm})$ in $13(15 \%)$. Of the 20 EBS "failures" (24\%) papillotomy was required to clear the duct in 7 (9\%). A pigtail stent was inserted in 13 (15\%) to maintain biliary drainage a) as a temporary measure because of doubt about residual stones $(n=7,9 \%)$, or $b)$ as a definitive measure in elderly high risk patients with multiple stones $>15 \mathrm{~mm}(\mathrm{n}=6,6.5 \%)$. ERCP was repeated in 14 (16\%) for stent removal +/- replacement or repeat EBS-duct clearance $(n=4)$. There was no papillary haemorrhage, while uncomplicated pancreatitis was observed in 4 patients $(5 \%)$.

Conclusion EBS is a safe and effective sphincter preservation technique for the management of BD stones up to $20 \mathrm{~mm}$ in size, which significantly reduces the need for papiliotomy. 
EARLY CLINICAL EXPERIENCE WITH A REAL-TIME, 3DIMENSIONAL, ELECTROMAGNETIC IMAGING SYSTEM TO AII COLONOSCOPY

${ }^{1}$ BP Saunders, ${ }^{1}$ GD Bell, ${ }^{2}$ CB Williams, ${ }^{3}$ JS Bladen, ${ }^{3}$ AP Anderson

Department of Medicine, Ipswich Hospital, Ipswich, UK, ${ }^{2}$ Department of Endoscopy, St.Mark's Hospital, City Rd, London UK and ${ }^{3}$ Department of Electronic Engineering, University of Sheffield, Sheffield, UK

INTRODUCTION Uncertainty in anatomic location of the colonoscope tip can be misleading prior to surgery, whilst difficulty in assessing or controlling shaft looping is responsible for much of the difficulty in performing and teaching colonoscopy. We have independently developed two safe and inexpensive non-X-ray systems for imaging the colonoscope within the abdominal cavity; Lancet 1993; 341 $719-22$. and Lancet 1993; 341:724-5. We report here on our updated clinical experience with the former system.

METHOD Magnetic fields are generated external to the patient which are then detected by sensor coils mounted inside the colonoscope. Electrical signals processed from the sensors enable the position and orientation of each sensor to be calculated. By fitting a smooth curve through each of the calculated points an image of the colonoscope shaft is built-up and displayed on a computer monitor: the 3-D effect is created by differential grey shading and the image is updated at least every 0.2 seconds so that the system is effectively real-time. Images produced can be stored on disk and replayed for teaching or research purposes.

RESULTS Preliminary clinical experience has shown the suprisingly variable looping configurations that may occur during colonoscopy and confirmed that without the benefit of the imager view, even an experienced endoscopist is unable to accurately identify the type of loop that has formed or the anatomical location of the colonoscope tip. With the imager view however, loops were easily straightened by a combination of withdrawal, torque and appropriate abdominal pressure.

CONCLUSION Real-time electromagnetic imaging of colonoscopy facilitates the straightening of loops that occur during intubation and accurately identifies the colonoscope tip. It has major beneficial implications for the practice and teaching of colonoscopy.

\section{Diet and intestinal disease T98-T102}

T98

\section{HUMAN COLONIC MOTILITY IS UNAFFECTED BY SHORT CHAIN FATTY ACIDS IN VIVO}

\section{S J Warren, M G Lord and N S Williams}

Surgical Units of The Royal London and Newham General Hospital

Short chain fatty acids (SCFAs), bacterial metabolites of fibre, largely influence colonic $\mathrm{pH}$ and are thus putative intraluminal motility stimulants. We have previously communicated that SCFAs reduce human colonic motility in vitro, and now investigate their $\mathbf{l n}$ vivo effects in normal and constipated groups.

A colonic probe featuring pressure transducers, was placed into the transverse colon at colonoscopy in 5 normal and 5 severely constipated patients. At 72 hours post colonoscopy, either a physiological mixture of SCFAs or isotonic $\mathrm{pH}$ balanced saline solution was randomly infused $\left(7.5 \mathrm{ml} / \mathrm{min}\right.$ at $\left.37^{\circ} \mathrm{C}\right)$. Intraluminal contractile activity during infusion was related to preceding periods of spontaneous activity by a computer derived motility index, and similarly changes in baseline indicating changes in colonic tone.

\begin{tabular}{|c|c|c|c|c|}
\hline & Basal & $\begin{array}{l}\text { SCFA } \\
\text { Infusion }\end{array}$ & Basal & $\begin{array}{l}\text { Control } \\
\text { Infusion }\end{array}$ \\
\hline VORM & $\begin{array}{c}9.2 \\
(1.2-17.6)\end{array}$ & $\begin{array}{c}18.0 \\
(10-19.5)\end{array}$ & $\begin{array}{c}12.4 \\
(7.4-13.2)\end{array}$ & $\begin{array}{c}21.4 \\
(5.0-24.8)\end{array}$ \\
\hline CON & $\begin{array}{c}2.5 \\
(0.0-12.0) \\
\text { Motility In }\end{array}$ & $\begin{array}{c}2.0 \\
(0.0-8.4)\end{array}$ & $\begin{array}{c}9.1 \\
(1.2-15.0) \\
\text { Lan (interqu }\end{array}$ & $\begin{array}{c}12.4 \\
(0.8-14.2) \\
\text { artile range) } \\
\end{array}$ \\
\hline CONSTIPATED & $\begin{array}{r}100 \% \\
100 \% \\
\text { Mean \% b }\end{array}$ & $\begin{array}{l}80.1 \% \\
81.3 \% \\
\text { seline char }\end{array}$ & $\begin{array}{l}100 \% \\
100 \% \\
\text { during ir }\end{array}$ & $\begin{array}{l}106 \% \\
82.6 \% \\
\text { usion peri }\end{array}$ \\
\hline
\end{tabular}

In both normal and constipated patients there are no significant differences in motility indices (Wilcoxan Rank Sum) nor baseline colonic tone (Repeated Analysis of Variance) during intracolonic SCFA infusion. Caution should be exercised when relating in vitro models to clinical in vivo situations.
DIETARY FACTORS RELATED TO THE LOW INCIDENCE OF COLON CANCER IN AFRICANS.

SJD O'Keefe, M Kidd, GE Noel, K Jaskiewicz and GO Young. Gastrointestinal Clinic \& Anatomical Pathology, Groote Schuur Hospital \& University of Cape Town, South Africa.

The dramatic difference in colon cancer incidence between black $\left(0.7 / 10^{5}\right.$ population) and white $\left(17 / 10^{5}\right)$ South Africans may be explained by dietary differences. A study of samples $(n=40)$ of the two populations was therefore conducted to examine differences in dietary intake, blood levels and colonic mucosal immunohistochemistry and metabolism. Body mass indices were similar $\left(25+5\right.$ vs $\left.26 \pm 6 \mathrm{~kg} / \mathrm{m}^{2}\right)$. While whites consumed a "westernized" diet, blacks had lower intakes of animal products, as well as vitamins A,C,E and calcium, but consumed a high carbohydrate diet (70-85\% of energy) chiefly consisting of refined maize-meal. There was no overall difference in fibre intake $(17.5 \pm 7$ vs $18.4 \pm 7 \mathrm{~g} / \mathrm{d})$. Blood tests reflected these differences with lower cholesterol, lipid and vitamin $A, C$ and $E$ levels in blacks. Breath $\mathrm{H}_{2}$ and $\mathrm{CH}_{3}$ excretion was higher in blacks $(56 \pm 35$ vs $17 \pm 5: \mathrm{p}<0.025$. $20.9+11.6$ vs $10.2 \pm 9.1 \mathrm{ppm}: \mathrm{p}<0.05$ respectively) following a $200 \mathrm{~g}$ maize meal indicating higher carbohydrate malabsorption and increased colonic metabolism. All black subjects became $\mathrm{CH}_{4}$ "producers" after the meal in contrast to only $40 \%$ of whites. Finally immunohistological examination of rectal mucosal biopsy material demonstrated a lower $(p<0.01)$ prevalence of $\mathrm{Ki}-67$ (i.e. $23 \%), \quad$ p53(15\%) and $\operatorname{TGF} \alpha(31 \%)$ confirming the association between these markers and colon cancer risk. In conclusion, the low incidence of colon cancer in blacks could not be explained by dietary differences in fibre. vitamin or calcium intakes, but may be related to increased colonic metabolism of undigested carbohydrate by methogenic bacteria to $\mathrm{H}_{2}, \mathrm{CH}_{4}$ and short chain fatty acids-which have antineoplastic properties and are the preferred fuel of colonocytes.

LONG CHAIN TRIGLYCERIDES ADVERSELY AFFECT DIETARY TREATMENT OF ACTIVE CROHN'S DISEASE S.J. Middleton, J.T. Rucker. G.A. Kirby, J.O. Hunter

Department of Gastroenterology, Addenbrooke's Hospital. Cambridge.

Elemental diets (ED) are effective in the treatment of active Crohn's disease, but are often unpalatable. To improve taste and energy content the long chain triglyceride (LCT) content of 2 modified elemental diets, EO28 extra liquid (EL) and EO28 extra powder (EP) was increased. Their efficacy was compared with the original ED (EO28) and a peptide based feed. Pepdite 2+ (P).

$\begin{array}{lcccc}\text { Diet } & \text { Fat content } & \text { \% fat } & \text { \% energy } & \text { Remission } \\ & (G) & \text { as LCT } & \text { from LCT } & \text { rate }(\%) \\ \text { EO28 } & 6.64 & 100 & 16.4 & 92 \\ \text { P } & 17.30 & 65 & 23.8 & 87 \\ \text { EP } & 17.45 & 100 & 36.8 & 5.5 \\ \text { EL } & 17.50 & 65 & 20.5 & 92\end{array}$

57 patients with active Crohn's disease were randomised to EO2 8 (17), EP (22) or P (18) and a further 19 received EL. A significunt correlation was found between remission rate and \% energy derived from LCT $(r=-0.968, p=0.016)$ but not other constituents such as carbohydrate (CHO), nitrogen (N), total fat or total energy. Analysis of previously reported studies confirmed correlations between remission rate and LCT $(r=-0.73, p=0.005)$ and also $\mathrm{CHO}(r=$ $0.616, p=0.022$ ). If the results of the current and previous studies are combined, it is apparent that when LCT provides $>15 \%$ of dietary energy, remission rate falls sharply with rising LCT giving a negative correlation $(-0.761, p=0.009)$ but the positive correlation of remission rate and $\mathrm{CHO}$ is lost. This association between dietary LCT and efficacy of ED has not been previously reported. Dietary LCTs may have a pathogenic role in Crohn's disease. 
T101

POSITIVE BENEFIT OF SELENIUM SUPPLEMENTATION IN CROHN'S DISEASE.

A J Morris, M Mokhashi, R Park, A Rumley, A Cruikshank, G Fell, R I Russell

Gastroenterology Unit and Biochemistry Dept., Glasgow Royal Infirmary.

Selenium is known to be an important factor in preventing oxidant damage. Crohn's patients with malabsorption and those requiring long term nutrition support are at risk of developing selenium deficiency. We have studied the effect of supplementation with "Bioselenium + zinc" in 8 Crohn's patients (5M:3F) attending our nutrition clinic who had selenium deficiency.

Methods: Patients received three months "Bioselenium + zinc" in a double blind placebo controlled cross over

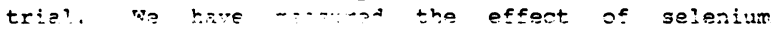
supplementation on biochemical and clinical indices. The biochemical indices were selenium levels (Se), red blood cell glutathione peroxidase ( $\mathrm{rbc}$ GSH-PX), malondialdehyde (MDA) and C-reactive protein (CRP). Clinical indices were modified Crohn's disease activity index (CDI) and Nottingham health profile.

Results: Treatment resulted in significant increase in Se from median 0.66 (range $0.43-0.97$ ) to median 1.48 (range 0.85-2.43) umol/l $(p<0.05)$ and rbc GSH-PX from median 10 (range 6-18) to median 14 (range 11-22) $\mathrm{O} / \mathrm{g} \mathrm{Hb}$ $(p<0.05)$. There was no significant change in CRP or MDA $(p=N S)$. Of the clinical indices there was no significant change in modified CDI but a significant improvement in Nottingham health profile score from median 60.13 (range $0-193$ ) to median 34.27 (range $0-74.79)$ units $(p=0.05)$. Conclusions:

1) Treatment with "Bioselenium + Zinc" increases plasms selenium and rbc GSH-PX in selenium deficient Crohn's patients.

2) Selenium replacement significantly improves perceived well being in Crohn's disease independent of disease activity.

3) Selenium deficiency may contribute to impaired perception of quality of life in Crohn's disease.

\section{Colorectal T103-T111}

T103

COST EFFECTIVENESS OF COLONOSCOPIC SCREENING OF COLON CANCER FAMILIES

\section{P. Isaacs, A Dailianas}

Gastroenterology Unit,Victoria Hospital, Blackpool

AIM To find the cost effectiveness of a colonoscopic surveillance programme for persons over 40 at moderate ( 1 first degree and at least 1 second degree relative) and high ( 2 or more first degree relatives) genetic risk of colon cancer.

CASE FINDING 1. After full publicity 32 patient selfreferred and 42 referred by their GP, were offered colonoscopy. 2. 634 patients with colon cancer or their families were given questionnaires to identify candidates for colonoscopy, giving a total colonoscopy population of 254 (92 at high and 162 at moderate risk).

RESULTS OF COLONOSCOPIES Of 92 high risk candidates offered colonoscopy, 44 accepted and 11 adenomas (6 larger than $1 \mathrm{~cm}$ ) and 3 cancers were found. Of 162 moderate risk candidates, 90 accepted colonoscopy and 11 adenomas (2 larger than $1 \mathrm{~cm}$ ) and 1 cancer were found.

COST EFFECTIVENESS The costs of a 2 year project (including secretarial, equipment, medical and nursing time) when apportioned to the detected diseases were

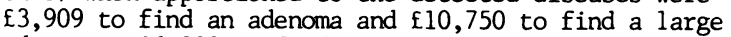
adenoma, $£ 26,000$ to find a cancer and $£ 8,666$ to find either a cancer or a large adenoma.

With adjustment for the stage of the cancer and cost of surgery; prevention of a colon cancer death will cost

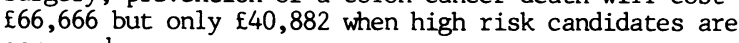
screened.

CONCLUSION Selective colonoscopic screening of high risk members of colon cancer families is more cost effective than indiscriminate screening and is recommended as a priority for introduction into district gastroenterology services.

\section{T102}

NUTR ITIONAL, SUPPLEMENT WITH ELEMENTAL DIET AS A STEROID REPLACFMENT IN PATIENTS WITH STEROID-DEPENDENT CROHN'S DISEASE at? H, tidsworth CD.

Elemental diet is now an established primary therapy for acute crohn's disease with efficacy comparable to that of steroids. However the role of nutritional support in maintaining clinical remission remains to be clarified. This study was therefore designed to examine if remission can be sustained and i mmuno-suppressive therapy withdrawn with nutritional supplement in patients with steroid-dependent Crohn' disease. Steroid-dependence was defined as the continued need for small dose of prednisolone to maintain clinical remission and documented relapse if such therapy was withdrawn. $50 \%$ of the calculated total daily calorie intake was provided by the enteral teeds, the remaining $50 \%$ by normal food. once established on enteral feeding steroids were gradually withdrawn and follow up continued for 12 months The tollowing were monitored: CDAI, CRP ESR, Albumin and platelet count.

Inirty four patients with steroid-dependent crohn's disease in remission (CDAI $\leq 150$, normal laboratory tests) were studied. There were 22 females and 12 males with a mean age of 40 years. Crohn's disease had been present for a mean of 10.4 years (range 135). All patients had been maintained on prednisolone (mean dose $=6.5 \mathrm{mg}$, range $=5-15$ ) for an average of 6.8 years. Three patients declined consent because of inconvenience and an other six were intolerant to the enteral feeds. The remaining 25 were randomised to EO28 Extra $(n=13)$ and Forticips $(n=12)$. $\operatorname{six}$ patients (three from each group) had clinical relapses (CDAI increased by $\geq 100$ points) and needed steroid treatment. Complete withdrawal of steroids was achieved in all of the remaining 19 patients who sustained remission on dietary supplement alone for an average of 6 months (range 3-9).

Nutritional supplement can sustain clinical remission in patients with crohn's disease and often enables the complete withdrawal of chronic steroid therapy in steroid-dependent patients.

\section{T104}

ESTIMATED COST AND RESOURCE IMPLICATIONS OF POTENTIAL STRATEGIES FOR COLORECTAL CANCER SCREENING IN SCOTLAND A J K Williams. Royal Infirmary, Edinburgh

Colorectal cancer is a major health issue in Scotland. It is the second commonest cause of cancer death in adults in Scotland with 1.748 deaths in 1991. The life-time risk of developing colorectal cancer in Scotland is $4.3 \%$ for men, and $3 \%$ for women. Less than $40 \%$ will survive 5 years because of the advanced stage of the cancer at presentation

There are no national recommendations for colorectal cancer screening in Scotland or the UK. The 2 screening methods available are faecal occult blood testing (FOBT) and flexible sigmoidoscopy. FOBT has a positive predictive value for colorectal neoplasia of $22-58 \%$, and screening studies in the USA have shown a $33 \%$ reduction in mortality (Minnesota Colon Cancer Study). There is a 60\% acceptance of the test with $3 \%$ showing a positive result. Flexible sigmoidoscopy should detect $60 \%$ of colorectal neoplasms. Seventy per cent acceptance rate has been reported in screening studies. Screening sigmoidoscopy with polyp removal reduces the risk of developing colorectal cancer by $45-70 \%$ (St Mark's London, Selby Northern California).

There are 326.810 adults in Scotland aged 55-60 years. The estimated cost of FOBT screening for this population group is $f], 270,637$, and would require 5.883 additional colonoscopies to be performed. Offering flexible sigmoidoscopic screening to those aged 55-60 years with a $70 \%$ acceptance rate would require 228.767 procedures costing f11.438,350. and occupy 46 one-roomed endoscopy units for 12 months.

Current facilities and staffing in Scotland could not support a flexible sigmoidoscopic screening programme. However, the estimated cost of such a programme at $£ 8.500$ per cancer death prevented (Aitken St Mark's London) compares favourably with cervical and breast cancer screening ( $\$ 30-50.000$ per cancer death prevented).

Adequate staffing and facilities are mandatory before embarking on a national screening programme for colorectal cancer. 
PREDICTING SURVIVAL IN OBSTRUCTING COLORECTAL CANCERS. $\frac{\mathrm{M} \text { Skelly, }}{\text { Gastroenterology \& Liver Unit and Department of Pathology, St. }}$ Vincent's Hospital, Dublin, Ireland.

Introduction: The outcome of patients undergoing curative surgery for obstructed colorectal cancer is poor, even in those surviving the postoperative period. These obstructing cancers behave in an agressive manner, and factors influencing recurrence and death are poorly understood. Aim: To identify features associated with long term survival in obstructing colorectal cancers. Patients: Of 736 consecutive patients with colorectal cancer admitted to a single institution (1983-1991), $155(21 \%)$ presented with bowe obstruction. 57 of these $(37 \%)$ underwent palliative procedures or died in the postoperative period, and were excluded from study. The remaining 98 cases were included (M:F.52:46, mean age 69; range 44-87). Follow-up was complete to July 1993. Methods: 21 discrete clinical, operative, morphological and histological variables were studied. Clinical data were obtained from a prospective database. All histological slides were retrieved and examined by a pathologist blinded to clinical features and outcome. Results: 5 year cancer specific survival was $32 \%$ overall. Variables significantly related to poor outcome included tumour stage (Logrank analysis $\mathrm{p}=0.0001)$ tumour necrosis $(\mathrm{p}=0.0003)$, poor tumour differentiation $(\mathrm{p}=0.003)$, mucin production $(\mathrm{p}=0.008)$, vascular invasion $(p=0.009)$, perineural invasion $(p=0.009)$, absence of a lymphocytic infiltrate $(\mathrm{p}=0.02)$ and the presence of concomitant bowel perforation (0.04). No other variables were significantly associated with survival. Regression analysis identified tumour stage (Relative risk (RR), 3.1; $p=0.0005$ ), bowel perforation ( $R R$ 3.4; $p=0.001$ ), mucin production (RR 2.8; $p=0.003$ ) and tumour differentiation ( $R R 2.0$ $\mathrm{p}=0.04$ ) as independent predictors of prognosis. From this analysis two groups emerged. Group 1 included 34 patients without poor prognostic features ( 5 year survival, $58 \%$ ). Group 2 contained the remaining 64 patients with at least one poor prognostic feature (5 year survival, 16\%) (logrank analysis; $\mathrm{p}<0.00001$ ). Conclusion. Conventional prognostic indicators can identify the majority of patients with malignant large bowel obstruction who are at high risk of tumour recurrence and death. Such patients might reasonably be included into trials of adjuvant therapy in the future.

IS A BARIUM ENEMA OF USE IN THE DIAGNOSIS OF CANCER IN PATIENTS WITH RECTAL BLEEDING?

S. R. Dodds, M. R. Thompson

St. Mary's Hospital, Milton Road, Portsmouth

Bleeding per rectum (BPR) is one of the classical symptoms associated with colorectal cancer. Traditionally investigation is by rigid sidmoidoscopy and double contrast barium enema (DCBE). The use of the $60 \mathrm{~cm}$ flexible sigmoidoscope (FS) has been shown to reduce the need for DCBE.

Aim: To examine the diagnostic yield of DCBE in patients presenting with BPR after FS.

Method: A seven year prospective study comparing the history and final diagnosis in 1821 patients referred to a colorectal outpatient clinic for investigation of BPR. All patients had FS, 219 had DCBE.

Results: 121 cancers were diagnosed. The diagnosis was made by FS in 115 patients (95\%), colonoscopy in 3(2.4\%) and DCBE in $3(2.4 \%$ of cancers; $1.4 \%$ of all DCBE). Of the 6 cancers not diagnosed by FS, 2 had anaemia and right sided cancers, 2 had FS only to $30 \mathrm{cms}$ wi th a tumour at $40 \mathrm{cms}$, one patient had a large rectal metaplastic polyp and a caecal carcinoma.

Conclusion: In patients presenting with BPR and no history of anaemia, a normal FS to $60 \mathrm{cms}$ is sufficient to exclude a colorectal cnacer in the vast majority of patients. It is now questionable whether DCBE should ever be used in the investigation of BPR.
PROGNOSTIC SIGNIFICANCE OF RETINOBLASTOMA GENE PRODUCT EXPRESSION IN COLORECTAL CANCER

E Ryan, A Kitching, E Mulligan, P Mac Mathuna, R Merriman, $\mathrm{P}$ Kelly ${ }^{1}$, TF Gorey ${ }^{2}$, JR Lennon \& J Crowe. Gastrointestinal Unit, Departments of Pathology ${ }^{1}$ and Surgery ${ }^{2}$, Mater Misericordiae Hospital, University College Dublin, Ireland.

Loss or inactivation of the retinoblastoma $(\mathrm{Rb})$ gene has been demonstrated in several nonGI human malignancies. Recently, altered $\mathrm{Rb}$ gene expression has been reported in colorectal cancer (CRC) but the prognostic significance of this finding has not been determined. The aim of this study therefore was to correlate $\mathrm{Rb}$ gene product expression with longterm survival in CRC.

PATIENTS AND METHODS CRC samples from 76 patients collected over 3 years $(1984-86)$ were analysed for $\mathrm{Rb}$ gene product nuclear protein expression by immunohistochemistry using thé monoclonal antibody PMG3.245. Unlabelled CRC tissue and bladder cancer tissue were used as negative and positive controls, respectively. Prognostic significance was established from Kaplan-Meier curves which were generated from actliarial disease free survival, with differences in survival being compared by means of logrank analysis.

RESULTS Positive Rb expression of > $80 \%$ in tumolir cells was observed in $33 / 76$ (44\%) patients. Heterogenous $\mathrm{Rb}$ expression $(20-80 \%)$ was seen in $39 / 76(51 \%)$ patients, while no Rb expression occured in the remaining $4 / 76(5 \%)$. Rb expression of $>80 \%$ correlated closely with poor survival $(p=0.03)$.

CONCLUSION. These findings suggest that the Rt gene is of prognostic significance in CRC and has an oncogenic-like function, in contrast to its reported tumour suppression activity in otricr human malignancies.

ANAL ENDOSONOGRAPHY AFTER FAILED ANTERIOR SPHINCTER REPAIR FOR OBSTETRIC TRAUMA IS IMPERATIVE. AF Engel, MA Kamm, AH Sultan, RJ Nicholls, CI Bartram. St Marks' Hospital, City Road, London EC1V 2PS.

This study was performed to identify factors associated with failure after anterior sphincter repair for obstetric trauma related sphincter defects.

PATIENTS. Anterior sphincter repair for obstetric trauma related faecal incontinence was performed in 55 consecutive patients; 32 (Group A) with incontinence directly after delivery and 23 (Group B) with late onset.

METHODS. Endosonography and physiological tests were performed before and after surgery. RESULTS. After a median follow up of 15 months (range 6-36), 42 patients were improved, 11 were not improved and 2 were awaiting colostomy closure. Improved patients had a greater increase in postoperative squeeze pressure $\left(20\right.$ vs $5 \mathrm{~cm} \mathrm{H}_{2} \mathrm{O}$, $\mathrm{P}=0.05)$ and endosonographically the external anal sphincter (EAS) was more frequently intact (good vs bad outcome, intact/not intact EAS ring $32 / 3$ vs $5 / 6, \mathrm{P}=0.003)$. Patients with an intact EAS had higher postoperative squeeze pressures (intact vs defect EAS: 50 vs $\left.20 \mathrm{~cm} \mathrm{H} \mathrm{H}_{2} 0 . \mathrm{P}=0.004\right)$. Group $B$ patients were older than group A (median $59 \mathrm{vs}$ 32 years, $\mathrm{P} 0.001$ ), had longer pudendal nerve terminal motor latencies $(2.3$ vs $2.1 \mathrm{~ms} . \mathrm{P}=$ $0.003)$ but this had no significant effect on postoperative continence grade. Examination of subsets of patients with pudendal nerve terminal motcr latency ranging from 2.2 to $2.7 \mathrm{~ms}$ showed no influence on outcome.

CONCLUSION. Late onset incontinence due to obstetric sphincter rupture, even in the presence of prolonged PNTML does not preclude a favourable outcome after sphincter repair. Sphincter repair failure is related to persistent endosonographic EAS defect. 
Effect of anal sphincter repair on anal endosonography

H.D. Mulder. R.J.F Felt-Bersma. M. Koorevaar, M.A. Cuesta. S.G.M. Meuwissen. Depts. of surgery and gastroenterology, Free University Hospital, Amsterdam, the Netherlands.

Sphincterdefects after surgical or obstetric trauma can cause fecal incontinence. Surgical therapy intends to repair the anal sphincters. Anal endosonography enables visualisation of the anal sphincters, and defects of the sphincters can be demonstrated. This study was done to investigate the effect of anal sphincter repair on the endosonographic appearance of the sphincters.

A group of 17 patients ( 7 male, 10 female, mean age 48.4, range 33-72) was studied before and after sphincter repair with endosonography and anal manometry. The mean follow-up was 13.7 months, ranging from 2 to 39. The cause of the fecal incontinence was obstetric trauma in 6 patients, surgical trauma in 8 and both of them in 3 patients. Five patients had previous surgery for their incontinence. Thirteen patients were incontinent for solid feces, 2 only for liquid feces and 2 had soiling. Preoperatively endosonography showed a defect of both sphincters in 8 patients, a defect of the external anal sphincter in 5 patients and a defect of the internal anal sphincter in 4 patients.

Defects of the sphincters were treated by overlapping sphincteroplasty. If the other sphincter was intact, it was reefed.

Post-operatively in $10(59 \%)$ patients continence had improved, in 7 (41\%) patients the complaints had not changed. The post-operative endosonographic images had improved in 8 patients, the defects of the sphincters were smaller or had disappeared. In the other 9 patients the images were unchanged. In two patients the overlapping of the muscle was clearly visible with anal endosonography. The clinical results of the sphincteroplasty were not related to the changes with anal endosonography.

In Conclusion: In half of our patients after sphincteroplasty the endosonographic sphincter defect had deminished or disappeared. Sometimes overlapping of the muscle was clearly visible. However there was no relationship between the clinical effect of the sphincteroplasty and the endosonographic changes.

SELECTIVE AUTONOMIC DEFICITS IN SLOW TRANSIT CONSTIPATION

I Raethjen, G Warner. MA Pilot. P Anand. NS Williams.

Surgical Unit and Neurology Department, The London Hospital Medical College, Turner St, London E1 2AD, UK.

Chronic idiopathic constipation is likely to be a heterogeneous condition. Our previous studies suggested that autonomic dysfunction may be a cause in a subset of patients: their stimulated sweating response was lower than controls. We have now tested selectively the neural and sweat gland components of the sweat response, and extended our studies to tests of unmyelinated sensory fibres, so as to determine whether these patients have a small fibre neuropathy.

The sensory tests included thermal thresholds and axon reflex vasodilatation in response to intradermal capsaicin, measured with a laser Doppler. Direct and axon reflex sweating was induced with intradermal methacholine and nicotine respectively, and measured with an evaporimeter. Nonparametric tests (Kruskal-Wallis, Mannn Whitney U) were used for statistical comparison with a group of seven control subjects.

Results are expressed as medians and range. All four patients who reported constipation from childhood had a selective deficit of unmyelinated afferent fibres in the foot, with markedly elevated thresholds to warm sensation (Controls 5.2; 4.3-10.6, Patients 13.8; 11.8-16.1 $\partial \mathrm{T}^{\circ} \mathrm{C}, \mathrm{P}<0.02$ ) and heat pain (Controls 10.6; 8.2-14.7, Patients $18.1 ; 13.9-22.6 \partial^{\circ} \mathrm{C}, \mathrm{P}<0.05$ ), and a reduced response to capsaicin (Controls 47.0; 24-117, Patients $13.5 ; 12-30 \partial$ Flux $\mathrm{V}, \mathrm{P}<0.005)$. In contrast, patients with adult onset constipation $(n=7)$ had a selective neural sweating deficit (Controls 49.8; 32.0-61.8; Patients 27.7; 7.3-44.3 g/m $2 \mathrm{~h}$, $\mathrm{P}<0.05$ ), indicating dysfunction of post-ganglionic sympathetic cholinergic fibres. All patients were shown to have normally functioning sweat glands in response to methacholine.

Our findings suggest that patients with severe chronic idiopathic constipation may have selective small fibre neuropathies, of which constipation is a manifestation.
THE HUMAN RECTOCOLONIC INHIBITORY REFLEX:NORMAL AND CONSTIPATED PATIENTS

\author{
S I Warren, M G Lord and N S Williams \\ Surgical Units of The Royal London and Newham General Hospital
}

We have recently described the human rectocolonic inhibitory reflex whereby rectal distension inhibits the motility of the proximal colon. This reflex may have important clinical significance in constipated patients with rectal distension compounding their problem.

A probe which had pressure transducers and balloons positioned to lie within the transverse colon and rectum was placed at colonoscopy in $\mathbf{5}$ normal and 5 severely constipated subjects. This allowed measurements of right colonic activity provoked by local and rectal balloon distension to be related to preceding periods of basal intraluminal pressure activity on 3 consecutive days. Activity was computer analysed and a motility index derived.

\begin{tabular}{|c|c|c|c|c|}
\hline & Basal & $\begin{array}{l}\text { Local } \\
\text { distension }\end{array}$ & Basal & $\begin{array}{c}\text { Rectal } \\
\text { distension }\end{array}$ \\
\hline NORMAL & $\begin{array}{c}7.2 \\
(3.6-12.1)\end{array}$ & $\begin{array}{c}17.0^{*} \\
(8.5-20.4)\end{array}$ & $\begin{array}{c}7.8 \\
(3.5-16.1)\end{array}$ & $\begin{array}{c}1.2^{*} \\
(0.1-8.1)\end{array}$ \\
\hline CON & $\begin{array}{c}3.1 \\
(0.6-10.4)\end{array}$ & $\begin{array}{c}164^{*} \\
(9.8-21.9)\end{array}$ & $\begin{array}{c}3.8 \\
(0.2-12.4)\end{array}$ & $\begin{array}{c}0.0^{*} \\
(0.0-0.5)\end{array}$ \\
\hline
\end{tabular}

Motility Indices - median (interquartile range)

Wilcoxon Matched Pairs Signed Ranked Sum * $\mathrm{p}<0.05$

In both normal and constipated groups local distension significantly increases motility, and rectal distension reduces proximal colonic motility, although the magnitude of this response is the same between groups ( $p=0.36$ Mann Whitney $U$ test). This human rectocolonic inhibitory reflex is potentially capable of exacerbating constipation and theraples should perhaps address this possibility.

\section{Small intestine T112-T118 \\ T112}

SMALL INTESTINAL PERMEABILITY, MORPHOLOGY AND BRUSH BORDER ENZYME ACTIVITIES IN IMMIGRANTS RESIDENT IN A BRITISH INNER CITY.

T.H.Iqbal, M.A.Cox, K.O.Lewis, J.C.Gearty, \& B.T.Cooper. Gastroenterology Unit, Dudley Road Hospital, Birmingham.

Asymptomatic residents of tropical countries have minor abnormalities of small intestinal (SI) morphology. Little is known about SI structure and function of immigrants to the West. We have studied SI morphology, permeability and brush border enzyme activities in 2 immigrant groups resident in the UK (West Birmingham) and compared the results with those from white residents. 28 white Caucasian, 101 Indian and 49 Afro-Caribbean adults with dyspepsia but no evidence of SI disease had endoscopic distal duodenal biopsies and a lactulose/mannitol permeability test. 20 normal white subjects had the permeability test. Lactulose/mannitol excretion ratios (LMER) were: white subjects $0.022 \pm 0.001$ (mean \pm SE), white patients $0.022 \pm 0.0015$, Indians $0.036 \pm 0.002$, Afro-Caribbeans $0.046 \pm 0.005$. Differences between the immigrant groups and the 2 white groups were significant $(P<0.001) ; 33 \%$ of Indians and $45 \%$ of Afro-Caribbeans had LMER outside the normal white range. Afro-Caribbeans born in the UK had significantly lower LMER than those born abroad $(P<0.05)$; a similar trend was seen in Indians. Villous height/mucosal thickness ratios were lower in the immigrant groups and correlated inversely with LMER $(r=0.28 ; P<0.05) .10 \%$ whites, $51 \%$ Indians and $81 \%$ Afro-Caribbeans were lactase deficient. Brush border sucrase, maltase and alkaline phosphatase activities, while not significantly depressed in any individual, were significantly lower in Indians than in the other groups; country of birth did not influence the results. We conclude that there are differences in SI permeability morphology, and enzyme activity between immigrants and the native white population. Our data suggest that these differences are related to environmental factors. 
A COMPARATIVE, PROSPECTIVE STUDY OF RECTAL GLUTEN CHALLENGE IN THE DIAGNOSIS OF GLUTEN-SENSITIVITY (GS) A.Ensari.M.N.Marsh. S.Morgan, K.Moriarty. R.Lobley. D. Unsworth University Depts. Medicine/Gastroenterology, Hope Hospital and Manchester Royal Infirmary, Manchester, and Clinical Immunology, Addenbrooke's, Cambridge

We previously defined the specific response of rectal mucosa to gluten challenge in GS. In order to determine its diagnostic potential we undertook a prospective, unselected study of all patients referred with malabsorption/malnutrition, comparing rectal challenge with jejunal biopsy, and other clinical/serological markers, from Jan 92-Dec 93. Methods: Using a flat jejunal biopsy as diagnostic histologic criterion, 52 patients were designated GS (22) or disease control 30 (DC). Rectal challenge was performed with $6 \mathrm{~g}$ gluten (BDH): pre, $2 \mathrm{~h} / 4 \mathrm{~h}$ post-challenge mucosae were reacted with monoclonal abs to CD3; $\gamma \delta$; CD15; CD68; DR: IL-2R and positive cells counted per $10^{4} \mu \mathrm{m}^{2}$ muscularis mucosae. $\gamma \delta / \mathrm{CD} 3$ ratios were determined in jejunum. ELISA was used for antigliadin and fluorescence for antireticulin/antiendomysial antibodies. Brush border enzyme activities were assayed biochemically but were unhelpful. Full haematological/ biochemical work-up, including xylose and faecal fat, were also performed. Results: Rectal challenge produced significant rises in $\mathrm{CD}^{+}$and $\gamma \delta^{+}$cells both within lamina propria and epithelium (surface + crypt) at 2 and 4 hours $(p<0.001)$. The $4 \mathrm{hr}$ challenge also evoked significant increases in CD15 (neutrophils) CD68 (macrophages) CD25 (IL2R) and HLA-DR expression. Linear discriminant analysis of all rectal challenge material yielded diagnostic scores based on a combination of post-challenge CD $3^{+}$IEL + pan-mucosal $\gamma \delta^{+}$cells. All scores were positive for GS patients (flat JB) and negative for DC (sensitivity and specificity $=100 \%$ ). Corresponding values of AGA were 61/93; ARA 40/100; and AntiEndo 45/98; all other traditional parameters yielded values $\sim 50-70 \%$. A raised $\gamma \delta / C D 3$ ratio was absent in some flat jejunal biopsies.

Conclusions: 1. Rectal challenge is a dynamic test of $T$ cell reactivity at mucosal level; 2 . A highly accurate diagnosis for GS, based on discriminant analysis is provided by a single, $4 \mathrm{hr}$ postchallenge rectal biopsy; 3 . This discriminant diagnostic score is dependent solely on CD 3 and $\gamma \delta$ responses; 4 . The $\gamma \delta$ response is slow and peaks later than the $\mathrm{CD} 3$ response.
DOES NEOMUCOSA INDUCED BY STEM CELL TRANSPLANTATION HAVE ADEQUATE MUCOSAL FUNCTION? IS Tait. GS Evans, JI Penny and FC Campbell. University Department of Surgery, Ninewells Hospital and Medical School, Dundee, U.K

Small bowel epithelium has a complex morphology which facilitates both digestive and absorptive function. Neomucosa with typical small bowel morphology can now be grown by transplantation of isolated small intestinal stem cells, but its functional capacity is unknown. This study examines apical brush border digestive enzyme activity, and nutrient transport function of stem cell induced neomucosa.

Methods: Stem Cells were isolated from rat intestine by enzymatic digestion then grafted subcutaneously to adult inbred rats. Developed grafts forming neomucosa were retrieved after 25 days, and brush border membrane vesicles (BBMV) prepared for functional assays. Protein concentrations were estimated from standard curves using the Bio-Rad assay. Substrate assays to assess neomucosal lactase, sucrase, aminopeptidase and alkaline phosphatase activity were performed Neomucosal nutrient transport function was measured in BBMV by $\mathrm{Na}$-dependent glucose uptake. Comparative assays were performed in BBMV from age matched normal rat small intestine.

\begin{tabular}{||l|c|c||}
\cline { 2 - 3 } \multicolumn{1}{c|}{ Results: } & Normal SI & Neomucosa \\
\hline \hline Lactase $^{1}$ & $0.18(0.12-0.21)$ & $0.75(0.70-0.82)$ \\
\hline Sucrase $^{2}$ & $0.42(0.32-0.55)$ & $0.52(0.46-0.65)$ \\
\hline A-peptidase $^{3}$ & $1.44(1.25-1.53)$ & $1.40(1.29-1.51)$ \\
\hline Alk.Phosp. $^{4}$ & $0.80(0.66-0.95)$ & $2.48(2.41-2.62)$ \\
\hline Glucose Uptake $^{5}$ & $51.2(43.6-58.8)$ & $45.8(41.5-61.9)$ \\
\hline \multicolumn{2}{|l|}{${ }^{-4}-\mu \mathrm{mol} / \mathrm{min} / \mathrm{mg} . p r o t e i n ;{ }^{5}-\mathrm{pmol} / \mathrm{mg} . \mathrm{protein} / \mathrm{sec}$} \\
\hline
\end{tabular}

Conclusion: Small intestinal neomucosa induced by stem cell transplantation has specific digestive and absorptive (glucose transport) functions similar to age matched control normal small intestine.
HISTOLOGICAL CHANGES IN DUODENAL MUCOSA PRODUCED BY SOLUBLE MEDIATORS FROM GLIADIN SENSITIVE T-CELLS. RT Przemioslo, KEA Lundin*, LM Sollid*, PJ Ciclitira. St.Thomas' Hospital, London. Institute of Transplantation Immunology, Oslo.

Gliadin sensitive T-lymphocytes may mediate the lesion seen in coeliac disease (CD). Following isolation of these cells from coeliac jejunal biopsies we investigated whether their immune activation produces histological changes in normal small bowel mucosal biopsies cultured invitro and whether such effect might in part be due to interferon- $\gamma$ (Ifn- $\gamma$ ).

Two gliadin sensitive DQ2 restricted T-cell clones (MW4.32 \& MN1.27) were cultured for $48 \mathrm{~h}$ with a peptic-tryptic digest of gluten in the presence of irradiated EBV transformed B-cells. Supernatants from the T-cell culture were removed before (' $A$ ' supernatant) and after (' $\mathrm{B}$ ' supernatant) their stimulation. Duodenal biopsies were obtained from twelve non coeliac patients with normal histology. One biopsy was immediately fixed. The other biopsies were cultured individually in media as follows; (i) organ culture medium alone (OCM) (ii) OCM with a 1:100 dilution of ' $A$ ', (iii) $O C M$ with a 1:100 dilution of ' $B$ ', (iv) $O C M$ with $100 I U / \mathrm{ml}$ Ifn- $\gamma$ or (v) OCM with $200 \mathrm{IU} / \mathrm{ml}$ Ifn- $\gamma$, the latter two serving as positive controls. After 24 hours the biopsies were fixed in formalin. Sections were cut, stained with $H \& E$ and assessed for changes in epithelial cell height (ECH). A further six non coeliac subjects with normal small intestinal histology were investigated with a fixed concentration of the 'B' supernatant in OCM to which increasing concentrations of anti-Ifn- $\gamma$ antibody were added.

There was no significant reduction in ECH expressed in um.(SEM) between biopsies fixed immediately, 26.6(1.6) and after $24 \mathrm{hr}$ with $\mathrm{OCM}$ 24.6(1.9) in the twelve patients studied. Eight biopsies were grown with MW and 4 with the MN supernatants. There was no significant difference in $\mathrm{ECH}$ in biopsies grown with the unstimulated ' $\mathrm{A}$ ' supernatant, $22.8(2.1) \mathrm{MW} \& 25.1(2.5) \mathrm{MN}$. However, there was a significant reduction in ECH in biopsies grown with the post-activation 'B' supernatants, 16.8(3.3) MW [p<0.01] \& 21.4(1.8) MN [p<0.05], similar to that produced by Ifn- $\gamma 100 \mathrm{IU} / \mathrm{ml}, 18.9(2.2)[\mathrm{p}<0.05] \&$ Ifn- $\gamma$ $200 I \mathrm{U} / \mathrm{ml} 15.9(4.2)[\mathrm{p}<0.01]$. In six subjects increasing concentration of anti-Ifn- $\gamma$ antibody prevented the changes produced by the stimulated 'B' supernatants; $[1: 500 ; 20.1(2.3) ; \mathrm{p}<0.05$. 1:250; 22.6(1.2), $\mathrm{p}=0.11$. $1: 125 ; 24.8(1.0), \mathrm{p}=0.52]$.

These figures show that gut derived gliadin sensitive T-cells can secrete products which cause a significant reduction in $\mathrm{ECH}$. Prevention of this effect by anti-Ifn- $\gamma$ antibody suggests a role for this cytokine, secreted by gliadin sensitive T-cells, in the pathogenesis of $C D$.

\section{DETERMINANTS OF VILLUS SHORTENING IN ZAMBIAN PATIENTS WITH HIV RELATED DIARRHOEA}

Kelly P, Davies SE, Ngwenya B, Mandanda B, Hosp M, Fuchs D, Wachter H, Luo N, Farthing MJG. University of Zambia School of Medicine, Lusaka; Medical College of St Bartholomew's Hospital, London, UK; Institute for Medical Chemistry, Innsbruck, Austria.

Pathogenetic mechanisms involved in HIV related diarrhoea and wasting remain poorly defined. We therefore investigated determinants of villus shortening in a group of 68 Zambian AIDS patients with chronic diarrhoea, and in 10 diarrhoea-free controls undergoing diagnostic endoscopy. All underwent anthropometric assessment, stool parasitology, and endoscopic distal duodenal biopsy on the same day.

Villus height was reduced in patients compared to controls (mean 210 vs 304um; $p=0.002$ ), but crypt depth was increased (227 vs 178um; $p=0.02$ ). Villus height and total mucosal thickness were not related to body mass index (BMI), but strongly related to mid upper arm circumference $(p=0.02)$ and sum thickness of three skin pinches $(p=0.002)$. Increased inflammatory infiltrate was found in $97 \%$ of biopsies from diarrhoea patients: plasma cell in $89 \%$ and eosinophil in $11 \%$. Eosinophil infiltration was associated with isosporiasis $(p=0.01)$, but otherwise there was no effect of parasitosis upon biopsy appearances. Intraepithelial lymphocyte (IEL) counts were increased in patients vs controls $(p=0.01)$. Villus height was 244 um in biopsies with IEL counts $<20$ per 100 enterocytes, but 212 um with IEL counts $20-40$, and $166 u m$ with IEL count $>40 \quad(p=0.002)$

Serum neopterin (a marker of macrophage activation and inflammation) concentrations in patients were very high (mean $62.3 \mathrm{nmol} / 1$, range $4-381$; normal $<8.5 \mathrm{nmol} / 1$ ), were higher in patients with elevated IEL counts $(70.2$ vs. $38.5 \mathrm{nmol} / 1 ; p=0.005)$, but were not related to villus height.

We conclude that villus height is related to nutritional state and to intestinal inflammation, and is reduced in patients with HIV related diarrhoea in Africa. 
OMEPRAZOLE TREATMENT, A POTENT RISK FACTOR FOR CAMPYLOBACTER GASTROENTERITIS. HM Scott. KR Neal. RCB

Slack. REA Logan. Dept. of Public Health Medicine and

Epidemiology, University of Nottingham Medical School, NG7 2UH.

Reduction in gastric acid secretion has been shown to increase susceptibility to Salmonella infections but whether the same applies to Campylobacter is unknown. We have used the statutory notifications of food poisoning confirmed as being due to Campylobacter infection and general practice records to carry out a case-control study enquiring about drug usage and history of gastric surgery. Conditional logistic regression was used to estimate relative risk (RR) and 95\% confidence limits $(\mathrm{CL})$ adjusted for $\mathrm{H}_{2}$ antagonists, antibiotics and gitract surgery. Records of 147 cases of Campylobacter infection all aged $\geq 45$ years and 294 age, sex and practice matched control subjects were examined. Overall, cases $(59 \%)$ were slightly more likely than controls $(51 \%)$ to be receiving regular prescription drugs ( $p$ $=0.15$ ).

In the month prior to a case's infection 7 cases and 1 control had been prescribed omeprazole (RR 15.5, CL 1.9-130, $p=0.012$ ). No association was seen with the prescription of omeprazole in the 2-12 months prior to infection, or ever prescribed, after allowing for the current use of omeprazole or any other drugs. A weak non-significant association was seen with $\mathrm{H}_{2}$ antagonists prescribed in the month prior to infection, $11(7 \%)$ cases and $12(4 \%)$ controls having taken one of these drugs (RR 1.4, CL 0.8-2.5) and previous gastric surgery ( 1 case and 7 controls, RR 0.3, CL 0.01-2.3). Only 1 case and 4 controls had been prescribed hydroxocobalamin injections and the case was also receiving $\mathrm{H}_{2}$ antagonist therapy simultaneously.

We have also linked the statutory notifications with those of a post marketing surveillance study of patients taking omeprazole long-term $(n=1515)$ to confirm the increased risk with omeprazole (odds ratio 3.5, $\mathrm{CL}$ 2.0-6.2, $\mathrm{p}=0.0002$ ).

In conclusion, omeprazole appears to be associated with an increased risk of Campylobacter infection, a risk which was not seen with $\mathrm{H}_{2}$ antagonists or previous gastric surgery. These results are consistent with in-vitro data indicating that campylobacter survival is dependent on a higher $\mathrm{pH}$ than salmonella.
A PROSPECTIVE, RANDOMISED, PLACEBO-CONTROLLED TRIAL OF SINGLE DOSE CIPROFLOXACIN FOR THE TREATMENT OF TRAVELLERS' DIARRHOEA. I Salam, PH Katelaris, S Leigh-Smith, MJG Farthing. Dept of Medicine, Queen Elizabeth Military Hospital, Woolwich, Royal Marine Commando, Arbroath \& Dept of Gastroenterology, St Bartholomew's Hospital London.

Travellers' diarrhoea (TD) is the most common illness affecting travellers to developing countries. When indicated, it is conventionally treated with a 3-5 day course of an antibiotic. The aim of this study was to compare the efficacy of a single dose of ciprofloxacin $500 \mathrm{mg}$ (CIPRO) with placebo for the treatment of acute diarrhoea in travellers. British soldiers, within eight weeks of deployment in Belize, who presented with diarrhoea within $24 \mathrm{~h}$ of onset (defined as one or more unformed or liquid stools), were randomised to receive either CIPRO or placebo. Each subject recorded the number and consistency of stools and the presence of associated symptoms (cramps, pain, vomiting, anorexia) for $72 \mathrm{~h}$ or until recovery. The duration of illness was measured to the nearest hour using two end points (i) last liquid stool, (ii) last unformed stool.

Eighty three soldiers (all male) received CIPRO $(n=45)$ or placebo $(n=38)$. Groups did not differ with regard to duration or severity of diarrhoea before presentation. The mean duration of diarrhoea (to last liquid and last unformed stool respectively) was reduced from $50.4 \pm$ 4.5h and $53.5 \pm 4.4 \mathrm{~h}$ in the placebo group to $20.9 \pm 3.4 \mathrm{~h}$ and $24.8 \pm$ $3.8 \mathrm{~h}$ in the CIPRO group ( $\mathrm{p}<0.0001$ for each). The mean number of liquid stools was reduced from $11.4 \pm 1.2$ in the placebo group to $5.0 \pm$ $0.7 \mathrm{~h}$ in the CIPRO group $(p<0.0001)$. The cumulative percentage of subjects with the last unformed stool within $24 \mathrm{~h}, 48 \mathrm{~h}$ and $72 \mathrm{~h}$ was $64 \%, 82 \%$ and $93 \%$ in the CIPRO group and $11 \%, 42 \%$ and $79 \%$ in the placebo group $(p<0.0001, p<0001, p=N S$ respectively). Associated symptoms similarly resolved more quickly in the CIPRO group. This study demonstrates that single dose ciprofloxacin is effective empirical treatment for shortening the duration and severity of TD. It maximises compliance and reduces the cost of therapy but the risk of drug resistance has yet to be evaluated.
CONTINUOUS HEPATIC ARTERY FLOXURIDINE (FUDR) INFUSION PROLONGS OVERALL AND NORMAL-QUALITY SURVIVAL IN COLORECTAL LIVER METASTASIS PATIENTS.

Sally Barlam, Carol Fordy, K Abrams*, T.G. Allen-Mersh Chelsea \& Westminster Hospital and *CRC Clinical Trials Centre, London.

Hepatic artery FUDR infusion (HAI) produces the highest reported response in colorectal liver metastases (CLM) but survival benefit has not been demonstrated. We report the results of a prospective randomised trial which has now assessed quality of life (Q०L) and survival in patients with CLM.

100 patients were randomised to HAI $(n=51)$ of FUDR $(0.2 \mathrm{mg} / \mathrm{kg} / \mathrm{d}$ for 2 weeks per month) via an implantable Infusaid pump or 'conventional palliation' ( $n=49)$ involving any management (except HAI) which the referring clinician believed would optimise QoL. Physical symptoms (Rotterdam symptom checklist, upper limit of normal $=20$ ), anxiety and depression (Hospital anxiety and depression (HAD) scale, upper limit of normal $=8$ ) were measured monthly. Survival was analysed as days (either overall, or with normal QoL score) from randomisation.

$\begin{array}{llll} & \text { Control } & \text { HAI } & \text { P } \\ \text { Overall } & 215 & 425 & 0.03 \\ \text { Physical }<20 & 205 & 415 & 0.04 \\ \text { Anxiety }<8 & 210 & 330 & 0.04 \\ \text { Depression }<8 & 210 & 350 & 0.03\end{array}$

Repeated measures analysis of covariance did not reveal any significant HAI related adverse effects on physical symptoms, anxiety or depression.

HAI produced a $40 \%$ (95\% CI 5-62\%) reduction in relative risk of death during the first two years after initiation of treatment compared with conventional palliation alone. This resulted in a doubling in overall survival. These results suggest that CLM patients benefit from hepatic artery FUDR infusion.
PROLIFERATIVE ACTIVITY IN DMH-TREATED MOUSE COLONIC MUCOSA IS ENHANCED BY SULINDAC

M Moorghen ${ }^{1}, \mathrm{KJ}$ Finney ${ }^{2}$, DR Appleton ${ }^{3}$ and AJ Watson ${ }^{2}$

1- Department of Pathology and Microbiology, University of Bristol. 2- Department of Pathology, University of Newcastle-upon-Tyne. 3Department of Medical Statistics, University of Newcastle upon Tyne

In a previous study we reported that the NSAID sulindac had a marked inhibitory effect on the development of DMH-induced colonic tumours in mice. In this study we examined the effects of sulindac in respect of cell kinetic changes as determined by labelling with bromodeoxyuridine (BrdU) in mouse colonic mucosa at varying intervals during the process of DMH-induced carcinogenesis. We also investigated the possibility that these changes may be modulated by misoprostol, a $\mathrm{PGE}_{1}$ analogue. Four groups of 36 mice each were treated for 18 weeks with the following drug/s respectively: (1) DMH (2) DMH and sulindac (3) DMH, sulindac and misoprostol and (4) DMH and misoprostol. Three animals from each group were killed each week between the sixth week and the eighteenth week after the start of the experiment. A one-hour BrdU-flash-label technique was employed and paraffin sections of colonic mucosa were examined. For each animal a total of 50 perfect axially cut crypts were chosen and the following parameters determined: crypt length, labelling index and labelling index distribution; the data were analysed using the computer program GLIM. For each of the four groups crypt lengths increased significantly with the duration of treatment with no significant difference between the groups. In sulindac-treated animals the labelling index for all positions increased with duration of treatment whereas for animals not treated with sulindac there was no significant difference in labelling index with respect to duration of treatment. The administration of misoprostol did not appear to significantly alter the effects of sulindac. The finding of an increase in cell proliferation mediated by a chemopreventive agent is unexpected and indirectly questions the rationale behind the therapeutic manipulation of crypt cell proliferation in order to reduce the risk of colon cancer. 
THE INFLUENCE OF ONE YEAR CALCIUM SUPPLETION ON COLORECTAL EPITHELIAL CELL PROLIFERATION IN COLORECTAL ADENOMA PATIENTS* FJGM Kubben ${ }^{1}$. LGJB Engels ${ }^{1}$. JW Arends ${ }^{2}$. CGMI Baeten ${ }^{3}$. GH Bliiham ${ }^{1}$. B Schutte ${ }^{4}$. RW Stockbrugger. . Depts. of ${ }^{1}$ Internal Medicine, ${ }^{2}$ Pathology, ${ }^{3}$ Surgery, and ${ }^{4}$ Molecular Cell Biology; Academic Hospital, P.O. Box 5800, $6202 \mathrm{AZ}$ Maastricht, The Netherlands

Colorectal epithelial cell proliferation is increased in patients at risk for colorectal cancer. Medium-term calcium suppletion can decrease cellular proliferation, but long-term data are lacking. The effect of one year calcium suppletion in patients with colorectal adenoma was studied. After polypectomy of colorectal adenomas > $1 \mathrm{~cm}, 35$ patients (mean age $57 \mathrm{y} ; 21 \mathrm{~m}, 14 \mathrm{f}$ ) were randomized to 1 g elementary calcium daily $(n=18)$ or no treatment $(n=17)$. At 0 , 3 , and 12 months, rectal biopsies were taken for bromodeoxyuridine (BrdU) and proliferating cell nuclear antigen (PCNA) immunohistochemistry. The epithelial cell proliferation index (PI) was defined as $\%$ immunoreactive nuclei per total number of colonic crypt nuclei counted. At the present, results are evaluable for 11 patients (6 on calcium, 5 controls)

\begin{tabular}{||l|l|l|l|l|}
\hline \hline PI(SD) BrdU & $n=7$ & baseline & 3 months & 1 year \\
\hline controls & $\mathrm{n}=4$ & $3.3(1.2)$ & $4.1(1.7)$ & $6.5(1.4)$ \\
\hline calcium & $\mathrm{n}=3$ & $4.7(1.9)$ & $3.6(1.2)^{*}$ & $5.9(2.3)^{*}$ \\
\hline \hline PI(SD) PCNA & $n=9$ & baseline & 3 months & 1 year \\
\hline controls & $\mathrm{n}=4$ & $10.5(3.1)$ & $9.6(2.4) \#$ & $9.4(4.8)$ \\
\hline calcium & $\mathrm{n}=5$ & $6.9(4.5)$ & $5.1(1.3) \#$ & $11.6(4.4)$ \\
\hline
\end{tabular}

(* $\mathrm{p}=0.009 ; \# \mathrm{p}=0.02)$

With both staining methods, in the calcium treated group there was a tendency to a decrease of PI at 3 months, which may be the result of the recent replacement of colonic contents and/or the given treatment. *Funded by Dutch Cancer Foundation, Sandoz and Glaxo.
INTEGRINS AND MIGRATION OF OESOPHAGEAL KERATINOCYTES H. Dobson, D. Hopwood and C. D'Arrigo

Department of Pathology, Ninewells Hospital, Dundee.

Cell migration is known to play a fundamental role in wound healing. In the oesophagus it is important in resolution of ulcerative lesions. Furthermore, if Barrett's oesophagus arises as a result of a dysfunction of keratinocyte migration during repair, it may be possible to restore the normal cesophageal covering by modulating migration.

To study migration we used a modified Boyden chamber, where the upper and lower chambers were separated by a $150 \mu \mathrm{m}$ thick mixed cellulose ester filter with $8 \mu \mathrm{m}$ diameter pores. We examined the response of cells to filter-bound gradients of molecules. A suspension of freshly dissociated basal and prickle cells from oesophageal endoscopic biopsies was added to the upper chamber $\left(1200 / \mathrm{mm}^{2}\right)$ and incubated for variable times at $37^{\circ} \mathrm{C}$. We investigated the ability of collagen, laminin, fibronectin (Fn) and a dissociated, solubilised basement membrane preparation (Matrigel - MG), to promote migration. After migration filters were fixed and stained. Profile and leading front analysis was performed. Only Fn and MG induced migration and, in each case, about $20 \%$ of cells migrated into the filter. However, on Fn the leading front was at $50 \mu \mathrm{m}$, compared to $25 \mu \mathrm{m}$ for MG. No increased migration was seen after $4 \mathrm{~h}$, so this time point was used for all further experiments.

Incubating the gradient coated filters with anti-Fn antibodies prior to the addition of cells abolished migration on Fn but not on MG, suggesting that components other than $F n$ in MG are able to support migration.

Using filter-bound gradients of fibronectin, we showed that addition of anti-integrin- $\alpha_{v},-\beta_{4},-\beta_{5}$ or- $\alpha_{v} \beta_{3}$ antibodies with the cells did not affect migration, while anti- $\beta_{1}$, or a combination of anti- $\alpha_{2},-\alpha_{3}$ and $\alpha_{6}$ completely abolished it, implicating a role for these integrins in migration.

If this migration were integrin mediated it should be $\mathrm{Mg}^{2+}$ (but not $\mathrm{Ca}^{2+}$ ) ion dependent. Ion dependency experiments showed that migration on Fn was abolished by chelation of divalent cations, restored by addition of $\mathrm{Mg}^{2+}$ and only partly restored $(30 \%)$ by addition of $\mathrm{Ca}^{2}+$

Finally, we have shown previously that the peptide GRGDS, but not GRGDTP, inhibits adhesion of these cells to Fn. When added with cells neither peptide inhibited migration, suggesting that sites other than the RGD-containing cell binding site of Fn are important in mediating migration.

This is the first report of migration of oesophageal keratinocytes in vitro. We have demonstrated that migration on fixed Fn gradients is integrin mediated but not RGD dependent.
C-ERBB-2 GENE EXPRESSION IN NON-METASTATIC COLORECTAL CANCER

H Mulcahy, E Kay, M Leader \& DP O'Donoghue. Gastroenterology \& Liver Unit, St, Vincent's Hospital, Dublin and Department of Pathology, Royal college of Surgeons in Ireland.

Introduction: Dukes' B disease accounts for over one third of all colorectal cancers. Outcome is especially variable in this group and additional indicators of disease progression would be of value. The cerbB-2 oncogene encodes for a putative membranous growth factor receptor related to the EGF receptor. Membranous staining correlates with c-erbB-2 amplification, but while such staining is a common feature of breast carcinomas, it appears limited in colorectal cancer. Cytoplasmic c-erbB-2 staining also correlates with gene amplification in bladder, breast and colorectal cancer, though its biological and prognostic significance is uncertain. Aim: to examine the incidence and prognostic significance of c-erbB-2 protein expression in Dukes B colorectal cancer. Patients: 164 consecutive Dukes' B patients admitted to a single institution (1983-88). Follow-up: Mean 6.3 years; range, 3.5-10. Methods: Paraffin wax sections were examined with the monoclonal antibody NCL-CB11 (Novocastra) using the avidin-biotin immunoperoxidase technique. Slides were reviewed by a single pathologist blinded to clinical details and outcome. Membrane and cytoplasmic staining were assessed separately. Results: Membranous staining was not detected in any case. Cytoplasmic c-erbB-2 staining was seen in 55 cancers $(34 \%)$. Cytoplasmic staining was unrelated to patient age $(p=0.31)$, sex $(p=0.69)$, tumour site $(p=0.69)$, size $(p=0.57)$ or histological grade $(p=0.42)$, but was weakly related to tumour ploidy status $(p=0.21)$ and found more frequently in obstructing cancers $(p=0.03)$. Five year survival estimated by the Kaplan-Meier lifetable method was 47 per cent for those with cytoplasmic c-erbB-2 staining and 77 per cent for those without such staining (Logrank analysis; $\mathrm{p}<0.0001$ ). Stepwise regression analysis identified c-erbB-2 staining (Relative risk, 2.51; $p=0.0005$ ) and bowel obstruction (Relative risk, 1.99; $p=0.015$ ) as the only independent predictors of outcome. Conclusion: These results suggest that genetic events may be involved in the progression of lymph node negative colorectal cancer and that cytoplasmic c-erbB2 staining may provide a useful marker of tumour behaviour in the Dukes' B group.

\section{ALLELIC HETEROGENEITY IN FAMILIAL} ADENOMATOUS POLYPOSIS (FAP); A FAMILY WITH MILD PHENOTYPE AND A MUTATION NEAR THE 5' END OF THE APC GENE.

DR Davies*, JG Armstrong. I Frayling, T Clancy, SP Guy, TW Warnes*. DGR Evans. *Department of Gastroenterology, Manchester Royal Infirmary and Department of Medical Genetics, St. Mary's Hospital, Manchester.

An attenuated form of FAP has been described where affected individuals develop relatively few colonic polyps but still carry a significant risk of colorectal cancer. Mutations in the APC gene on chromosome 5q21-22 have recently been described in families with attenuated FAP. These were notable in that they were all located towards the 5' end of the APC gene.

A previously reported family includes a fifty nine year old woman who is an obligate gene carrier and has not developed any polyps. Her brother and two of her four children have developed over a 100 colorectal adenomas. Some individuals had abnormalities on orthopantograms. Linkage studies were consistent with a disease asssociated allele being present at the APC locus. Using single strand conformation polymorphism (SSCP) analysis we found an abnormal conformer in exon 3 segregating with the disease phenotype in this family. Sequencing revealed an $\mathrm{A}$ to $\mathrm{T}$ transversion at codon 121 changing AGA to TGA, producing a premature stop codon.

This supports the observation that mutations towards the 5 ' end of the APC gene are associated with a mild phenotype; however, there is marked variability within family members in terms of age of onset, number of polyps and presumably cancer risk. 
FASTING AND MEAL-STIMULATED GASTRIN LEVELS PRE-AND POST-OPERATIVELY IN COLORECTAL TUMOUR PATIENTS.

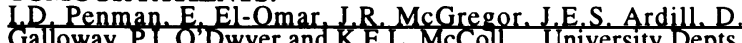
of Medicine and Surgery, Western Infirmary, Glasgow.

Introduction: Gastrin stimulates the growth of experimental colonic tumours and colon cancer cell lines in vitro. In addition, several reports have claimed that patients with colorectal cancer have elevated havm clastrin which falls post-operatively, implying have elevated serum gastrin which falls post-operatively, implying production of the hormone by the tumour. Aim: To measure fasting and peak meal-stimulated plasma
ime gastrin levels in pre-operative colorectal tumour patients before bowel preparation $(n=42)$ and in age \& sex matched $(n=34)$ controls (pre-operative hospital inpatients awaiting minor surgery) Eighteen patients were re-studied 1-6 months following curative resection. $H$ pylori status was also examined as it affects gastrin. Methods: Gastrin was measured fasting and at 15, 30, 45 and 60 minutes after a standard test meal. H pylori status was assessed using the ${ }^{14} \mathrm{C}$-urea breath test.

\begin{tabular}{lll} 
& \multicolumn{2}{c}{$\begin{array}{c}\text { Results (ng/L, medians + inter quartile ranges): } \\
\text { Controls }(\mathbf{n}=\mathbf{3 4})\end{array}$} \\
Tumours (preop, $\mathbf{n}=\mathbf{4 2})$ \\
Fasting gastrin & $77.5(53.7-137.5)$ & $55(45-82.5)$ \\
Peak gastrin & $247.5(147.5-375)$ & $200(137.5-312.5)$
\end{tabular}

There was no significant difference in either fasting or peak gastrin levels between tumours and controls, nor was there any correlation between gastrin levels and either tumour site or Duke's stage. Prevalence of HP infection in tumours $(60 \%)$ and controls $(53 \%)$ was similar in both groups. Plasma gastrin was not lowered following curative resection:

\section{Patients with Curative Resection (n=18) \\ $\begin{array}{ll}\text { Pre-op } & \text { Post-op } \\ \text { Fasting gastrin } & \text { 52.5 (43.8-76.2) }\end{array}$}

$\begin{array}{lll}\text { Fasting gastrin } & 52.5(43.8-76.2) & 52.5(43.8-71.3) \\ \text { Peak gastrin } & 150(117.5-240) & 162.5(120-270)\end{array}$

Five tumour patients who were HP+ve pre-op. were HP-ve post-op. and their median peak gastrin level fell from $200 \mathrm{ng} / \mathrm{L}$ to (Ong $\mathrm{L}$

Conclusions: Gastrin levels are not raised in colorectal tumour patients when compared with well-matched control patients. Previously noted falls in gastrin after tumour resection may be due to eradication of $H P$ infection associated with peri-operative antibiotics.
COELIAC DISEASE AND INTESTINAL LYMPHOMA

M Ilyas, A E Read, R E Barry and N Rooney

Department of Histopathology, Bristol Royal Infirmary, Bristol.

Coeliac disease is characterised by an intolerance to one of the gliadin components of gluten. Patients with Coeliac disease have an increased risk of malignancy, especially the development of high grade $\mathrm{T}$ cell lymphoma of the small bowel (Enteropathy Associated $\mathrm{T}$ cell Lymphoma - EATL). Current teaching is that lymphoma develops many years after the onset of Coeliac disease.

166 patients with Coeliac disease were followed over a period of 25 years. 13 developed primary small bowel lymphoma and the histology and clinical notes were reviewed. 11 cases presented with Coeliac disease after the age of twenty whilst only 2 had childhood onset disease. 6 developed lymphoma less than 2 years after diagnosis of Coeliac disease ("early onset") whilst 7 of these cases developed lymphoma over five years after diagnosis of the disease ("late onset"). On histological review, 11 cases were EATL whilst two were B cell lymphomas. Both the B cell lymphomas were of "late onset" type. 6 of the EATLs were "early onset" type and 5 were "late onset" type

From this series it appears that most lymphomas develop in patients presenting with Coeliac disease in adulthood and that both $B$ cell and $T$ cell lymphomas may develop. The bi-modal distribution of this group of EATLs into early and late onset type diseases and evidence from other studies suggests that these may be two different diseases with different aetiologies. The late onset lymphomas are probably arising from genuine Coeliac disease and chronic gliadin driven immunoproliferation is important in the development of this type of disease. The early onset cases are, however, probably malignancies from the outset. In the initial stages, they are low grade lymphomas and they mimic the histological features of Coeliac disease. They soon undergo high grade transformation and develop the typical features of EATL.
NEW GASTRIN RECEPTOR ANTAGONISTS (GRAs), POSSIBLE TREATMENT FOR COLON CANCER Romani R., Howes L.G., and Morris D.L. University Department of Surgery, The St George Hospital Kogarah, N.S.W. 2217, Australia

Three new GRAs C1-988, CAM 1715 and CAM 1481 (ParkeDavis, Cambridge), with varying affinity for the cholecystokinin (CCK) A and B (or gastrin) receptor and Proglumide, the only clinically available GRA, were tested against the growth of colon cancer cell lines. Cells from six human colon cancer cell lines (LoVo, C146, IM 1215, LIM 2412, C170 and LIM 2463) were set up in standard in vitro cell culture containing the GRAs at $1 \times 10^{-11}$ to $1 \times 10^{-7} \mathrm{M}$, with $\mathrm{N}=5$. Cells were incubated for 24,48 and $72 \mathrm{hrs}$ and cellular respiration measured by an MTT assay.

The basal growth of four of the cell lines (LoVo, $C \pm 46$, LIM 2142 and LIM 2463) was significantly reduced $(\mathrm{P}<0.05$, Mann-Whitney $U$ test) by $\mathrm{C} 1-988$ (a gastrin/CCK B antagonist) to $30.43+/-15.5 \%$ of control and by CAM 148 (CCK A and B antagonist) to $52.17+/-11.29 \%$ of control. Significant inhibition of growth occurred at concentrations as low as $1 \times 10-11 \mathrm{M}$. CAM 1715 (a CCK A antagonist) had modest inhibitory activity against three cell lines (LoVo, C146 and LIM 2463). Proglumide had no inhibitory effects on the growth of any cell lines.

Nude mice with subcutaneous xenografts from LoVo received $\mathrm{Cl}-988$ (10mg/ $/ \mathrm{kg} / \mathrm{day})$ orally $(\mathrm{N}=13)$ or saline $(\mathrm{N}=14)$. Treatment continued for 20 days. $\mathrm{C} 1-988$ inhibited in vivo growth of LoVo by $53 \%$ ( $\mathrm{P}<0.05$, ANOVA) over 20 days.

These are the first studies of these new pot?nt GRAs in any cancer system. The finding that four out of six colon cancer cell lines are inhibited in vitro by physiologically relevant concentrations of $\mathrm{Cl}-988$ and CAM 1481, supported by the marked inhibition of growth of LoVo by C1-988 in vivo is most encouraging and suggests GRAs could have therapeutic utility in colon cancer.
IMAGING OF SECONDARY CARCINOID TUMOURS OF THE LIVER: COM PARISON OF I'23-METAIODO BENZYLGUANIDINE (MIBG) AND IN"11-LABELLED OCTREOTIDE SCANS. JK Ramage, *M Buxton-Thomas, Roger Williams. Institute of Liver Studies and *Department of Nuclear Medicine, Kings College Hospital, London, SE5 9RS.

Therapeutic options for hepatic neuroendocrine tumours include octreotide, interferon, chemotherapy, liver transplantation and radioiodine therapy using $\mathrm{I}^{131}$-labelled MIBG. With new therapy it is increasingly important to image the extent of tumour metastases. Currently whole body scans can be obtained using I $^{12.3}$ MIBG which depends on amine uptake into tumour cells and In ${ }^{111}$-DTPA-D-Phe-Octreotide (Octreoscan), which depends on the presence of somatostatin receptors.

The two techniques were compared in 13 patients with known secondary neuroendocrine tumours. Nine patients had secreting tumours with carcinoid syndrome (four with known primary in the ileum,one an anal primary and four with unknown primary); all nine had high levels of 5-HIAA and were on treatment with octreotide at the time of the scans. Four patients had non-secreting apudomas, one had had the primary removed (pancreas) and two had known primaries (pancreas and stomach). Two patients had multiple recurrences of secreting tumour post liver transplant (primaries previousiy removed). All patients were injected with $185 \mathrm{MBq} \mathrm{I}^{123}$ MIBG (scanning at 4 hrs and $24 \mathrm{hrs}$ ) and subsequently with $120 \mathrm{MBq}$ In $^{111}$-DTPA-D-PheOctreotide(scans at $24 \mathrm{hrs}$ and $48 \mathrm{hrs}$ ). All 13 of the In $^{111}$ octreotide scans showed definite lesions at the sites known to be affected by secondary tumour whereas only three of the patients had definite lesions in the same areas using MIBG. No new primary sites were detected.

$I^{111}$ Octreotide scanning is considerably superior to $I^{123}$ MIBG scanning in identifying hepatic neuroendocrine tumours and also of extrahepatic spread. Concurrent octreotide therapy does not interfere with octreotide imaging. 


\section{Helicobacter pylori T131-T141}

T131

\section{EFFECT OF HELICOBACTER PYLORI ERADICATION ON} PRECANCEROUS LESIONS OF THE STOMACH

\section{JM Marrero, C McCormick*, M Mendall, RP Jazrawi, CM Corbishley*} TC Northfield. Dept of Medicine and Histopathology*, St. George's Hospital Medical School, London SW17 ORE. UK

Gastric cancer is a late complication following Bilroth II (BII) operation for peptic ulcer. In comparison with other operations, BII patients also have greater frequency and severity of gastric dysplasia and more progression over time. Evidence suggests that $\mathrm{H}$. pylori is associated with both gastric cancer and gastric dysplasia. In the post gastrectomy stomach the histological diagnosis of $\mathrm{H}$. pylori infection is difficult. Serology, however, can reliably diagnose $H$. pylori infection and eradication The aims of this study were to assess in BII subjects the efficacy of eradication therapy for $\mathrm{H}$. pylori and to determine whether this caused regression of dysplasia. Methods: Twenty four subjects who had a BII operation more than 20 years earlier had four upper GI endoscopies at 6 months before treatment, at baseline, 1 month post treatment with triple therapy (Bismuth, metronidazole and tetracycline) and 6 months later. At each endoscopy 6 biopsies were obtained from stoma, 3 from body and 3 from fundus. Serum was also obtained for $\mathrm{H}$. pylori IgG titres. Two histopathologists unaware of patient details or the time of the biopsies graded specimens for dysplasia and inflammation as the worst grade for each area, producing a total score for each patient. Eradication of $\mathrm{H}$. pylori was diagnosed when a 50\% fall in IgG titres was found at six months (as previous validated). Results: 22 out of 24 subjects were positive for $H$. pylori 6 months before treatment and at baseline endocopies. There was no difference in total inflammation and dysplasia scores (mean 6.4 vs 6.5 ; and 1.5 vs 1.5 at 6 months before treatment and at baseline respectively). One month post treatment total inflammation scores significantly decreased from 6.4 to $3.3 \mathrm{p}<0.0001$ but dysplasia score was unchange from 1.5 to 1.1 , NS. Six months after treatment, eradication on serological criteria was achieved in 15 out of 21 . Both inflammation and dysplasia scores were significantly reduced in eradicators (3.9 vs $6.9, \mathrm{p}<0.005$ and 0.3 vs $1.5, \mathrm{p}<0.0005$ respectively). No reduction was found in non-eradicators ( 3.3 vs 5.5 , and 0.8 vs 1.2 , NS respectively) Conclusions: A fall in serological titre suggestive of eradication following treatment is associated with a regression in dysplasia and inflammation, not found in those in whom titres did not change. These results suggest that $H$. pylori contributes to gastric carcinogenesis.
ERADICATION OF HELICOBACTER PYLORI REDUCES GASTRIC EPITHELIAL CELL PROLIFERATION.

R.J. Cahill, J. Gilvarry, S.Beattie, H.Hamilton, C.A. O'Morain Department of Gastroenterology, Meath and Adelaide Hospitals. Trinity College, Dublin, Ireland.

Recent studies have identified a link between $H . p y /(r) i$ infection and gastric cancer and have proposed that effective eradication of $\mathrm{H}$. pv/(or: may reduce the risk of gastric cancer. Clarithromycin is the most effective monotherapy in the eradication of $H$. pylori. Increased epithelial cell proliferation is an indicator of risk of cancer.

The aim of this study was two fold a)to assess the efficacy of lanzoprazole and clarithromycin in eradicating $H$. pylori b)to assess the effect of eradication of $H$. pvlori on gastric epithelial cell proliferation.

a) 24 patients with H.pylori positive gastritis were recruited for the study. The patients were treated with clarithromycin 50() $\mathrm{mg}$ TID and lanzoprazole $30 \mathrm{mg} / \mathrm{day}$ for two weeks. The diagnosis was confirmed by histology and the H.pylori status was assessed using Clo® test. histology, gram stain and culture and $\mathrm{Cl}^{3}$ breath test. 19 subjects returned for a 38 day assessment and the eradication rate with this therapy was $47 \%$. 5 subjects were excluded from final analysis: 2 were not compliant to therapy and 3 suffered side effects from medication.

b) Four mucosal pinch biopsies were taken from the antrum at endoscopy for gastric epithelial cell proliferation using the in vitu bromodeoxyuridine immunohistochemical technique. Labelling index percent $(\mathrm{LI} \%)$ was calculated as the percent ratio of proliferating cells to the total number of cells in the gland. H. pylori was eradicated in 12 of the subjects (Hp E) and not eradicated in seven subjects (Hp NE). The results are expressed as mean and standard error

$\begin{array}{lllll} & \mathbf{n} & \text { LI\% (pre) } & \text { LI\%(post) } \\ \text { Hp E } & 12 & 5.4(0.4) \div & 3.5 & (0.2)^{*} \\ \text { Hp NE } & 7 & 4.4(0.4) \div & 5.7 & (0.5) \\ \text { Hp Negative } & 20 & 3.60(0.4) & & \\ \text { Normal } & 20 & 3.5(0.3) & & \end{array}$

* $\mathrm{p}<0.01$ compared with pre-therapy $\mathrm{LI} \%,+\mathrm{p}<0.01$ compared with $\mathrm{Hp}$ negative and normal controls. In conclusion. one week therap! witl low dose lanzoprazole and clarithromycin has a $47 \%$ eradication rate. Eradication of H.Pylori reduces gastric cell proliferation to normal levels and may therefore reduce long term the risk of gastric carcimoma.
Gastrimmune inhibits the growth of two gastrin receptor positive rat colon cancers.

S.A. Watson, D. Michaeli, T. M. Morris, G. Robinson, J. D.

Hardcastle. Department of Surgery, Queens Medical Centre, Nottm. NG7 2RD,UK and Aphton Corporation, California, USA The growth of colorectal cancer is enhanced by the hormone, gastrin. An immunogen has been developed, named Gastrimmune, which is composed of the amino terminus of gastrin-17(G-17) linked to diptheria toxoid (DT), and raises neutralising anti-G17 antibodies which do not cross react with gastrin-34 or cholecystokinin.

Gastrimmune was administered to rats in two colorectal cancer models. Model 1 involved implantation of the rat colon line, DHDK 12 into the peritoneal wall of BDIX rats. The mean weight of the DHDK12 tumours in Gastrimmune treated rats was significantly reduced to $1.18 \mathrm{~g}$ compared to $2.44 \mathrm{~g}$ in the DT treated controls $(p=0.0045)$. Histological analysis of the Gastrimmune-treated tumours revealed that the outer zone of proliferative cells was markedly reduced compared to the DT treated tumours. The former tumours were associated with a greater degree of fibrosis and inflammatory cell infiltration. The trabecular pattern of growth seen in the DT treated tumours was disrupted in the tumours from rats treated with Gastrimmune. The DHDK12 tumours were gastrin receptor positive as determined with a monoclonal antibody directed against the receptor, $2 \mathrm{Cl}$, and gastrin receptor expression of the Gastrimmune treated tumours appeared to be similar to that of the DT treated tumours.

Model 2 involved intraperitoneal wall implantation of the rat colon line, WB2054M. This invasive tumour breached the peritoneal wall and grew locally within the peritoneal cavity and distantly within the lungs. Gastrimmune treated rats had reduced peritoneal tumour growth (mean weight of $0.71 \mathrm{~g}$ compared to $9.1 \mathrm{~g}$ for the DT treated tumours, $\mathrm{p}=0.006$ ). In comparison to the DT treated tumours, which contained both glandular arrays and nests of tumour cells, the Gastrimmune treated tumours predominantly comprised nests of tumour cells, they also expressed less gastrin receptor immunoreactivity. Although the tumours in the lungs were histologically similar in both groups, they were smaller in the Gastrimmune treated group.

Gastrimmune is now being evaluated in a clinical trial in colorectal cancer to determine its therapeutic potential.
T132

GASTRIC JUICE EPIDERMAL GROWTH FACTOR IN HELICOBACTER PYLORI ASSOCIATED GASTRITIS AND DUODENAL ULCER DISEASE. DAF Lynch, NP Mapstone, $F$ Lewis, J Pentith, ATR Axon, MF Dixon, $P$ Quirke. Centre for Digestive Diseases, The General Infirmary at Leeds, UK

Introduction: H.pylori (HP) is the cause of chronic (Type B) gastritis and the major factor in the causation of duodenal ulceration (DU) though the underlying mechanisml remains speculative. Smoking is another strong predictor of DU and is associated with delayed ulcer healing. Epidermal growth factor (EGF) is produced in the salivary and Brunners glands of the upper gastrointestinal tract and plays a role in maintaining the integrity of the gastroduodenal mucosa. Using a commercial ELISA (British Biotechnology) we have measured gastric juice EGF (GJ-EGF in controls $(n=15)$, smokers $(n=10)$, subjects with HP gastritis (HPG) with $(n=9)$ and without $(n=15)$ DU, and have studied the effect of eradicating the organism from subjects DU disease 4 weeks [I] (non-eradicated; $n=8$ : eradicated I; $n=16$ ) and 12 months (range 6-18) [II] after eradication therapy (eradicated II; $n=9$ ). Results: Median (quartile) GJ-EGF (pg/ml) are as follows:

Controls $=957(544-1399)$, Smokers $=496(359-660)$, HP non-ulcer $=391(221-532)$, HP DU $=260(209-411)$, non-eradicated $=203(73-294)$, eradicated $I=386(225-534)$. eradicated $I I=391(303-493)$. Luminal EGF was reduced in smokers compared to controls ( $P=0.008$; Wilcoxon Rank Sum) Subjects with HPG had reduced GJ-EGF compared to controls $(P=0.0002)$. HP DU subjects had lower GJ-EGF than HP non-ulcer though the difference was not statistically disease increased GJ-EGF by $33 \%$ from patients with DU significant. The levels of GJ-EGF remained below normal on follow-up. Conclusions: 1. Subjects with HPG or who smoke have low concentrations of luminal EGF whether duodenal ulcer is present or not. 2. Cure of HP infection in DU subjects does not return the concentration of EGF to normal. 
CELL PROLIFERATION IN THE GASTRIC CORPUS IN HELICOBACTER PYLORI ASSOCIATED GASTRITIS AND THE POST-SURGICAL STOMACH. DAF Lynch, NP Mapstone, AMT Clarke, P Jackson, MF Dixon, $P$ Quirke, ATR Axon. Centre for Digestive Diseases, The General Infirmary at Leeds, UK.

Introduction: Patients with a post-surgical stomach are at increased risk of carcinoma of the gastric remnant where bile reflux is believed to play a role in carcinogenesis. Increased cell proliferation (CP) increases the chances of a neoplastic clone of epithelial cells emerging particularly in the context of epithelial injury associated with bile reflux. H.pylori (HP) is a major risk factor for the development of gastric cancer in the intact stomach. We have shown previously that antral $\mathrm{CP}$ is increased in HP gastritis (HPG) and falls to normal levels after HP eradication. Little is known of corpus CP in HPG or in the post-surgical stomch (PSS). Methods: Endoscopic corpus (2) biopsies were taken from intact stomachs and gastric remnant for in-vitro bromodeoxyuridine (BrdU)

immunostaining. The Labelling Index (LI\%) was determined in the 3 zones of the gastric glands (Zone $1=$ surface + gastric pit; Zone $2=i$ sthmus; Zone $3=g l$ and base). At least $500 \mathrm{cells} / z$ ne were counted in controls with normal endoscopy+ histology $(n=13)$, subjects with HPG affecting antrum and corpus $(n=33)$, and patients with PSS $(n=15)$ : truncal vagotomy+gastroenterostomy $(n=2)$, partial gastrectomy $(n=2)$, Bilroth I $(n=5)$, Bilroth II $(n=2)$, antrectomy+Roux-en-Y $(n=3)$, vagotomy and pyloroplasty $(n=1)$. Results: The LI\% of all 3 zones varied in the same direction. The majority were situated in Zone 2. The Median LI\% (quartiles) for Zone 2 for Controls $=9(4.9-10.6)$; $H P G=14.4(10.3-17.4)$; PSS=22(16.2-29.3); [PSS HP+ve $(n=7)=33.7(23.2-35.1) ; \operatorname{PSS}(n=8)=16.9(12.6-19.6)]$. Corpus $C P$ is increased in HPG $(P=0.001$; Mann-Whitney). $C P$ is greater in corpus biopsies of PSS than in HPG $(P=0.001)$. Sub-group analysis of patients with PSS indicates that $H P+v e$ subjects had higher $C P$ than HP-ve $(P=0.01)$. Conclusion: These findings provide further evidence for the role of $\mathrm{HP}$ and bile in gastric carcinogenesis and suggest that their presence has a synergistic effect on gastric mucosal proliferation.
T135

HELICOBACTER PYLORI INDUCED GASTRIC EPITHELIAL
INTERLEUKIN-8 SECRETION IS ASSOCIATED WITH THE CagA POSITIVE PHENOTYPE

JE Crabtree, "A Covacci, SM Farmery, * $Z$ Xiang, DS Tompkins, S Perry, "JJD Lindley, "R Rappuoil Hospital and PHLS, Leeds; " Sandoz Research Institute, Vienna, Austria and "IRIS, Siena, Italy.

Helicobacter pylori directly increases gastric epithelial IL-8 secretion in a strain specific manner. IL-8 is induced by strains expressing the vacuolating cytotoxin $\left(\mathrm{Vac}^{+}\right)$ and the strongly associated $128 \mathrm{kD}$ protein $\left(\mathrm{CagA}^{+}\right)$. The role of these two virulence determinants in epithelial IL-8 induction was investigated using phenotypic variants. Two cytotoxic strains (G104, BA142), negative for the $\operatorname{cagA}$ gene and CagA protein, and one non-cytotoxic VacA- strain (931) which expressed the cagA gene and CagA protein were used. Positive and negative controls were the cytotoxic type strain NCTC 11637 $\left(\mathrm{cagA}^{+} ; \mathrm{CagA} \mathrm{A}^{+} / \mathrm{VacA}^{+} ; \mathrm{VacA}^{+}\right)$and non-cytotoxic $\mathrm{G50}$ (cagA-;CagA-/vacA ${ }^{+} ; V^{-} A^{-} A^{-}$). Kato 3 and AGS gastric epithelial cells $\left(5 \times 10^{5}\right)$ were cultured for 24 hours with $2 \times 10^{7} \mathrm{H}$. pylori. Secreted IL-8 was measured by ELISA.

IL-8 secretion from Kato 3 cells following co-culture with BA142 (mean \pm SEM, $1.41 \pm 0.29 \mathrm{ng} / \mathrm{ml}$ ), G104 $(1.55 \pm 0.39)$ and $G 50(1.3 \pm 0.23)$ was not significantly different from secretion by uninfected control cell cultures $(1.47 \pm 0.19)$ ( $\mathrm{n}=4)$. IL-8 secretion induced by NCTC 11637 (11.4 \pm 1.67$)$ and the $\mathrm{CagA}^{+} \mathrm{VacA}^{-}$strain 931 (4.56 \pm 0.64$)$ was significantly greater ( $p<0.05$ ) than secretion from both uninfected control cultures and cultures with G104, BA142 and G50 strains. NCTC 11637 and 931 similarly induced significant $(p<0.02)$ IL-8 secretion from the AGS gastric epithelial cells, which was not observed on co-culture with BA142, G104 or G50.

These data demonstrate that $H$. pylori induction of gastric epithelial IL-8 secretion is associated with the CagA protein not the vacuolating cytotoxin. Increased IL-8 induced by CagA positive strains may explain the association of these strains with active neutrophilic gastritis and gastroduodenal disease.
HELICOBACTER PYLORI (HP) STATUS, ENDOSCOPIC FINDINGS AND SEROLOGY IN HIV-1 SEROPOSITIVE PATIENTS. D Vaira, M Miglioli, *A Boschini, **J Holton, M Menegatti, P Mule, C Ainley***, L Barbara, 1st Medical Clinic, University of Bologna, *S. Patrignano Community, Forlì, Italy, **Dept. of Microbiology, University College London Medical School, ${ }^{* * *}$ London Hospital Medical College, London, UK.

HP infection is less common in HIV-1 +ve subjects but there is little data on associated gastrointestinal (GI) pathology or serology.

Methods: In a closed community of ex-drug addicts with known HIV-1 status we studied patients with upper gastrointestinal symptoms (UGI symptoms) $(n=210 ; M / F$ 153/57; age range 18-52, mean 30 yrs) by endoscopy and serology. Controls included ex-drug addicts in the community without UGI symptoms $(n=259)$, patients with UGI symptoms not at high risk of HIV-1 infection $(n=219)$ and asymptomatic blood donors $(n=322)$.

Results: HP was present in biopsies from $52 \%$ of the ex-drug addicts with UGI symptoms. HP was less common in HIV-1 sero+ve $(44 / 111 ; 40 \%)$ than those who were HIV-1 sero-ve $(65 / 99 ; 66 \%$; $\mathrm{P}<0.001)$. In patients with AIDS $(24 / 73 ; 33 \%) \mathrm{HP}$ was less common than HIV-1 sero+ve patients without AIDS (20/38; 53\%; $\mathrm{P}=0.05$ ). Peptic ulcer was more common in HP+ve ex-drug addicts (31/109; $28 \%$ ) compared with those who were HP-ve $(0 / 101)$, but there was no differences compared with patients with UGI symptoms not at high risk of HIV-1 infection (24/120;20\%; P=NS). Apart from candidiasis in HIV-1 sero+ve patients there was no unusual upper GI pathology in any of the ex-drug addicts with UGI symptoms. Both for HIV-1 +ve and for HIV-1 -ve ex-drug addicts raised titres of anti HP IgG were present in $99 \%$ of those HP+ve by histology compared with 3\% with negative histology (sensitivity 100\%, specificity 97\%). The seroprevalence of HP was similar in ex-drug addicts with UGI symptoms $(52 \%)$, ex-drug addicts without UGI symptoms $(56 \%)$ and patients with UGI symptoms not at high risk of HIV-1 infection $(55 \%)$, but was reduced in asymptomatic blood donors $(33 \% ; \mathrm{P}<0.001)$.

Conclusion: 1) HP is reduced in HIV-1 infection, 2) peptic ulcer is associated with HP in HIV-1 infection, 3) unusual GI pathology is rare in HIV-1 sero+ve patients with UGI symptoms, 4) positive HP serology is a reliable marker of infection in HIV-1 sero+ve ex-drug addicts.
DETECTION OF CAgA POSITIVE HELICOBACTER PYLORI : A COMPARISON OF POLYMERASE CHAIN REACTION AND IMMUNOBLOTTING PROTOCOLS.

\section{SM Farmery, EM Pyrah, JE Crabtree, Department of Clinical} Medicine, St James's University Hospital, Leeds, LS9 7TF.

The virulence of Helicobacter pylori appears to be related to expression of the highly immunogenic CagA protein. CagA can be detected reliably by immunoblotting, but the technique is time consuming. A polymerase chain reaction (PCR) protocol may be more suitable for screening purposes. However, the cagA gene is highly polymorphic, particularly in the 3 ' region, which complicates the design of suitable primers. We here describe a PCR analysis of the urease $A$ and $\operatorname{cag} A$ genes in cultured $H$. pylori, and compare the cagA detection rate with immunoblotting for the CagA protein.

Bacterial strains cultured from gastric biopsies were inoculated from agar plates into sterile water. The bacterial suspensions were then boiled and used as templates in the PCR amplifications. Separate PCR amplifications were undertaken using primers for the Urease $A$ gene ( $411 \mathrm{bp}$ product), and for the more highly conserved 5 ' region of $\mathrm{cag} A$ (400bp product). Western blots of denatured bacterial protein were probed with anti-CagA sera, and visualised by alkaline phosphatase .

A total of 25 strains were analysed, as well as the $H$. pylori type strain NCTC 11637 which is urease and CagA positive. By PCR, all isolates produced a band of the expected size for urease, and 14/25 were positive for the $\operatorname{cag} A$ gene. Twelve of the strains ( 5 cagA positive, 7 cagA negative) were further analysed by Western blotting and the results for two of the strains were inconsistent. In one, the cagA gene could be detected by PCR but the protein was not expressed, and in another the gene failed to amplify but CagA protein product was readily visualised.

In conclusion, urease primers probably detect all strains of $H$. pylori but give no indication of their potential pathogenicity. Interpretation of $\operatorname{cag} A$ PCR results, however, are complicated by the degree of heterogeneity of sequence within the $\operatorname{cag} A$ gene. A panel of different primers will probably be required to generate definitive results 


\section{INCREASED LOCAL PRODUCTION OF IL-8 AND} TNF IN PATIENTS WITH $H$. PYLORI INFECTION.

X.G. Fan, A. Chua, X.J. Fan, P.W.N. Keeling Department of Clinical Medicine, St. James's Hospital, Trinity College, Dublin 8 , Ireland

Aims: In order to investigate the roles of interleukin 8 (IL-8) and tumour necrosis factor (TNF) in Helicobacter. pylori $(H$. pylori) positive patients, IL-8 and TNF levels in plasma, gastric juice and supernatants of gastric biopsy homogenate from $H$. pylori negative and positive individuals have been measured.

Methods: Fifty-two patients attending for upper gastrointestinal endoscopy for dyspepsia were studied. Of 52 cases, 35 had $H$. pylor infection, 17 were $H$. pylori negative hosts. IL- 8 and TNF levels were measured by RIA and L929 cell bioassay respectively.

Results: The concentrations of IL-8 and TNF in gastric juice (IL-8: $26.03 \pm 12.72$ vs $19.06 \pm 9.92 \mathrm{ng} / \mathrm{ml}, \mathrm{p}<0.01$; TNF: $329.89 \pm$ 126.96 vs $202.17 \pm 82.42 \mathrm{pg} / \mathrm{ml}, \mathrm{p}<0.05$ ) as well as in gastric biopsies (IL-8: $10.19 \pm 5.51$ vs $7.82 \pm 2.96 \mathrm{ng} / \mathrm{g}$ wet $\mathrm{wt}, \mathrm{p}<0.05$; TNF: $181.07 \pm 71.97$ vs $97.32 \pm 30.44 \mathrm{pg} / \mathrm{g}$ wet $w t, p<0.001$ ) were significantly greater in patients infected with $H$. pylori. Among $H$. pylori positive patients, IL-8 levels in gastric juice and biōpsies were significantly higher in those with moderate gastritis than in those with mild gastritis $(p<0.05)$. There was a significant positive correlation between IL-8 and TNF concentrations in gastric juice $(\mathrm{n}=26, \mathrm{r}=0.481, \mathrm{p}<0.01)$ and supernatants of gastric biopsy homogenate $(\mathrm{n}=27, \mathrm{r}=0.364, \mathrm{p}<0.05)$ of $H$. pylori positive patients. There were no significant differences $(p>0.05)$ between $H$. pylori positive and negative groups for IL-8 and TNF levels in plasma.

Conclusions: This study suggests that increased local gastric tissue production of IL-8 and TNF may be involved in the pathogenesis of $H$. pylori associated gastroduodenal diseases.

\section{SUCRALFATE SUPPRESSES H PYLORI INFECTION \&}

\section{REDUCES GASTRIC ACID SECRETION BY $50 \%$ IN}

\section{DU PATIENTS S Baneriee* E EI Omar A Mowat JES Ardill,}

\section{RHR Park*, W Watson*, AD Beattie*, KEL McColl.}

* Gastrointestinal Centre, Southern General Hospital , \& Dept. of Medicine \&Therapeutics, Western Infirmary, Glasgow, UK.

Sucralfate is as effective as $\mathrm{H}_{2}$ receptor blockers in healing duodenal ulcers. Although several protective mechanisms have been proposed, no single mechanism convincingly explains Sucralfate's efficacy. We have recently shown that chronic $H$ pylori (HP) infection leads to a six fold increase in basal \& gastrin releasing peptide (GRP) stimulated acid secretion in duodenal ulcer (DU) patients, which is likely to play a key role in the pathogenesis of DU disease.

We have studied basal \& GRP stimulated $(40 \mathrm{pmol} / \mathrm{kg} / \mathrm{h})$ gastrin release \& acid secretion in $11 H P+v e$ DU patients, prior to, \& on the final day of 4 weeks treatment with Sucralfate $2 \mathrm{~g}$. b.d. The histological gastritis score, HP colonisation density score, \& 20 minute value of the ${ }^{14} \mathrm{C}$ Urea breath test ( ${ }^{14} \mathrm{CUBT}$ ) were also assessed. 8 patients were re-examined 21 days following withdrawal of treatment with Sucralfate.

Results: There was no signficant change in basal gastrin with treatment. GRP stimulated plasma gastrin concentrations fell from median 325 (range 110-900 ng/l) to $180(65-450)(p=0.002)$ with treatment, and again rose significantly to $210(75-560)(p=0.04)$ 21 days after discontinuing treatment. The median basal acid output fell from $7.2(2.5-11.8 \mathrm{mmol} / \mathrm{hr})$ at entry, to $3.5(0.36-7.9)(p=0.003)$ with treatment, and again rose to $5.1(2.3-10.7)(p=0.02)$ following discontinuation of treatment . The median GRP stimulated acid output fell from $36.6(21-50.6 \mathrm{mmol} / \mathrm{hr})$ to $20.5(12.7-44.9) \quad(p=0.002)$ with treatment, \& again rose to $37.4(23.7-47.5)(p=0.006)$ following withdrawal of treatment. There was no significant change in the corpus or antral gastritis scores. However, the antral $H P$ colonisation density score fell from $3(2-3)$ to $1(0-3)(p=0.009)$, \& the 20 minute value of the ${ }^{14} \mathrm{CUBT}$ fell from $122(41-254)$ to $18.8(10-56)(p=0.006)$ with treatment. Following withdrawal of Sucralfate the 14CUBT value rose to $104(81-163)(p=0.009)$

Conclusion: In DU patients Sucralfate lowers basal acid output by $50 \%$, and GRP stimulated acid output by $44 \%$. This fall in acid secretion may be explained by the observed suppression of $H$ pylori infection by Sucralfate therapy.

\section{SERUM CagA IgG ANTIBODIES IN HELICOBACTER} PATIENTS WITH DYSPEPTIC DISEASE

\section{JE Crabtree, "E El-Omar, "M Bugnoli, "** A Covacci.}

\section{Eyre "* Rappuoli, "KEL McColl}

Department of Clinical Medicine, St. James's University Hospital, Leeds; " University Department of Medicine and Therapeutics, Western Infirmary, Glasgow; and **IRIS, Siena, Italy

The immunogenic $128 \mathrm{kD}$ CagA suface protein of Helicobacter pylori (HP) is not expressed in all strains. Increased systemic IgG recognition of CagA is evident in patients with duodenal ulceration. In this study serum IgG antibody responses to CagA in $\mathrm{HP}^{+}$duodenal ulcer (DU) $(n=25)$ and non-ulcer dyspepsia (NUD) $(n=25)$ patients have been compared with $\mathrm{HP}^{+}(n=25)$ and $\mathrm{HP}^{-}$ $(n=25)$ healthy volunteers. In the healthy volunteers, HP status was determined by the ${ }^{14} \mathrm{C}$ urea breath test and in the DU and NUD patients by histology and CLO test. CagA IgG antibodies were measured by ELISA using a recombinant fragment of CagA. Results were expressed as ELISA units (0-100), the cut-off for positivity being 7.5 units.

In healthy volunteers, median (interquartile range, IOR) CagA IgG units in $\mathrm{HP}^{-}$and $\mathrm{HP}^{+}$subjects were 3.7 (1.15$4.8)$ and $8.6(1.3-31.1)$ respectively $(p<0.001)$. The median CagA IgG units in HP* NUD patients, 5.1 (2.8543.7) did not differ from $\mathrm{HP}^{+}$healthy volunteers. Median CagA IgG antibody levels in DU patients $(26,9.85-66.7)$ were significantly higher ( $p<0.02$, Mann Whitney test) than $\mathrm{HP}^{+}$healthy volunteers and NUD patients. The percentage CagA seropositivity (i.e. $>7.5$ units) in DU patients $(80 \%)$ was significantly greater than NUD patients $(44 \%)$ and $\mathrm{HP}^{+}$healthy volunteers $(52 \%)$ (each $\mathrm{p}<0.02, \mathrm{Chi}^{2}$ ).

In conclusion 1) CagA seropositivity may be a useful marker to identify patients with increased risk of duodenal ulceration 2) $\mathrm{HP}^{+}$healthy volunteers and NUD patients have similar serum CagA IgG titres.

\section{OMEPRAZOLE CAN INHIBIT CELL VACUOLATION IN VERO} CELLS INDUCED BY CULTURE SUPERNATANTS OF HELICOBACTER PYLORI. Q.B.Zhang. R.I.Russell. C.G.Gemmell. Departments of Gastroenterology and Bacteriology, Royal Infirmary. Glasgow G31 2ER

Recent studies have shown that culture supernatants of Helicobacter pylori(Hp) can cause cell vacuolation in vitro. Such cell vacuolation may be associated with peptic ulceration. It is not known whether current antiulcer drugs have some protective effect on the cell vacuolation.

Aim: To investigate if some anti-ulcer drugs can protect cell vacuolation of Vero cells induced by $\mathrm{Hp}$ culture supernatant.

Methods: Solutions of cimetidine, ranitidine, famotidine, sucralfate. misoprostol, tripotassium dicitratobismuthate and omeprazole at concentrations ranging from $0.1-100 \mathrm{mg} / \mathrm{ml}$ were prepared. Cytotc xin positive culture supernatants from 8 strains of $\mathrm{Hp}$ were incubated with drug solutions for $1 \mathrm{~h}$ and then tested against cultured Vero cells. Every test was done in triplicate and repeated 4 times. The presence of intracellular vacuolation was examined microscopically and veritied by the assay of neutral red uptake. Urease activity was determined spectrophotometrically. The inhibitory effects of various drugs on cell vacuolation and urease activity was calculated as a percentage of that in the absence of any drug.

Results: Omeprazole effectively inhibited Vero cell vacuolation and urease activity by $75-90 \%$ and $90-100 \%$ respectively at concentratirns $>25 u \mathrm{~g} / \mathrm{ml}(\mathrm{p}<0.01)$ in all 8 strains. Preliminary experiments with puritied urease and cytotoxin suggest that the drug inhibits only the urease. Sucralfate at concentrations $>10 \mathrm{mg} / \mathrm{ml}$ also reduced cell vacuolation activity by $30-50 \%$ and urease activity $(50-70 \%)(\mathrm{p}<0.05)$. Other drugs including cimetidine, ranitidine, famotidine. tripotassium dicitratobismuthate and misoprostol failed to inhibit either activity.

Conclusion: Omeprazole can inhibit cell vacuolation in Vero cells induced by Hp culture supernatants. On the understanding that cytotoxin and/or urease are implicated in the histological damage seen in Hp related gastritis and peptic ulcer, drug induced impairment of cytotoxicity might be considered as an additional factor in the use of this drug. 
RELATIVE ROLE OF CYTOTOXIN AND UREASE OF HELICOBACTER PYLORI IN CELL VACUOLATION OF CULTURED VERO CELLS. O.B.Thang. C.G.Gemmell. R.LRussell Departments of Gastroenterology and Bacteriology, Royal Infirmary, Glasgow G31 2ER

Previous studies have shown that culture supernatants of Helicobacter pylori(Hp) induce intracellular vacuolation of cultured cells and that a specific cytotoxin has been implicated. However the role of this cytotoxin in cell vacuolation remains unclear.

Aim: To identify the agent(s) causing intracellular vacuolation by $\mathrm{Hp}$ culture supernatant.

Methods: $3 \mathrm{Hp}$ strains were cultured in Brucella broth for $\mathbf{4 8}$ hours at $37^{\circ} \mathrm{C}$. 15-fold concentrated culture supernatants(CCS) were chromatographed on Sephadex G-200. Cytotoxicity on Vero cells was assessed by microscopy and the assay of neutral red uptake. Urease activity was determined spectrophotometrically. Toxic fractions were further purified by DEAE-Sepharose CL-6B ion exchange chromatography. Sodium dodecyl sulphate-polyacrylamide gel electrophoresis(SDS-PAGE) was used to determine the molecular weight of denatured toxic protein.

Results: Gel chromatography of CCS provided two distinct proteins. Only the first caused cell vacuolation and contained urease activity. Cell vacuolation was potentiated by the addition of urea $(5-10 \mathrm{mM})$ and reduced $78-85 \%(\mathrm{p}<0.01)$ by acetohydroxamic acid $(500 \mathrm{ug} / \mathrm{ml})$. Cytotoxin could be separated from the urease using ion exchange chromatography and the molecular weight of the denatured toxin was determined as 86Kd by SDS-PAGE. Doses of purified toxin $\geq 5 u \mathrm{~g} / \mathrm{ml}$ could cause cell vacuolation. Urease per se caused little cell vacuolation, but in the presence of urea, even at $3 \mathrm{mM}$, it induced cell vacuolation. CCS of all 3 strains of $\mathrm{Hp}$ produced similar purification profiles but different yields of each product; in one strain urease and cytotoxin yields were 2-3 times higher than in the other two.

Conclusion: Cytotoxin and urease have been separated from culture supernatants of $\mathrm{Hp}$. Both are capable of causing cell vacuolation; the cytotoxin does so directly, the urease through ammonia production.
T143

MARKED REBOUND ACID HYPERSECRETION FOLLOWING TREATMENT WITH RANITIDINE E. El-Omar. S. Baneriee, A. Wirz. I. Penman. J.E.S. Ardill. K.E.L. Glasgow and Queen's University, Belfast, U.K.

Dyspeptic symptoms frequently rapidly recur following withdrawal of $H$ antagonists and this might be related to reboun acid hypersecretion. To investigate this we have studied basal an gastrin releasing peptide (GRP) $(40 \mathrm{pmol} / \mathrm{kg} / \mathrm{h})$ stimulated acid output and gastrin concentration in 18 healthy volunteers $(9 \mathrm{H}$ pylor + ve). Studies were performed before and at 2 and 10 days after completing a 60 -day course of ranitidine $300 \mathrm{mg}$ nocte.

Results: Results are expressed as medians of absolute values and for acid also as percentage change from pre-treatment values.

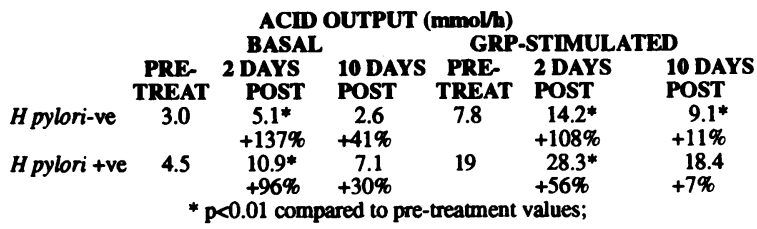

\begin{tabular}{|c|c|c|c|c|c|c|}
\hline \multirow[b]{3}{*}{$\begin{array}{l}\text { H pylori -ve } \\
\text { H pylori +ve }\end{array}$} & \multicolumn{6}{|c|}{ PLASMA GASTRIN (ng/) } \\
\hline & $\begin{array}{l}\text { PRE } \\
\text { TREAT }\end{array}$ & $\begin{array}{l}2 \text { DAYS } \\
\text { POST }\end{array}$ & $\begin{array}{l}\text { 10 DAYS } \\
\text { POST }\end{array}$ & $\begin{array}{l}\text { PRE } \\
\text { TREAT }\end{array}$ & $\begin{array}{l}2 \text { DAYS } \\
\text { POST }\end{array}$ & $\begin{array}{l}\text { 10 DAY } \\
\text { POST }\end{array}$ \\
\hline & $\begin{array}{l}25 \\
35\end{array}$ & & $\begin{array}{l}35 \\
45\end{array}$ & $\begin{array}{l}45 \\
95\end{array}$ & $\begin{array}{l}45 \\
130\end{array}$ & $\begin{array}{l}30 \\
80\end{array}$ \\
\hline
\end{tabular}

Summary: (1) Ranitidine causes marked rebound hypersecretion of both basal and GRP stimulated acid output in healthy volunteers with and without $H$ pylori infection. (2) This resolves almost completely by Day 10 post-treatment. (3) The rebound is not related to any significant change in gastrin concentration. Conclusion: This rebound hypersecretion may contribute to
rapid resurgence of symptoms following discontinuation of therapy rapid resurgence of symptoms following

\section{Stomach/duodenum T142-T149}

OMEFFAZOLE IN MAINTENANCE THERAFY FOF DUDDENAL ULCER: EFFECT ON GASTFIN AND FEFSINOGEN A AND C BASAL SERUM LEVE C. M. De Eone. A. Bellemat. C. Doglioni. M. De Eoni.

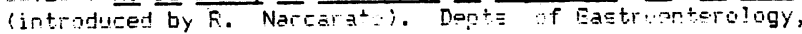
City Hocpita!, Feitre (EL:, Itaiy.

We povinuly fescrbed a significent incrazse in

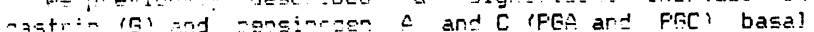
serum levels after omeprazole (OME) short-term treatment in patients with duodenal ulcer. In this study we investigated $G$, FGA and PGC serum level modifications during OME longterm therapy. Study design. 122 patient.s with successfully healed duodenal ulcer were enrolled in the study within 3 days after completing the short-term OME therapy. They were randomly assigned to 6-month treatment with either OME $20 \mathrm{mg} /$ day (GROUF I; $n=60$ ) or OME $20 \mathrm{mg} / \mathrm{every}$ other day (GROUF II; $n=62$ ). Endoscopy, routine histology and laboratory screening were performed at admission (TO) and at 6 months $(T i$ ) or eariier if patients had a recurrence of symptoms. Ulcer reiapse was defined as Eymptimitic or ssymptomatic endoscopics!?y verified recurrence of ulcer. Patients completed the study after b months or earlier, if a relapse occured. Statistice! analysis. Wilcoxon test, chi-square test; a $p$ value 0.05 was taken as significant. Fesults. 117 patients completed the study. At 6 months, endoscopically proved ulcer relapse occurred in $0 \%$ of pts receiving OME $20 \mathrm{mg} / d a y$ and in $13.5 \%$ of those receiving OME $20 \mathrm{mg} /$ every other day $(p=0.01)$. At the end of treatment, basal $G$ levels ( $\mathrm{pg} / \mathrm{ml}$; mean $\pm \mathrm{SD})$ were not significantly decreased in either groups $(T \overline{1}$ vs TO): GROUF II $101.5 \pm 49.3$ vs $107.7+47.8$ (ns); GROUF II: $92.4 \pm 49.7$ :5 100.5 \pm 47.2 (ns). Contrariwise, PGA and PGC lovels (ng/ml) were sigrificantly der-eaced in hath GFOI!P I (PGA: $166+84.1$ vs $246.3 \pm=1.7$

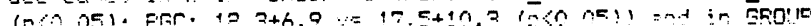
II (PGA: $160.1+105.9$ vs $255.9+130.7$ (p<0.05); PGC: $12.5 \pm 9.1$ vs $18.3+11.7(\bar{p}<0.05))$. Conclusions. After 6 monthmaintenance therapy, FGA and PGC basal serum levels were significantly decreased in both OME groups. These results differ from previous data showing significant FGA and FGC increases after short-term OME administration, and may indicate more complex physiopathological mechanisms in pepsinogen secretion during long-term OME administratiun.
SECRETION OF EPIDERMAL GROWTH FACTOR BY THE STOMACH IN RESPONSE TO HISTAMINE: A DIFFERENCE BETWEEN DUODENAL ULCER AND OTHER SUBJECTS M Tunio, M Hobsley

Department of Surgery, UCL Medical School, 67-73 Riding House Street, London, W1P 7LD

Gastric secretion was measured under basal conditions and during a continuous intravenous infusion of histamine acid phosphate, 0.13 $\mathrm{mmol} \mathrm{kg}{ }^{-1} \mathrm{~h}^{-1}$. Three samples of saliva were obtained in the basal and in the histamine-stimulated periods. The salivary samples, and samples of contemporaneous gastric secretion, were analysed for epidermal growth factor (EGF). Measurements of acid secretion in the gastric juice samples included checks for sequestration and pyloric losses (phenol red) and for duodenogastric reflux (sodium).

The total of 46 subjects studied comprised 13 normal volunteers, 14 patients with duodenal ulcer (DU), and 19patients with non-ulcer dyspepsia(NUD).

Results. Basal salivary EGF concentrations were (means and standard deviations in order of controls, DU, NUD) :-0.605 (0.244); $0.922(1.215) ; 0.406(0.304) \mathrm{ng} / \mathrm{ml}$. Basal gastric juice concentrations of EGF were similar. Salivary EGF concentrations rose about $50 \%$ with histamine, but much more (about fourfold, $t=$ $7.04, p<0.0001$ ) in the gastric juice. Measured duodenogastric reflux showed no correlation with changes in the gastric juice EGF concentration, so the source could not have been the duodenum. Moreover, the saliva could not have contributed the EGF to the gastric juice because the salivary concentration was much lower than the gastric.

This is the first demonstration that the stomach itself can secrete large amounts of EGF and that histamine is a potent stimulus. Also, EGF concentrations in gastric juice in DU were significantly higher than in controls (Wilcoxon, $p<0.05$ ) or in NUD (Wilcoxon, $p<$ 0.05 ) and so it is likely that EGF is responding to the presence of an ulcer that needs healing, rather than that lack of EGF is responsible for persistence of the ulcer. 
NON-ANXIOUS PATIENTS PREFER THROAT SPRAY ALONE RATHER THAN IV SEDATION FOR UPPER ENDOSCOPY (OGD) SP Pereira". SH Hussaini*. PJV Hanson. ML Wilkinson. GE Sladen. Gastro Unit, Guy's Campus, UMDS of Guy's \& St Thomas' Hospitals, London.

Sedation during diagnostic OGD is standard practice in Britain, and is thought to improve patient comfort. Most, but not all, previous studies have shown that OGD with spray alone is tolerated less well. However, it is also well recognised that anxious patients tolerate OGD poorly. We proposed that such patients would benefit most from sedation, but that OGD with spray alone would be preferred by most non-anxious patients. METHODS: In a prospective study, 200 outpatients underwent diagnostic OGD by two endoscopists* after introduction of two detailed information sheets, which (i) offered patient choice between spray or sedation $(n=100)$, or (ii) offered the same choice but encouraged those who were anxious about OGD to choose sedation. Patient anxiety, reasons for sedation choice, discomfort and overall satisfaction with the test were assessed by questionnaire (five-step nominal scales), and compared with the endoscopist's assessment of patient anxiety, ease of intubation, and patient discomfort. RESULTS: In the first 100 patients, 59 opted for spray alone (lignocaine $100 \mathrm{mg}$ ) $-93 \%$ in order to avoid post-procedure drowsiness. The remaining 41 who were sedated with diazepam (mean $12.2 \mathrm{mg}$, range 5-20 mg), gave as reasons that they were worried about the diagnosis $(15 \%)$ or possible discomfort $(\mathbf{4} \%)$, or they had been given sedation for a previous OGD $(41 \%)$. Anxiety about OGD discomfort was similar in both the spray and sedation groups. In the spray group, introduction of the gastroscope was easier $(p=0.03)$ and patients appeared to be more comfortable $(p=0.04)$, although they actually reported more discomfort than the sedation group $(p=0.02)$. However, after introduction of the second information sheet, those in the spray group were less anxious $(p<0.001)$, and did not experience greater discomfort $(p=0.96)$ than those in the sedation group. If the OGD were to be repeated, $73 \%$ of the spray group and $77 \%$ of the sedation group would make the same choice again. 33 of the 200 patients $(17 \%)$ had undergone two or more previous OGDs with sedation. They reported less anxiety $(p<0.0001)$, and experienced less discomfort $(p=0.014)$, than those without OGD experience. 26 of 33 patients $(79 \%)$ who chose spray but had been given only sedation for a previous OGD, would again choose spray at a future $O G D$. CONCLUSION: When given an informed choice, most patients prefer not to be sedated during diagnostic OGD. If patients who are anxious about the procedure are advised to choose sedation, those who opt for topical throat spray alone find the OGD just as comfortable. Patients should be given the choice between spray or sedation for diagnostic OGD.
GASTRIC MUCOSAL DAMAGE AND ADAPTATION OCCURS WITH ENTERIC COATED NSAIDS IN MAN, G.R.LIPSCOMB, G.ARMSTRONG M.J.GOODMAN, W.D.W.REES DEPARTMENTS OF MEDICINE AND HISTOPATHOLOGY, UNIVERSITY OF MANCHESTER SCHOOL OF MEDICINE, HOPE HOSPITAL, SALFORD \& BURY GENERAL HOSPITAL

Topical application of NSAIDs to the human gastric mucosa causes initial damage and subsequent adaptation with concomitant changes in mucosal blood flow. The damaging and adaptive responses of gastric mucosa to enteric coated NSAIDs has not previously been investigated. Ten healthy volunteers were gastroscoped before, one, seven and twenty eight days during treatment with enteric coated diclofenac $50 \mathrm{mg}$ bd. Macroscopic mucosal damage was assessed using a modified Lanza score $(0=$ normal, $4=$ severe $)$ and biopsies were taken from normal mucosa for assessment of microscopic damage $(0=$ normal, $4=$ severe $)$ and presence of helicobacter pylori. Mucosal blood flow was measured using laser doppler flowmetry. Five further volunteers underwent the same protocol but did not take NSAIDs during the study period.

Enteric coated diclofenac caused significant macroscopic mucosal damage at day 1 (score $0.8+0.5$ ) which persisted to a lesser extent at day 7 (score: $0.5 \pm 0.3$ ) and had resolved in all but one patient by day 28. Assessment of microscopic damage showed no significant change. Antral mucosal blood flow was significantly reduced at day 1 (48.9 \pm 12.1 vs $59.0 \pm 10.6$ arbitrary units), and then returned to normal by day 28. Fundal mucosal blood did not significantly fall $(56.6 \pm 14.5$ vs 64.1 $\pm \mathbf{8 . 6}$ arbitrary units). The five volunteers who took no medication had no significant changes in mucosal blood flow and no macroscopic or microscopic damage. All fifteen volunteers had no evidence of H.Pylori infection.

In conclusion; enteric coated diclofenac causes mild acute damage to the gastric mucosa which adapts to continued NSAID exposure. Acute damage is associated with a fall in antral mucosal blood flow which returns to normal in parallel with mucosal adaptation.
EFFECT OF A SELECTIVE 5HT3 ANTAGONIST ONDANSETRON, ON FUNCTIONAL DYSPEPSIA.

R. Barbera and N.W.Read. Gastrointestinal Motility Unit, University of Sheffield, Northern General Hospital, Sheffield, UK.

Abnormal visceral sensitivity could play an important role in the genesis of symptoms in patients with functional dyspepsia (FD). As serotonin (5HT) may mediate visceral sensitivity of the gut through activation of $5 \mathrm{HT} 3$ receptors, the AIM of this study was to evaluate the effect of the selective $5 \mathrm{HT} 3$ receptor antagonist Ondansetron on symptoms in patients with FD. METHODS: Twelve patients with FD ( 7 female, mean age $42 \mathrm{yrs}$ ) were allocated to two groups ( $A$ and $B, n=6$ ) matched for sex and age. They were randomized into a placebo controlled cross-over study of Ondansetron, $8 \mathrm{mg}$ /day for group A, and $16 \mathrm{mg} /$ day for group B. The study consisted of two treatment periods of 4 weeks separated by two weeks washout. During the study, each patient completed a daily symptoms diary reporting the symptoms scores on a visual analogue scale (0-10 score). Efficacy of the treatment was assessed by recording changes in eight symptoms: early satiety, fullness, epigastric pain, heartburn, nausea, vomiting, regurgitation and belching.

RESULTS: One patient dropped out after the first week of treatment with $16 \mathrm{mg}$ of Ondansetron because of severe headache. One patient reported chest pain during placebo. Four patients of group $\mathrm{A}$ and two of group $\mathrm{B}$ complained of consipation during the active treatment, none during placebo. Ondansetron, either with 8 or $16 \mathrm{mg} /$ day, did not improve the overall symptoms in comparison with placebo, and the score of each symptom analysed separately did not significantly change during both treatments. Symptoms variations after 16 $\mathrm{mg}$ did not differ from those observed after $8 \mathrm{mg}$. CONCLUSIONS: The selective 5HT3 receptor antagonist Ondansetron, did not improve the symptomatology of patients with FD, suggesting that serotonin may not be the main mediator involved in the trasmission of symptoms in these patients.
SUBSTANCE P CONTAINING ENTERIC NEURONES AND PROSTAGLANDIN $E_{2}$ IN NON-STEROIDAL, ANTIINFLAMMATORY DRUG ULCERATION. DJE Cullen, MA

Hull, *P Facer, *AE Bishop. *JM Polak, C J Hawkey, Div of Gastroenterology, University Hospital, Nottingham NG7 2UH and *Dept Histochemistry, Royal Postgraduate Medical School, London W12 ONN, UK

Recent data suggest that prostaglandins and neuropeptides acting via an enteric nerve reflex interact to protect the gastric mucosa. We investigated the hypothesis that deficiencies of prostaglandin (PG)E, and substance $P$ might both contribute to non-steroidal, antiinflammatory drug (NSAID) associated ulcers.

METHODS: We studied 68 patients undergoing endoscopy concurrently (45 NSAID patients, 13 with ulcers and 23 age and sex matched controls (6 with ulcers). Endoscopy was performed 8-12 hours after the last dose of NSAID except with long acting single dose NSAIDs. All but 2 patients were off ulcer healing drugs and density of substance $P$ containing enteric neurones (graded histologically on a 5 point scale).

RESULTS: Patients taking NSAIDs had significantly lower PGE levels $(18.1, \mathrm{CI} 12.2-26.7 \mathrm{pg} / \mathrm{mg})$ compared to controls $(35.7$, CI $21.9-58.3, \mathrm{pg} / \mathrm{mg}, \mathrm{p}<0.05)$, but active ulceration was not associated with additional changes in either NSAID users $(14.3, \mathrm{CI} 6.0$ $34.1 \mathrm{pg} / \mathrm{mg}$ vs $17.0, \mathrm{CI} 10.1-28.5 \mathrm{pg} / \mathrm{mg})$ or non-users $(30.2, \mathrm{CI} 7.4-$ $123.1 \mathrm{pg} / \mathrm{mg}$ vs 30.2 , CI $15.2-59.8 \mathrm{pg} / \mathrm{mg}$ ). Density of enteric neurones containing substance $P$ was somewhat lower in NSAID users than non-users ( $38 / 45$ vs $14 / 23$ grade $0-2$, not significant). Substance $\mathbf{P}$ was unrecordable or depressed at the ulcer rim compared to intact mucosa in 10 out of the 13 ulcer rims biopsied (9 NSAID).

CONCLUSION: Whilst depression of $\mathrm{PGE}_{2}$ predisposes NSAID patients to ulcer development our study shows no evidence of a constitutional deficiency in ulcer patients. Local deficiencies of substance $P$ containing enteric neurones might, however, contribute to ulcer localisation. 
FASTING MAY PREVENT INDOMETHACIN-INDUCED JEJUNAL ULCERATION IN THE RAT BY REDUCING ENTEROHEPATIC CYCLING OF DRUG A Anthony, A Bahl", AP Dhillon. G Nygard RE Pounder. AJ Wakefield. Inflammatory Bowel Disease Study Group, Roval Free Hospital, London, UK; "Gastrointestinal Pharmacology, Glixo Group Research Ltd, UK.

Indomethacin (IN) undergoes extensive enterohepatic cycling and bile duct ligation increases NSAID blood levels as well as preventing NSAID jejunal injury in rats. Fasting prevents IN-induced jejunal ulceration (JU) that is normally preceded by early villus shortening (EVS) in the fed rat (Anthony et al Aliment Pharmacol Ther 1993:7:2(9-40). Fasting reduces bile flow, jejunal mucosal blood flow and absorption. We present evidence that fasting of rats reduces biliary cycling of IN. METHODS: Four groups of fasted or fed rats ( $n=6 /$ group) received oral IN $15 \mathrm{mg} / \mathrm{kg}$ followed by fixation of the jejunum at 3 or $24 \mathrm{~h}$ post-IN. IN levels were analysed in plasma $(\mu \mathrm{g} / \mathrm{ml})$ and jejunal luminal fluid $(\mu \mathrm{g} / \mathrm{ml}$ and $\%$ of IN dose in the $3 \mathrm{rd}$ quarter of jejunum). The 2 nd quarter of the jejunum $(\sim 60$ sections/rat) was assessed histologically. A control group received vehicle only. The \% of sections showing EVS or JU was determined per rat. and terminal plasma and luminal IN data for each group are presented as mean \pm SEM, ${ }^{*}=\mathrm{P}<0.05$ and ${ }^{* *}=\mathrm{P}<0.01$.

RESLLTS: Fasting increased plasma IN levels at both 3 and $24 \mathrm{hs}$ post-IN (3h: fed $=36 \pm 4$, fasting $=59 \pm 4^{\circ} \mu / \mathrm{ml} ; 24 \mathrm{~h}$ : fed $=4 \pm 1$, fasting $=17 \pm 2 * \mu \mathrm{g} / \mathrm{ml})$. Fasting reduced total $\mathrm{IN}$ within the lumen at $3 \mathrm{~h}$ (fed $=0.2(0 \pm 0.02$, fasting $=0.026 \pm 0.01 \% \%$ of IN dose). Fasting did not affect mean luminal IN concentrations $(\mu \mathrm{g} / \mathrm{ml})$ but luminal fluid volume $(\mathrm{ml}$ ) was significantly reduced in fasted rats (fed $13 \pm 6$ $\mu \mathrm{g} / \mathrm{ml}, 0.39 \pm 0.10 \mathrm{ml}$; fasted $\left.16 \pm 5 \mu \mathrm{g} / \mathrm{ml}, 0.05 \pm 0.01^{\circ} \mathrm{ml}\right)$. Fasting totally prevented both EVS at $3 \mathrm{~h}$ and JU at $24 \mathrm{~h}$. In fed rats, EVS at $3 \mathrm{~h}$ was seen in $47 \pm 3 \%$ and $\mathrm{JU}$ at $24 \mathrm{~h}$ in $49 \pm 6 \%$ of sections. All control sections were normal. CONCLUSIONS: Fasting may contribute to prevention of IN jejunal ulceration by decreasing biliary crcling of IN as suggested by elevated plasma concentrations and reduced luminal amount of drug in fasted rats. Fasting prevents both early and late phases of IN ulceration.
INCREASING AGE DOES NOT INFLUENCE OUTCOME IN PATIENTS TREATED EYDOSCOPICALIY TOR YAJOR PEPTIC ULCER HAEMORRHAGE.

CP Choudari, KR Palmer. GI Unit, western General Hospital, Edinburgh

Before the advent of therapeutic endoscopy it was established that an important risk factor for death from peptic ulcer haemorrhage was inceasing age. This was either because the elderly tend to have other diseases which put them at particular risk from emergency surgery or because the bleeding artery in this group is atherosclerotic and vasoconstriction is poor.

To test whether increasing age remains a risk factor following the introduction of endoscopic haemostatic therapy the outcome of all patients presenting with major peptic ulcer bleeding over a 4 year period was documented. 102 patients were aged less than 60 yrs (median 48 yrs), group $I$; 116 were aged 61 to 74 years (median 69 yrs), group II and 108 were older than 75 (median 80.5 yrs) group III. More of Group III patients were receiving NSAIDs $(p<0.0001)$. More of group II patients were receiving anticoagulant drugs $(p<0.005)$. A previous history of peptic ulcer was commonest in group I $(p<0.005)$ and DU was the most common cause (69 patients, $68 \%$ ).

The three groups were well matched in terms of endoscopic stigmata, haemoglobin and shock. Endoscopic therapy was possible in $95 \%$ of all patients. The need for surgical intervention tended to be lowest in group I $(11 \%, 19 \%$, and $18 \%$ in the three groups). Whilst hospital mortality $(3 \%, 6 \%$ and $4.6 \%$ ) was very similar. With modern endoscopic management increasing age is no longer an important risk factor for death from bleeding peptic ulcer.

\section{Endoscopy T150-T157}

FAILURES OF ENDOSCOPIC THERAPY FOR BLEEDING PEPTIC ULCER; AN ANALYSIS OF RISK FACTORS

CP Choudari, KR Palmer, GI Unit, Western General Hospital, Edinburgh

The value of therapeutic endoscopy in bleeding peptic ulcer is established, but failures of endoscopic therapy occur, and patients who fail to respond may be at increased risk of death by delay in definitive surgery. We have defined factors associated with failed endoscopic therapy, attempting to identify the subgroup of patients who should undergo early surgery rather than fruitless endoscopic treatment. Endoscopic intervention was attempted in 326 consecutive patients presenting with bleeding peptic ulcer; all had major stigmata of recent haemorrhage. Therapy was by injection with $1: 100,000$ adrenaline (72 patients), 1:100,000 adrenaline plus ethanolamine (178 patients) or the heater probe (58 patients).

Endoscopic therapy was possible in 308 (94\%) patients. Permanent haemostasis was achieved in $269(82.5 \%)$ patients. Fifty seven (17.5\%) patients continued to bleed or rebleed in hospital. Multifactorial analysis showed that patients who presented with active haemorrhage, shock and anaemia did least well $(p<0.001)$. A history of NSAID's or aspirin usage, coagulopathy, previous peptic ulceration and cardio-respiratory disease did not predict outcome. Age of the patient was not an independant risk factor for outcome of therapy. The position of a gastric ulcer did not affect outcome, but a posterior duodenal ulcer was significantly more commonly associated with failed endoscopic therapy than was the case with an anterior ulcer $(p=0.02)$.

Endoscopic interventional treatment should be offered to all high risk bleeding ulcer patients; no subgroup of patients unlikely to benefit from therapy could be identified.
COMPARISON OF ENDOSCOPIC MECHANICAL AND INJECTION METHODS OF HEMOSTASIS ON MESENTERIC VESSELS C.C. Hepworth, S.S Kadirkamanathan, C.P. Swain, E Gong. GI Science Research Unit. Royal London Hospital, London UK.

We tested the hypothesis that mechanical methods of endoscopic hemostasis offer greater hemostatic security for bleeding from medium and large bleeding arteries than injection methods. Arteries in human bleeding ulcers measure $0.1-3.45 \mathrm{~mm}$ diameter (median $0.9 \mathrm{~mm}$ ). No experimental data exists assessing either the efficacy of endoscopic mechanical hemostatic methods nor are there comparisons with injection sclerotherapy. A randomised controlled comparison of hemostatic efficacy of endoscopic mechanical methods and injection sclerotherapy was undertaken in canine mesenteric vessels. Arteries 1-5 mm diameter were treated and severed to assess hemostatic efficacy. Injection method used was epinephrine $1 / 10,000[6 \mathrm{ml}]+$ ethanolamine [2ml]. Mechanical methods studied were 1] Olympus clip fixing device HX-3, 2] Bard band ligator, 3] Sewing machine. RESULTS INJECTION failed to stop bleeding from all $1 \mathrm{~mm}$ and $2 \mathrm{~mm}$ vessels [ $\mathrm{n}=10$ ]. CLIPS failed to stop bleeding from $1 \mathrm{~mm}$ vessels[ $n=10]$.and failed to control bleeding in eight out of ten $2 \mathrm{~mm}$ vessels. Clips failed on $3 \mathrm{~mm}$ vessels [ $n=3$ ]. Extra pressure on clips stopped bleeding suggesting design modification could improve performance. 3] ELASTIC BANDS preloaded on a tube failed to stop bleeding from vessels of any size as they were overstretched. Unstretched bands stopped bleeding from $2 \mathrm{~mm}$ vessels [ $n=5$ ] but failed with $3 \mathrm{~mm}$ vessels $[\mathrm{n}=3$ ].ENDOSCOPIC SEWING MACHINE stopped bleeding from $4 \mathrm{~mm}$ vessels [ $\mathrm{n}=6$ ] but failed on $5 \mathrm{~mm}$ vessels [ $\mathrm{n}=2$ ] All control vessels bled briskly and were tied. CONCLUSIONS Both elastic bands and sewing machine were significantly $p<0.05$ more effective in stopping bleeding in vessels up to $2 \mathrm{~mm}$ than injection therapy. Injection therapy performed poorly in this model. Only sewing and tying stopped bleeding from vessels $2-4 \mathrm{~mm}$ diameter. Further development and application of mechanical endoscopic methods of hemostasis can improve hemostasis of large bleeding vessels encountered at flexible endoscopy. 
The endoscopic spectrum of primary non-Hodgkin's lymphoma of the stomach: the impact of the MALT (mucosa associated lymphoid tissue) classification.

\section{B.G. Taal ${ }^{1}$, H. Boot ${ }^{1}$, P. van Heerde ${ }^{2}$, L.M.V. Burgers ${ }^{3}$, R. Somers ${ }^{4}$} Departments of Gastroenterology ${ }^{1}$, Pathology ${ }^{2}$, Radiotherapy ${ }^{3}$ and Medical Oncology", Netherlands Cancer Institute/Antoni van Leeuwenhoekhuis, Plesmanlaan 121, 1066 CX Amsterdam, The Netherlands

The stomach is the main site of extranodal non-Hodgkin's lymphoma (NHL). Recently, the MALT concept has been adopted for NHL occurring in the mucosal sites of the GI-tract, lung and parotid gland deriving from the foregut which show special morphological features indicating a favourable prognosis.

We evaluated the endoscopic characteristics of patients with a MALT lymphoma compared to those with other histological subtypes of NHL of the stomach in stage I (confined to the stomach) and stage II (plus regional lymph nodes) disease.

In 86 out of 119 patients information of endoscopy was available, as well as slides for pathological review. Group A comprised 32 cases with MALT lymphoma (st. I 24 and st. II 8), group B 54 other NHL (st I 37 and st II 17).

At endoscopy three patterns were recognized: ulceration (A 53\% vs B $35 \%$ ), diffuse infiltration (A $22 \%$ vs B $19 \%$ ), or a polypoid mass (A $25 \%$ vs B $46 \%$ ). Differences failed, however, to reach statistical significance (NS). Multiple endoscopies and biopsies were needed in group A 6 cases (19\%), in group B 3 cases (6\%) NS for a diagnosis of NHL. Local response to treatment was excellent in group A: $94 \%$ and in group B $77 \%$ (NS). Severe side effects were minimal: no perforation, two cases of haemorrhage in group B.

Conclusions: in group A (MALT lymphoma) at endoscopy ulceration was most predominant (in group B a polypoid mass); more endoscopies with biopsies were needed for a definitive diagnosis; local control was excellent. All differences were NS. It remains difficult to predict the MALT type lymphoma on endoscopic features only, multiple biopsies are highly recommended.
A MANNITOL/PICOLAX B MIXTURE OR TWO-DOSE POLYETHYLENE GLYCOL LAVAGE SOLUTION AS BOWEL PREPARATION FOR COLONOSCOPY?

M Fukumoto, BP Saunders, T Masaki, S Halligan, CB Williams

Department of Endoscopy, St.Mark's Hospital, London, UK

INTRODUCTION From our experience a combination of mannitol and $\mathrm{Mg}$-citrate/Na-picosulphate (Picolax $($ ) as bowel prep. produces adequate cleansing with high patient acceptability. We have compared the safety, tolerability and cleansing of a mannitol/Picolax $®$ mixture (M/P) to a split administration of poly ethylene glycol- electrolyte lavage solution (PEG) as bowel prep. for colonoscopy.

METHOD Eighty nine consecutive patients attending for day-case colonoscopy were randomly allocated either two-dose PEG (2 litres the evening before, 2 litres on the morning of colonoscopy) or two $500 \mathrm{ml}$ fractions of $\mathbf{M} / \mathbf{P}$ as bowel preparation. 45 patients received PEG. 44 M/P. Patients were given a questionnaire asking about their experience of the preparation. One of two experienced colonoscopists (CBW, BPS). blinded as to the type of preparation given, scored the degree of bowel cleansing. In the first 42 patients lying/standing blood pressures. and venous blood were taken for packed cell volume and serum osmolarity. $\mathrm{CO}_{2}$ was used as the insufflating agent during all examinations.

RESULTS The two patient groups were similar with regared to age. sex, bowel habit and laxative administration. Good/excellent bowel cleansing occurred in significantly more patients given PEG, $43(96 \%)$. than in those allocated M/P, $34(77 \%), p=0.01$, Fisher's exact test. However $37(88 \%)$ patients receiving $\mathbf{M} / \mathbf{P}$ were able to complete the preparation in full compared to $28(62 \%)$ receiving PEG, $p=0.02$ Fisher's exact test. More patients found the taste of $\mathbf{M} / \mathbf{P}$ acceptable compared to PEG ( $88 \%$ vs $75 \%$ ). Both preparations had a similar side-effect profile: vomiting in the PEG group was $6 \%$, M/P $9 \%$. Three patients receiving $\mathbf{M} / \mathbf{P}$ had evidence of mild dehydration, none in the PEG group.

CONCLUSION Fractionated administration of PEG is well tolerated and superior as a cleansing agent to a $M / P$ combination Mannitol/Picolax@ is an acceptable alternative for patients intolerant of PEG, provided $\mathrm{CO}_{2}$ insufflation is used for safety.
ARE THERE DIFFERENCES IN COLONIC ANATOMY BETWEEN MEN AND WOMEN ?

M Fukumoto, BP Saunders, S Halligan, M E Moussa, CB Williams

Endoscopy Department, St.Mark's Hospital, City Road, London, UK.

INTRODUCTION It has been our experience at colonoscopy that women are technically more difficult to intubate than men. Most difficulty at colonoscopy is due to recurrent looping of the colonoscope in a long or mobile colon. We therefore wondered whether there were differences in colonic length and mobility between men and women.

METHOD Normal barium enemas of 161 male and 167 female patients were identified from "in file" records at St.Mark's Hospital. Colonic length was measured using an opisometer (mapping wheel) on the prone films. The upper border of the iliac crest was designated as the border between the sigmoid and descending colon. Mobility of the descending and ascending colon was measured by comparing left and right latereral decubitus films, and mobility of the transverse colon and splenic flexure by comparison of prone and erect films.

RESULTS Male and female groups had a similar age distribution; female mean age 52.4 yrs, range 19-94 yrs and male mean age 50.8 yrs, range 15-78 yrs. Total colonic length was greater in female compared to male patients, $p=0.0005$ by unpaired $t$-test. There was no significant difference in the length of the rectum and sigmoid but transverse colon length was greater in the female patients, $p=0.02$ by unpaired t-test. Redundancy of the transverse (transverse colon reaching the true pelvis in the erect film) was also more frequently seen in female $(58 \%)$ compared to male (27\%) patients, $p=0.0006$ by Fisher's exact test. Mobility of the descending and ascending colon, and both hepatic and splenic flexures were not significantly different in the two groups.

CONCLUSION We have shown that total colonic length is greater in females than males and that the difference is seen in the transverse colon. Recurrent looping of the colonoscope in a redundant proximal colon may therefore explain our clinical observation that colonoscopy is more difficult in women than men.
LASER RECANALISATION FOLLOWED BY BRACHYTHERAPY IN THE PALLIATION OF ADENOCARCINOMA OF THE OESOPHAGUS AND CARDIA - A PILOT STUDY.

GM Spencer, IR Sargeant, SM Thorpe, GM Blackman, JS Tobias, SG Bown. National Medical Laser Centre, University College London, London WC1E 6JJ, United Kingdom.

Laser recanalisation of obstructing oesophageal neoplasms provides excellent palliation from dysphagia. Unfortunately treatment has to be repeated at 5-6 weekly intervals to maintain adequate palliation. Brachytherapy (intra-luminal radiotherapy) allows irradiation of a tumour with little effect on distant surrounding tissues. In contrast to laser therapy brachytherapy when used alone has a delayed effect in relieving dysphagia and oscasionally induces a transient aggravation of symptoms. The aim of this study was to ascertain whether following laser recanalisation, brachytherapy could reduce the need for subsequent laser treatments whilst optimising the palliation from dysphagia.

Fourteen patients received palliative endoscopic laser recanalisation until able to swallow a soft diet. All patients then received a single fraction of $10 \mathrm{~Gy}$ at $1 \mathrm{~cm}$ generated by a high dose rate Iridium-192 source introduced via a naso-gastric tube and controlled by a Microselectron $®$. Further endoscopic therapy was only applied for recurrent dysphagia.

Four patients required no further treatment until death (median 10) weeks, range 7-15 weeks from first endoscopic procedure). Dysphagia warranted treatment at a median of 8 weeks following brachytheripy (range 4-15 weeks) for the remaining 10 patients. Only five of these patients subsequently required further laser treatment, the remainder requiring endoscopic dilatation for fibrous strictures. Four patients ultimately required endoscopic intubation. Two patients are still alive at 27 and 76 weeks, the remainder surviving a median of 23 weeks (range 10-58 weeks).

No complications were seen as a result of laser recanalisation. Brachytherapy did not lead to a deterioration in dysphagia. One patien developed radiation induced oesophagitis which resolved over 6 weeks.

In this study, the median time interval after brachytherapy, before further intervention was required for dysphagia was 8 weeks compared with 5 weeks in historical controls. This was achieved by a single. simple procedure often undertaken as a day case and with minimal morbidity. These preliminary results, which are comparable to those achieved previously with $30 \mathrm{~Gy}$ external beam radiotherapy in 10 fractions, justify a controlled study to assess brachytherapy which is now underway. 
SEWING AT FLEXIBLE ENDOSCOPY IN HUMAN GASTROINTESTINAL TRACT. C P Swain, S S Kadirkamanathan, $G$ Brown, E Gong, DF Evans, I N Mills. The Academic Department of Gastroenterology, The Royal London Hospital, \& Department of Medical Physics, University College, London, England.

We report the first application of sewing methods at flexible endoscopy in the human gastrointestinal tract in eleven patients. An endoscopic sewing machine was used for (1) long term pH monitoring, (2) to secure nasogastric feeding tubes to the wall of the stomach, (3) to close an oesophageal perforation and (4) to perform anti-reflux surgery. Long term pH monitoring was achieved in 2 subjects by sewing radiotelemetry capsules (RTC) to the gastric wall in a volunteer and a patient who had a vagal stimulator inserted by neurosurgeons to treat refractory epilepsy. The gastric RTCs transmitted for 159 and 90 days allowing continuous monitoring of $\mathrm{pH}$. They were removed by cutting the stitch at endoscopy and showed no calibration drift. In 6 subjects nasogastric feeding tubes were sewn to gastric wall of patients who had all failed to retain NG tubes for more than 12 hours on at least 3 occasions and were not candidates for percutaneous gastrostomy. Feeding tubes were retained for median of 30 days (range 8-69). The stitches were seen to be still secure at the time of removal. A 76 year old patient with terminal squamous oesophageal cancer who had a dilatation induced perforation of oesophagus followed by urgent thoracotomy at which the perforation could not be closed had the hole closed with stitches placed with sewing machine. Anti reflux surgery (endoscopic gastroplasty) was performed in 2 patients. A36 year old female and a 57 year old male with reflux unresponsive to omeprazole who declined conventional surgery had endoscopic gastroplasty. Stitches were placed to plicate the fundus internally elongating the intragastric oesophagus and narrowing the angle of His. Both patients had marked symptomatic improvement with abolition of 24 hour reflux of acid. These results indicate that stitching at flexible endoscopy in the human oesophagus and stomach is feasible for a variety of purposes and has allowed the development of a new type of less invasive surgery.

\section{Inflammation T158-T170}

CHILDHOOD RISK FACTORS FOR INFLAMMATORY BOWEL DISEASE, INCLUDING MEASLES INFECTIONS: A CASECONTROL STUDY. NP Thompson, RE Pounder. AJ Wakefield. Inflammatory Bowel Disease Study Group, Royal Free Hospital Schoo! of Medicine, London NW3, UK.

Breast feeding and passive smoking have been suggested as potential risk factors for inflammatory bowel disease. Clustering at birth and increased viral infections in utero, with a relative risk of 18 , have been reported in inflammatory bowel disease (IBD). Measles virus has been implicated as a causative agent for Crohn's disease. Method: A postal questionnaire, case-control study of 16,875 members of 2 British IBD patient support groups. A control group was obtained from friends or neighbours of members. Results: A response rate of $20.9 \%$ was obtained; 2169 cases with 2049 controls were analysed. There was no significant difference between those with ulcerative colitis or Crohn's disease and controls in exposure to smoking in childhood ( $p>0.1$ for both), frequency of breast feeding ( $p>0.5$ for both) or rate of prematurity ( $p>0.05$ for Crohn's disease and $>0.1$ for ulcerative colitis) using McNemar's matched $\chi^{2}$ test. Those with either ulcerative colitis or Crohn's disease had a mean birth weight $4 \%$ and $3.7 \%$ respectively greater than controls. There was no evidence of an increased frequency of those with Crohn's disease, as compared to controls, being exposed to a measles epidemic in utero (in any trimester), at birth or during the first year of life. There was a trend however that those with either ulcerative colitis and Crohn's disease were born in the first half of the year as compared with controls, though this did not achieve statistical significance, $p=0.07$ for Crohn's disease and 0.16 for ulcerative colitis. Conclusion: This study is the largest to date to examine these possible childhood risk factors; poor response rate with selection bias, recall bias and over-matching are potential problems but should not affect birth date details. We found no evidence that breast feeding, passive smoking, low birth weight or prematurity were risk factors for the development of IBD, neither could we find any epidemiological evidence to support early measles infection as being a risk factor for Crohn's disease.
T160

EXPRESSION OF INTERFERON- $\gamma$, TUMOUR NECROSIS FACTOR- $\alpha$ AND INTERLEUKINS -6 AND -2 IN POUCHITIS MUCOSA. M Kontakou*. PA Goldberg*t RT Przemioslo*. RJ Nicholls ${ }^{+}$. PJ Ciclitira**'St Thomas' \& +St Marks' Hospitals, London.

Pouchitis occurs in some patients following the formation of an ileoanal anastamosis. We wished to investigate the mRNA expression of interferon-gamma (IFN- $\gamma$ ), tumour necrosis factor-alpha (TNF- $\alpha$ ), IL6 and IL 2 in pouchitis by in situ hybridisation to study the role of these cytokines in the molecular pathogenesis of this condition.

Biopsies were obtained in thirty patients from (i) the ileum, prior to closure of the ileostomy and (ii) from the inflamed mucosa two months to three years post-operatively. Cryostat sections were cut and hybridised with specific ${ }^{35}$ S-labelled DNA oligonucleotide probes. Positive cells in the lamina propria (LP) were counted with an eye-piece graticule; values were expressed per $0.0025 \mathrm{~mm}^{2}$. In the surface epithelium positive cells were expressed as a percentage of total cells which includes both intraepithelial lymphocytes and enterocytes.

The number of cytokine mRNA-expressing cells in the lamina propria was increased significantly in the pouch mucosa compared with that from the ileum.

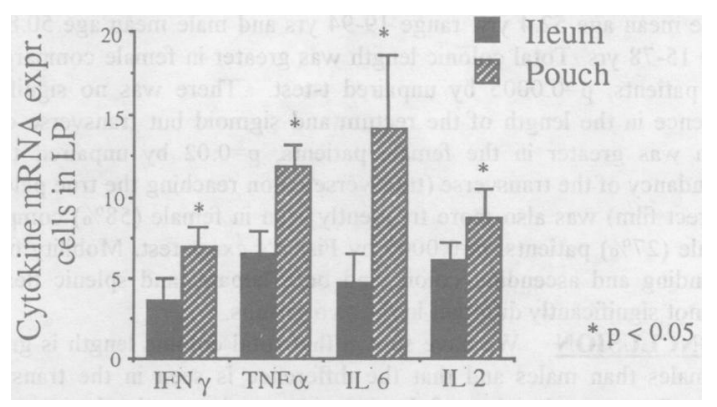

There were no significant differences in the number of epithelial cytokine mRNA-expressing cells between the ileum and pouch.

These results imply an immune aetiology for pouchitis that is mediated by pro-inflammatory cytokines, predominantly in the lamina propria. 
PROSPECTIVE COMPARISON OF RESTORATIVE PROCTOCOLECTOMY FOR INDETERMINATE COLITIS VERSUS ULCERATIVE COLITIS KMIOT W. REVIER D, COHEN $S$, LUCAS F. NOGUERAS J, JAGELMAN

Department of Surgery, Queen Elizabeth Hospital, Birmingham

As the diagnosis of ulcerative colitis (UC) prior to proposed ileal reservoir (IAR) formation may be uncertain, we have reviewed the pathology and clinical outcome in 112 consecutive patients following totally stapled IAR formation
for inflammatory bowel disease.

of the 112 patients, 96 had a preoperative diagnosis of ulcerative colitis (UC) and 16 had indeterminate colitis (IC). The 2 groups were matched by age, sex, duration of colitis, steroid therapy and incidence of previous colectomy. The duration of follow up after IAR formation was similar in both groups (median 18 months). Statistical analysis was by Wilcoxon's non pai

There was a significant change in pathological diagnosis in the IC group (Rreoperative 16 IC $\mathrm{v}$ Postoperative - $10 \mathrm{UC}$, IC, 2 Crohns) p<0.001, but not in the UC group (Preoperative 96 UC $v$ Postoperative - 94 UC, 2 IC). There as also a significantly higher proportion of major postthe UC group $n=17$ (188) $p=0.027$. UC group $\quad$ group Mortality (Total) Morbidity (Total) Pelvic Sepsis

- Fistula Pouch-Anal Stricture Small Bowel Obstruction

$\begin{array}{ll}(n=96) & \begin{array}{r}\text { group } \\ n=0\end{array} \\ n=17 & n=1 \\ n=6 \\ n=1 & n=2 \\ n=3 & n=2 \\ n=5 & n=2 \\ n=8 & n=0\end{array}$

These data show that the majority of patients with a preoperative diagnosis of IC will be reclassified post preoperative diagnosis of IC will be reclassified post complications may be higher than in those diagnosed pre complications may be highe
URINARY NITRITE DIPSTICK : A RELIABLE DISEASE ACTIVITY MARKER IN INFLAMMATORY BOWEL DISEASE

( IBD ).

A.K.Cherukuri,N.Mahmud,M.I.Khan,M.Goggins,D.G.Weir, D.Kelleher, P.W.N.Keeling. Gastroenterology Dept, St.James's Hospital, Trinity Medical School, Dublin-8, Ireland.

Nitric oxide(NO) is an endogenous mediator of smooth muscle relaxation.It is generated from L-Arginine by NO synthase. This enzyme can be induced by various cytokines and endotoxins Hence in IBD,NO production is enhanced which may play a role in regulating vascular permeability and colonic smooth muscle tone. NO has a short half life and is metabolised to its stable end products, nitrite and nitrate which are excreted in urine.Nitrite dipstick is based on Griess's test and is specific to nitrite.It's sensitivity limit is $0.05 \mathrm{mg} / 100 \mathrm{ml}$ and reveals the presence of nitrites by a pink to red discoloration of the test patch.

The aim of this study was to test the urine of IBD patients for nitrites and to correlate the results with the clinical and biochemical parameters of disease activity. We used the Nephur test+Leuco dipstick for this study.42 urine samples were tested randomly and were interpreted to be positive or negative.Urinary infection was excluded when these urine samples were collected previously,before they were stored at $-20 \mathrm{C}$. They were thawed to room temperature prior to the dipstick test.18 samples were positive for nitrites and 24 were negative.Clinical disease activity index(Harvey Bradshaw), ESR and C-Reactive protein were compared between the nitrite positive and negative groups using the student $t$ test.For all the three indices there was a significant difference between the two groups $(P$ value $<0.01)$ which also correlated well with the patient's relapses and remissions.

Our study shows that the nitrite dipstick is an inexpensive,rapid and reliable disease activity marker in IBD. We feel that a quantitative nitrite dipstick may be more useful in grading the disease activity and for the follow up of these patients
THE SOURCE OF SUPEROXIDE ANION IN ULCERATIVE COLITIS IS NOT XANTHINE OXIDASE

\section{R.D. Reynolds. S.T. Rhenius, J.O. Hunter}

Department of Gastroenterology, Addenbrooke's Hospital, Cambridge CB2 2QQ.

Reactive oxygen metabolites (ROMs) including superoxide anion are believed to be important in the pathogenesis of ulcerative colitis (UC). Xanthine oxidase (XO) metabolises xanthine to uric acid with the production of superoxide anion which may combine with nitric oxide to give peroxynitrite, a powerful oxidant which produces colonic inflammation in rats and which may oxidise sulphydryl groups, thus converting cysteine to cystine. The content of xanthine, uric acid, cysteine and cystine was determined by HPLC in snap frozen mucosa biopsies taken at colonoscopy in 21 patients with UC or normal mucosa.

$\begin{array}{ll}\text { CONTROLS } & \text { ULCERATIVE } \\ \mathrm{n}=10 & \mathrm{COLITIS} \\ \mathrm{n}=11\end{array}$

Cystine/Cysteine $0.18( \pm 0.08) * \quad 1.79( \pm 0.25) * \mathrm{p}<0.01$

Ratio ( \pm SEM)

Uric Acid $7.45( \pm 0.68) \quad 7.23( \pm 0.86) \quad$ NS

$\mathrm{mmol} / \mathrm{mg}$ protein

$( \pm$ SEM)

Urate/Xanthine $3.17( \pm 0.29) \quad 3.31( \pm 0.31) \quad$ NS

Ratio ( \pm SEM)

\section{${ }^{*} \mathrm{p}<0.01 \quad$ Wilcoxon rank sum test}

The increased cystine to cysteine ratio confirms the production of ROMs in active UC but, as no corresponding increase in XO activity was detectable, these must come from other sources. $\mathrm{XO}$ inhibitors such as allopurinol are unlikely to be effective in the treatment of UC.
SERUM CONCENTRATIONS OF INTERLEUKIN-1 RECEPTOR ANTAGONIST ARE A MARKER OF CROHN'S DISEASE ACTIVITY.

J.C.Mansfield. J.K.Tarlow, F.S.di Giovine. C.D.Holdsworth, G.W.Duff.

Section of Molecular Medicine, Department of Medicine and Pharmacology, University of Sheffield, and Gastroenterology Unit, Royal Hallamshire Hospital, Sheffield, S10 2JF.

Interleukin-1 receptor antagonist (IL-1 ra), an anti-inflammatory cytokine secreted by macrophages and present in an intracellular form in epithelial cells, has been proposed as an important regulator of intestinal inflammation in animal models of colitis and in inflammatory bowel disease (IBD). As a recombinant protein it may also have a role as a new therapeutic agent in IBD.

The aim of this study was to determine how serum concentrations of endogenous IL-1ra were related to Crohn's disease activity. In addition the serum concentrations of IL- $1 \alpha$ and IL- $1 \beta$ were assayed to study the relative balance of IL-1 agonist and antagonist.

Thirty nine patients with Crohn's disease and 22 healthy controls were studied. Serum concentrations of IL- $1 \mathrm{ra}, \mathrm{IL}-1 \alpha, \mathrm{IL}-1 \beta$ and sIL-2r (soluble interleukin-2 receptor) were measured by specific ELISAs

Serum concentrations of IL-1 ra were significantly higher in active Crohn's disease (median $376 \mathrm{pg} / \mathrm{ml}$ (SE 61)) compared to inactive patients $(213(60))$ or healthy controls $(188(31)) \mathrm{p}<0.0001$. Clinical disease activity estimated by the Harvey Bradshaw Simple Index correlated with serum IL-1 ra concentration $(r s=0.57, p=0.01)$. Serial measurements revealed that resolution of inflammation during enteral feeding was associated with a reduction in serum IL-1 ra in five out of seven cases. Serum levels of IL-1 $\alpha$ and IL- $1 \beta$ were detected in only 1 and 3 samples respectively. Serum slL-2r also reflected disease activity, but the association was weaker than that for IL-1ra and was independent of it.

Conclusion: IL-1ra, a protein capable of reducing inflammation in animal models of colitis, has been shown to be naturally elevated in active Crohn's disease. Its serum concentration correlates with clinical disease activity. This may explain the previously reported IL-1 inhibitory effect of serum from active Crohn's disease. It also suggests that regulation of IL-1ra production may be of importance in the pathogenesis of IBD. 
DETECTION BY POLYMERASE CHAIN REACTION OF MYCOBACTERIUM PARATUBERCULOSIS -SPECIFIC DNA IN CROHN'S DISEASE TISSUES.

JP Ibbotson. H Fidler, H Chahal, Y. Mussaddeg. RN Allan and JJ McFadden. Dept. of Infection, University of Birmingham, B15 2TT; Gastroenterology Unit, Queen Elizabeth Hospital, Birmingham; School of Biological Sciences, University of Surrey, Guildford.

The role of mycobacteria in Crohn's disease remains unclear. In one study, employing the polymerase chain reaction (PCR), $M$. paratuberculosis -specific DNA was detected in gut-wall homogenates from $65 \%$ of patients with Crohn's disease but also in a minority of controls. These findings, however, have not been reproduced elsewhere. The aim of this study was to employ mesenteric lymph node mononuclear cells in order to target samples rich in macrophages, in which mycobacteria would be expected to be found, and to reduce the possibility of contamination with environmental mycobacteria.

Ceils were obtained from 29 lymph nodes from patients with Crohn's disease (14 inflamed; 15 uninflamed) and 18 controls ( 9 inflammatory disease; 9 non-inflammatory disease). Samples were coded and extracted DNA analysed blind in separate PCRs, one based on 16S rRNA sequences, which are shared between $M$. paratuberculosis and $M$. avium, and one based on IS900 sequences specific to M. paratuberculosis.

Both primer pairs amplified DNA from $3 / 29$ cell preparations from patients with Crohn's disease $(10 \%)$, confirming the presence of $M$. paratuberculosis -specific DNA. The 3 samples were all from inflamed lymph nodes draining areas of active gut disease $(3 / 14 ; 21 \%)$ $M$. avium or $M$. paratuberculosis DNA was not detected in any other samples or in extraction and PCR negative controls performed at the same time.

This study provides further evidence of a specific association of $M$. paratuberculosis with Crohn's disease. The absence of M. paratuberculosis DNA from control tissues, either inflamed or noninflamed, suggests that this association may be relevant to the pathogenesis of disease at least in a small proportion of patients with Crohn's disease.

A RANDOMISED TRIAL COMPARING THE EFFICACY AND SAFETY OF 5-ASA AND PREDNISOLONE FOAM ENEMAS IN THE TREATMENT OF ACUTE DISTAL ULCERATIVE COLITIS E.J.Lee, D.P. Jewell* V.Mani ${ }^{*}$, M.R.B. Keighley $\$$, R.D. Kingston ${ }^{\oplus}$, S. Laing J. Patterson", S. Daniels *. Victoria Hospital, Blackpool; *John Radcliffe Hospital, Oxford; +Leigh Infirmary, Leigh, Manchester; §Queen Elizabeth Hospital, Birmingham; OTrafford General Hospital, Manchester; $\diamond$ SmithKline Beecham Pharmaceuticals, WGC.

Background Mesalazine (5-ASA) liquid enemas have been shown to be equivalent to steroid liquid enemas in the treatment of distal ulcerative colitis (UC), however many patients prefer a foam preparation. We have compared the efficacy and safety of a 5-ASA foam enema with a steroid foam (Predfoam $ه$ ) in patients with mild to moderate acute distal UC.

Methods In a multi-centre double-blind randomised study, 295 eligible patients, (range 18-88 yrs) received either 5-ASA $2 \mathrm{~g}(\mathrm{n}=147)$ or prednisolone foam enema $20 \mathrm{mgs}$ ( $n=148$ ) nocte for 4 weeks. Pre and post treatment symptoms (rectal bleeding and mucus, stool frequency and consistency, abdominal pain, urgency and tenesmus) sigmoidoscopy (scale 1-3) and histology (scale 0-9) were assessed. Patients completed a daily symptom diary.

Results Both groups were well matched with respect to age, sex, history, clinical and sigmoidoscopic baseline status. After 4 weeks patients in both groups improved. Significantly more patients in the 5ASA group achieved clinical remission ( $\leq 3$ stools/day, no blood) $52 \%$ vs $31 \%(p<0.001)$. Other symptoms improved to a similar extent in each group, this was confirmed by diary data. By week 4 prednisolone recipients had significantly fewer days with abnormal stool consistency [1 vs 0 days] ( $p=0.001$ ), and there was a trend towards fewer days with tenesmus in 5-ASA recipients. $(\mathrm{p}=0.038)$. Sigmoidoscopic remission showed a trend in favour of 5-ASA; $40 \%$ v $31 \%(\mathrm{p}=0.087)$. Histological remission was achieved by $27 \%$ of $5-A S A$ and $21 \%$ of prednisolone recipients respectively $(p>0.2)$. Both treatments were well tolerated.

Conclusion In this study 5-ASA foam enema was statistically superior to prednisolone foam enema with regards to clinical remission, this was supported by favourable trends in sigmoidoscopic and histological remission rates.
ANTI-NEUTROPHIL ANTIBODIES IN FAMILIAL INFLAMMATORY BOWEL DISEASE : SPECIFICITY FOR ULCERATIVE COLITIS BUT NOT CROHN'S DISEASE IN GENETICALLY RELATED INDIVIDUALS. L.C.W.Lee, G.Cambridge. J.E.Lennard-Jones. St. Mark's Hospital and Dept. of Rheum. UCL, London. U.K.

Evidence suggests there is genetic susceptibility in inflammatory bowel disease (IBD). Those at most risk are first degree relatives. Antineutrophil antibodies, commonly referred to as antineutrophil cytoplasmic antibodies (ANCA), occur more frequently in ulcerative colitis (UC) compared with Crohn's disease (CD). A higher prevalence of these antibodies has also been reported in relatives of UC patients compared with controls but not confirmed in a second report. We have investigated the prevalence of ANCA in families affected with IBD.

Fifty-three families with multiple (2 or more) members affected with IBD and their 1st degree relatives and spouses were recruited. These families consisted of 3 groups : affected with UC only (20), CD only (13), and those with both UC and CD present (mixed,20). Sera were obtained from these families, IBD patients without a positive family history and healthy controls. ANCA were detected using a standard indirect immunofluorescence (IIF) method with sera diluted 1:20.

\begin{tabular}{|c|c|c|c|c|c|c|c|c|}
\hline \multirow[t]{2}{*}{ Results: } & \multirow{2}{*}{\multicolumn{2}{|c|}{ Non familial }} & \multicolumn{4}{|c|}{ Familial } & \multirow[b]{2}{*}{$\begin{array}{l}\text { 1st degree } \\
\text { relatives }\end{array}$} & \multirow{2}{*}{$\begin{array}{c}\text { Controls } \\
\text { and } \\
\text { spouses }\end{array}$} \\
\hline & & & $\begin{array}{c}\text { UC } \\
\text { only }\end{array}$ & $\begin{array}{c}\text { CD } \\
\text { only }\end{array}$ & $\underset{\text { mixed }}{\mathrm{UC}}$ & $\underset{\text { mixed }}{\text { CD }}$ & & \\
\hline $\mathrm{n}$ & 55 & 59 & 59 & 42 & 31 & 29 & 195 & 45 \\
\hline ANCA + & $44 \varsigma$ & $3 \%$ & $47 \%$ & 0 & $38 \%$ & 0 & $3 \%$ & $2 \%$ \\
\hline
\end{tabular}

The predominant IIF staining pattern was perinuclear. There was no difference in the prevalence of ANCA between familial and nonfamilial IBD. ANCA did not occur more frequently in the unaffected relatives of IBD families compared to controls. In the mixed families these antibodies were detected in those with UC but not their genetically related kindred with $C D$.

Our results indicate the value of ANCA in IBD is its specificity for UC. We did not find an increased prevalence of ANCA in unaffected family members or those members affected with $C D$.

No correlation was found with lymphocyte activation.

We conclude that serum soluble ICAMM-1 is elevated in CD and is a marker of inflammation. The close correlation with inflammation and the lack of correlation with lymphocyte activation suggests its source may be inflamed and necrotic colonic endothelium, stimulated by

intlammatory cytokines rather than activated lymphocytes.

SOLUBLE ICAM-1 IN CROHN'S DISEASE: RELATIONSHIPS WITH DISEASE ACTIVITY, MJ Weldon, AG Lim, TC Northfield, JD Maxwell
M Dept. of Medicine, St George's Hospital Medical School, London.

Intercellular adhesion molecule 1 (ICAM-1) is presented on colonic endothelium and lymphocytes in association with active inflammation in patients with Crohn's disease (CD). It is important in the adhesion of inflammatory cells to target tissue. ICAM-1 is also measured by ELISA in $31 \mathrm{CD}$ patients and in 24 healthy controls. In all disease patients, corresponding CD activity index (CDAI) and Harvey-

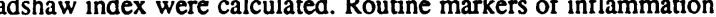

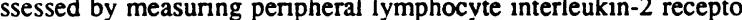

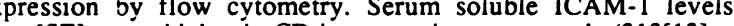
mean $S E$, were higher in $C D$ in comparison to controls $(313[13]$ vs $242[16], p<0.0005$ ). Although no significant correlation was found with clinical indices of disease activity, serum soluble ICAM-1 correlated closely with objective markers of inflammation.

\begin{tabular}{llllll} 
& Rs & P & & Rs & P \\
\hline CRP & 0.6 & 0.001 & PCV & 0.38 & 0.05 \\
ESR & 0.5 & 0.005 & haemoglobin & -0.36 & 0.05 \\
albumin & -0.4 & 0.02 & Platelets & 0.36 & 0.05
\end{tabular}




\section{MORPHOLOGICAL AND BIOCHEMICAL CHANGES IN THE RAT} INTESTINE IN RESPONSE TO CHRONIC INDOMETHACIN. G Nygård. A Anthony, K Khan. AP Dhillon, R Pounder, AJ Wakefield. Inflammatory Bowel Disease Study Group, Royal Free Hospital School of Medicine, London NW3, UK.

Chronic oral indomethacin (Indo) causes enteropathy affecting particularly, the rat caecum. This study compared the extent of gastrointestinal ulceration with changes in the arachidonic acid (AA) metabolism in blood, caecum, small intestine (s.int.) and colon, in the rat following long-term, low-dose Indo. METHODS: SpragueDawley rats (8/group) received Indo $(3 \mathrm{mg} / \mathrm{kg} /$ day) in a powdered diet for either 6 or 12 weeks. At termination animals were bled examined macroscopically for ulcers and the gut divided longitudinally. Adjacent tissue blocks of s.int., caecum and colon were either formalin fixed, snap frozen and homogenized in Tris buffer and the supernatant assayed for prostaglandin (PG) $E_{2}$ (EIA), or incubated in Krebs and stimulated with the ionophore $(10 \mu \mathrm{M}$ A23187) for leukotriene (LT)B $B_{4}$ analysis (EIA). Blood was assayed for thromboxane (TX)B $B_{2}$ (E.IA). RESULTS:

\begin{tabular}{|l|l|l|l|l|l|l|}
\hline \multirow{2}{*}{ Dosing } & \multicolumn{3}{|c|}{ PGE $_{2}$ (ng/g) } & \multicolumn{3}{c|}{ Ulcers (animals/group) } \\
\cline { 2 - 7 } & S.Int. & Caecum & Colon & S.Int. & Caecum & Colon \\
\hline \hline Control 6w & $151 \pm 24$ & $114 \pm 20$ & $30 \pm 5$ & $0 / 8$ & $0 / 8$ & $0 / 8$ \\
\hline Indo ow & $117 \pm 17$ & $42 \pm 4^{* * *}$ & $27 \pm 7$ & $2 / 8$ & $3 / 8$ & $1 / 8$ \\
\hline Control 12w & $188^{2} 22$ & $85 \pm 8$ & $43 \pm 3$ & $0 / 8$ & $0 / 8$ & $0 / 8$ \\
\hline Indo 12w & $71 \pm 12^{* *}$ & $41 \pm 7^{* *}$ & $25 \pm 5^{*}$ & $5 / 8$ & $8 / 8$ & $0 / 8$ \\
\hline
\end{tabular}

Mcian \pm SEM. ${ }^{*} p<0.05,{ }^{* *} p<0.01,{ }^{* * *} p<0.001$ Indo vs Control; Mann Whitney U tes The extracted $\mathrm{PGE}_{2}$ content in controls shoyed a significant site gradient. With Indo the blood $\mathrm{TXB}_{2}$ release was inhibited by $50 \%$ $(\mathrm{p}<0.05)$ at both time-points: increased $\mathrm{LTB}_{4}$ production $(0.4 \pm 0.01 \mathrm{vs}$ $4.0 \pm 1.0 \mathrm{ng} / \mathrm{g}$ wet weight; $\mathrm{p}<0.01)$ was observed in the caecum only at 12 weeks. CONCLUSIONS: There is a gradient of $\mathrm{PGE}_{2}$ in the rat intestine: low colonic levels may reflect an insensitivity to the effects of Indo. The rat caecum is particularly sensitive, in terms of ulceration and altered AA-metabolism that may be due to a combination of site-specific susceptibility and enterohepatic cycling.

PROGRESSION OF ULCERATIVE PROCTOSIGMOIDITIS TO MORE PROXIMAL REGIONS OF THE COLON.

\section{Ayres R C S, Gillen C D, Walmsley R S, Allan R N.}

GI Medical/Surgical Unit, West Ground, Queen Elizabeth Hospital, Birmingham, B15 2TH.

Between 1953 and 1993, 145 patients (72M 73F median age 31 years) were seen at the Birmingham General Hospital with proctosigmoiditis, all with sigmoidoscopic appearances consistent with the diagnosis, 132 with confirmatory histology and 133 with barium enema. Patients were followed up for a median 10.9 years (range $0.4-35.6$ years).

In 53 patients, disease extended beyond the rectosigmoid at a median 6.0 years (range $0-26.9$ years) and was preceded by a clinical flare-up in $36.17 / 53$ patients underwent colectomy at a median 4.6 years $(0.4-$ 25.1 years). Progression occurred in $16 \%$ of patients at 5 years by actuarial analysis with no differece between patients presenting with proctitis and proctosigmoiditis.

Compared with age and sex matched control patients whose disease remained confined to the rectosigmoid, there was no difference in age at symptom onset, age at diagnosis, smoking, parity in females, number of clinical flare-ups or flare-ups requiring systemic steroid treatment. Progression occurred more frequently in this series compared with published data although this may represent referral bias. Colectomy was more frequently undertaken in our patients and previously documented differences in outcome between patients presenting with proctitis and proctosigmoiditis were not seen in this series.

\section{CONTROLLED RANDOMIZED TRIAL OF BIOFEEDBACK} VERSUS MUSCLE TRAINING ALONE FOR INTRACTABLE CONSTIPATION

D.Koutsomanis, J.E. Lennard-Jones, A.J. Roy,M.A. Kamm

St.Mark's Hospital,City Road,London.

Biofeedback is an established treatment for idiopathic constipation. We aimed to determine whether a simplified method of muscle training (MT) without the biofeedback (B) component is succesful.

Sixty consecutive patients (median age 40 years, range 20-64,52 female) with severe constipation ( 15 patients $\leqslant 2$ bowel actions weekly, 45 severe straining) were randomized to muscle training with (B) or without (MT) visual biofeedback display.Patients were taught how to relax the pelvic floor during defecation straining and develop expulsive force in the pelvis. Assessment was by 7-day diary card, electromyographic evidence of pelvic floor relaxation and the ability to expel a balloon.Patients who failed one treatment were crossed-over to the other.Follow-up was at the end and 6 weeks after treatment.

The groups did not differ with regard to age,sex,symptoms or physiological parameters. One patient (B) withdrew;8 crossed-over after failure ( $3 \mathrm{~B} ; 5 \mathrm{MT}$ ) of whom only one improved with the second treatment(B).Results are expressed as those of the last treatment received(B:31,MT:28 patients).Bowcl frequency of $\leqslant 2 /$ week increased to normal ( $8 / 8$ vs $6 / 7$ patients, $B$ vs $M T)$.Straining time improved in 19/31 (B) and 21/28 (MT)patients. Digitation was discontinued by $9 / 21$ (B) and 4/15 (MT) patients (Fisher's Exact Test:NS).Abdominal pain improved in 19/31(B)and

20/28(MT)patients. A decrease in EMG straining occured in 22/31 (B) and 21/28 (MT) patients. Ability to expel a water-filled balloon was achieved by $11 / 19(\mathrm{~B})$ and $8 / 17(\mathrm{MT})$.

Visual feedback of muscular activity adds little, if any, benefit to muscle training alone. The effectiveness of muscle training without electronic equipment widens the availability of behavioural treatment for severe constipation.
GASTRIC EMPTYING AND INTRAGASTRIC DISTRIBUTION OF LOW AND HIGH FAT MEALS IN FUNCTIONAL DYSPEPSIA PATIENTS

M.A.Mesquita, R.J.M.Bennett', D.G.Thompson.

University Departments of Medicine and Medical Physics", Hope Hospital, Salford M6 8HD, UK.

Background: Although fat intolerance is commonly reported by Functional Dyspepsia (FD) patients, the effects of fat on gastric emptying are not known. Aims: To assess, in a group of FD patients, the effects of meals of different fat content on gastric emptying and intragastric meal distribution. Methods: 11 FD patients, and 11 healthy volunteers (V) were studied on two separate occasions, after ingestion of $415 \mathrm{ml}$ of a bland meal (chicken soup) labeled with $12 \mathrm{MBq}$ of ${ }^{99 \mathrm{~m}} \mathrm{Tc}$, with either low fat $(12 \mathrm{~g})$ or high fat $(60 \mathrm{~g})$ content. Serial 1 minute images of the gastric area in anterior and posterior projections were acquired over a period of $90 \mathrm{~min}$, the subjects standing in front of the colimator of the gammacamera. Regions of interest corresponding to proximal, distal and whole stomach were defined, and activity-time curves were derived from the geometric means of anterior and posterior counts of each region. Data analysis: The $50 \%$ emptying time ( $\left.T^{1 / 2}\right)$ for antrum, fundus and total stomach, and the proximal gastric residence, calculated as the area under the activity vs time curve derived from the fundus, and expressed as \% of total gastric residence, were calculated. Results are expressed as median values. Results: Symptoms: All patients complained of bloating after both meals. Total $T^{1 / 2}$ : Was similar $(p>0.05)$ for FD patients and $V$ for both meals, and was significantly increased after addition of fat (V:low fat:50, high fat:69min, $p=0.0003$; FD:low fat: 42 , high fat:84min, $p=0.004$ ). Intragastric distribution: FD showed an abnormal distribution of the low fat meal, with a lower \% proximal residence (FD:44\%; V:60\%; $\mathrm{p}=0.005$ ). In contrast, a similar distribution was found for both groups with the high fat meal (FD:55\%,V:57\%;p>0.05).

Conclusions: The mechanism for proximal gastric accomodation in FD patients appears to be impaired, responding only to high fat meals. However, the meal induced symptoms seem to be independent of either fat content or meal distribution. 
MOTILITY CHANGE AND PERCEPTION TO BALLOON DISTENSION IN THE JEJUNAL LOOP OF POSTGASTRECTOMY PATIENTS

Y.Fukunaga, J.Barlow, V.Drug, D.G.Thompson, J.Bancewicz, University Department of Surgery and Medicine, Hope Hospital, Salford M6 8HD, U.K.

Background: Distension of the human jejunum provokes the peristaltic reflex characterised by proximal excitation and distal inhibition mediated by intrinsic nervous pathways. Aim: To investigate enteric neural function of transposed jejunal loops following gastrectomy in patients with and without symptoms of loop dysfunction of stasis. Patients: Ten patients were studied (mean age: 63.1, sex: $\mathrm{M} ; 5, \mathrm{~F} ; 5)$, following partial gastrectomy in 5, total gastrectomy with Roux-en-Y in 3, and proximal gastrectomy and interposition of a jejunal loop in 2. Four patients were asymptomatic (AS) and six had postoperative symptoms (S). Methods: After an overnight fast a multilumen manometric catheter with a $4 \mathrm{~cm}$ silicone balloon was placed in the transposed jejunal loop, and stepwise balloon distension in 10ml increments was performed. Data Analysis: Manometric changes were recorded 2 and $4 \mathrm{~cm}$ proximal and distal to the balloon and assessed by measuring the area under the curve (AUC) and the peristaltic reflex assessed as ratios of proximal vs distal response. Perception at each volume was scored. Result: The ratios of AUC in AS group were higher than the $S$ group at each increment reached significance at $10 \mathrm{ml}$ distension (AS vs $S ; 3.32 \pm 1.50$ vs $0.84 \pm 0.20(p<0.05)$ ). The sensory thresholds in AS group were significantly higher than those in $S$ group (AS vs $S ; 46.5 \pm 2.4$ vs $30 \pm 4.8(p<0.05)$ ) and the sum of the perception scores in AS group were significantly lower than those in $S$ group (AS vs $S ; 1.25 \pm 0.5$ vs $7.8 \pm 2.2(p<0.05)$ ). Conclusion: In the $S$ group an abnormal peristaltic reflex and the lower sensory threshold in transposed jejunal loop correlates with the stasis symptoms. Both abnormalities may relate to the poor tolerance of food.
T174

MOTOR AND SENSORY RESPONSES OF HUMAN SMALL BOWEL TO DISTENSION: THE EFFECT OF RATE, DURATION AND LENGTH

V. Drug, A. Higham, L. Barlow, Y. Fukunaga, D. G. Thompson University Department of Medicine, Hope Hospital, Salford M6 8HD

Background: Distension of small intestine (S.I.) induces a characteristic peristaltic reflex but factors modulating the response are unknown. Aim: to study the influence of rate, duration and length of distension on motor and sensory responses to experimental distension of S.I. Method: Protocol 1: 12 normal volunteers underwent graded S.I. distension using an inflatable balloon attached to a multilumen manometry catheter. Inflation volume was increased in $10 \mathrm{ml}$ steps from $20 \mathrm{ml}$ to $50 \mathrm{ml}$, using slow $(5 \mathrm{ml} / \mathrm{sec}$ ) or rapid inflation (volume inflated in $1 \mathrm{sec}$ ). Duration of distension $(430 \mathrm{sec}$.) and interval between inflations (5 min) remained constant. Protocol 2: In 10 volunteers, distensions were performed using two balloons in series on the catheter to produce a distension length of either $4 \mathrm{~cm}$ (1 balloon) or $8 \mathrm{~cm} \mathrm{(2}$ balloons). Data analysis: Motor responses proximal and distal to distension were measured as area units (U.) under the manometric trace, and sensory threshold was noted. Results: Protocol 1: Both slow and rapid inflation induced a proximal stimulation of motility: increase vs predistension values $=3.6 \pm 2.4 \mathrm{U}$ (mean $\pm S E$ ) slow $(p<0.05)$ and $5.8 \pm 2.5 \mathrm{U}$ rapid $(\mathrm{p}<0.05)$. This response lasted throughout distension: first minute $0.2(-0.6-2) \mathrm{U}$ (median-IQR) vs last minute $5.4(1.8-8.6) \mathrm{U}$ $p>0.05$. Distal motor activity was inhibited by rapid distension (decrease vs predistension $-5.0 \pm 1.4 \mathrm{U}$. $\mathrm{p}<0.05$ ) but not by slow distension $(1.8 \pm 2.5 \mathrm{U})$ and the affect decreasing with time, $(-2.8 \pm 1.1$ $U)$ in first vs $(0.2 \pm 1.7 \mathrm{U})$ in last $\min$ of distension $p<0.05$. Sensory threshold: was lower for rapid $(33.3 \pm 2.2 \mathrm{ml})$ vs slow inflation $45.0 \pm$ $2.0 \mathrm{ml}(\mathrm{p}<0.05)$. Protocol 2: Dual inflation induced greater proximal stimulation $15.2(2.5-19.8) \mathrm{U}$ vs single balloon $4.8(1.1-14.3) \mathrm{U}$. $(p<0.05)$, and distal inhibition, $0.3(0-1.6) \mathrm{U}$ vs single $1.5(0.4-4.8) \mathrm{U}$ $(\mathrm{p}<0.05)$. Sensory thresholds were also lower with dual $(28 \pm 2.5 \mathrm{ml})$ vs either proximal $(40 \pm 4.7 \mathrm{ml})$ or distal balloon $(38.9 \pm 3.5) \mathrm{p}<0.05$. Conclusions: The S.I. mechanoreceptors mediating both the sensory and motor responses to distension are modulated by intensity, duration, speed, length of the stimulus applied.
ADRENOCEPTORS AND THE COLOCOLONIC INHIBITORY REFLEX.

SF Hughes. M Scott. MA Pilot. NS Williams.

Surgical Unit, Royal London Hospital, Whitechapel, London.

The colocolonic inhibitory reflex is characterised by inhibition of the proximal colon induced by distal colonic distension and is thought to be mediated via the prevertebral ganglia. The aim of this study was to investigate the effects of distal colonic distension on the motility of an isolated loop of canine proximal colon and to elucidate certain aspects of the underlying nervous mechanisms.

A Thiry-Vella loop was constructed from the proximal colon in 3 beagle dogs. Loop motility was recorded from serosal strain gauges connected to a digital data logger and chart recorders. The motility index was calculated by computor programme. All recordings were performed in the fasted state. After a baseline recording of 1 hour, a balloon was inserted into the distal colon at $20 \mathrm{~cm}$ from the anal verge. The balloon was inflated with warm water until the dog was aware of its presence $(33.3 \pm 2.1 \mathrm{ml})$. Motility was recorded for 1 hour with the balloon inflated and continued for 1 hour after deflation. $\alpha_{2}$ and $\beta$ receptor blockade was achieved with yohimbine $(200 \mu \mathrm{g} / \mathrm{kg})$ and propranolol $(100 \mu \mathrm{g} / \mathrm{kg})$ injected intravenously over 10 minutes immediately prior to balloon inflation.

The results are expressed as mean \pm SEM change in motility index compared with baseline motility standardised to $100 \%$.

$\begin{array}{llll} & \text { Control } & \text { Yohimbine } & \text { Propranolol } \\ \text { Balloon inflated } & 21 \pm 8 \% * & 228 \pm 19 \% * & 25 \pm 3 \% \%^{*} \\ \text { Balloon deflated } & 112 \pm 10 \% & 147 \pm 37 \% & 81 \pm 13 \%\end{array}$

Balloon inflation resulted in inhibition of motility in the Thiry-Vella loop. Motility returned to baseline levels after deflation. Following injection of yohimbine, balloon distension did not cause inhibition. Propranolol had no effect on the colocolonic inhibitory reflex. Motility returned to baseline levels after deflation in all studies.

We have confirmed that the colocolonic inhibitory reflex is mediated via the extrinsic nerves to the colon. This reflex is abolished by $\alpha_{2}$ receptor blockade, but is unaffected by $\beta$ receptor blockade.

We conclude that $\alpha_{2}$ receptors are involved in the colocolonic inhibitory reflex. However, the location of these receptors remains unknown. It is likely that they are presynaptic inhibitory $\alpha_{2}$ receptors acting on cholinergic extrinsic neurones.

$* p<0.05$ compared with baseline motility (Students $t$-test for paired data)

\section{Stomach F176-F180}

F176

PREVENTION OF NSAIDS-INDUCED GASTRODUODENAL LESIONS IN ARTHRITIC PATIENTS BY SUCRALFATE GEL.

M Miglioli, G Bianchi Porro, D Vaira, F Santalucia, M Menegatti, G Brunetti, F Montrone, G Grandinetti, L Frizziero, L Barbara. 1st Medical Clinic, University of Bologna \& Dept. of Rheumatology, Bologna (BO), GI Unit \& Rheumatology Unit, L. Sacco Hospital, Milano (MI), Italy.

Aim: to evaluate the efficacy of sucralfate gel (Gastrogel, SG) in the short term prevention of gastrointestinal (GI) pathology in arthritic patients (AP) receiving NSAIDs.

Methods: One hundred and seventy-one AP from two centres (MI and BO) were assessed for upper GI symptoms and underwent upper GI endoscopy before starting standard NSAID therapy. Patients without erosions or ulcers (grade $<2$ according to modified Lanza grading scale) were considered eligible for the study. Patients received diclofenac $200 \mathrm{mg} /$ day or naproxen $1 \mathrm{~g} /$ day plus either $\mathrm{SG}$ or placebo (P) bid for two weeks in a randomized double blind study. Repeat assessment of symptoms and endoscopy were performed after treatment.

Results: One hundred and seven patients (M/F: 18/89, mean age $55.2+/-9.7)$ with osteoarthritis $(n=56)$ or rheumatoid arthritis $(n=51)$ fulfilled the inclusion criteria and were randomly allocated to receive SG $(n=53)$ or $P(n=54)$. Ten patients ( 3 SG and 7 P) were lost to follow up.

The table shows the symptoms after treatment $(\mathrm{H}=$ heartburn. $\mathrm{EP}=$ epigastric pain, $\mathrm{N}=$ nausea).

\begin{tabular}{llll}
\multicolumn{2}{l}{ epigastric pain, $\mathrm{N}=$ nausea). } \\
\multicolumn{1}{l}{$\mathrm{H}$} & $\mathrm{EP}$ & $\mathrm{N}$ \\
\hline $\mathrm{SG}$ & $30 \%$ & $28 \%$ & $12 \%$ \\
$\mathrm{P}$ & $51 \% *$ & $49 \% *$ & $4 \%$ \\
\hline
\end{tabular}

The table shows the endoscopic findings after treatment ( $A G=$ antral gastritis, $\mathrm{AE} / \mathrm{DE}=$ antral/duodenal erosion, $\mathrm{PU}=$ peptic ulcer).

\begin{tabular}{lllc}
\hline & AG & AEDE & PU \\
SG & $31(62 \%)$ & $15(30 \%)$ & $4(8 \%)$ \\
P & $8(17 \%)^{*}$ & $26(55 \%)^{*}$ & $13(28 \%)^{*}$ \\
\hline${ }^{*}=\mathrm{P}<0.05$
\end{tabular}

An unexplained difference was found in the incidence of peptic ulcer between the two centeres: $\mathrm{MI}=32 \%, \mathrm{BO}=8 \%$.

Conclusion: SG reduces the frequency both of symptoms and of early upper GI pathology in AP receiving NSAIDs. 